U.S. DEPARTMENT OF COMMERCE

Technology Administration

National Institute of Standards and Technology
Office of Applied Economics

Building and Fire Research Laboratory

Gaithersburg, Maryland 20899

\title{
Multiattribute Decision Analysis Method for Evaluating Buildings and Building Systems
}

Gregory A. Norris and Harold E. Marshall

September 1995

Building and Fire Research Laboratory

National Institute of Standards and Technology

Gaithersburg, MD 20899

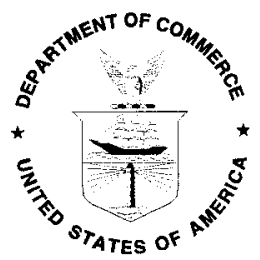

U.S. DEPARTMENT OF COMMERCE

Ronald H. Brown, Secretary

Technology Administration

Mary L. Good, Under Secretary for Technology

National Institute of Standards and Technology

Arati Prabhakar, Director 


\section{Abstract}

Multiattribute decision analysis (MADA) methods consider non-financial attributes (qualitative and quantitative) in addition to common financial worth measures when evaluating project alternatives. The building community needs MADA methods to evaluate building and building-related investment alternatives where non-financial attributes are important. The report reviews 14 classes of methods for performing MADA. It summarizes their usefulness for screening, ranking, and choosing among projects; their data input requirements; and how each method scores project alternatives. Two methods--the analytical hierarchy process (AHP) and non-traditional capital investment criteria (NCIC)--are described in detail. Assumptions, procedures, strengths, and limitations are described for each.

AHP was selected for detailed description because of four important strengths: it is well-known and well-reviewed in the literature; it includes an efficient attribute weighting process of pairwise comparisons; it incorporates hierarchical descriptions of attributes, which keeps the number of pairwise comparisons manageable; and most of all, its use is facilitated by available software. A case study of a hypothetical company choosing a new headquarters illustrates AHP in choosing among building alternatives.

NCIC was selected for detailed description because of four strong points: it was designed to address some of the criticisms of AHP which have appeared in the literature; it includes pairwise comparisons for efficiency; it incorporates hierarchical descriptions of attributes to keep the number of pairwise comparisons manageable; and most of all, it develops "scores" for alternatives which are denominated in monetary terms, making otherwise implied valuation of attributes explicit and allowing the results to be incorporated into traditional economic worth analyses. A case study of a hypothetical company selecting the location of a new branch office illustrates NCIC.

Detailed descriptions of some typical building-related decisions--choosing among office buildings, residences, building components, and building materials--provide additional examples of possible MADA applications. A list of 15 building-related attributes, with complete definitions, helps decision makers customize a MADA model for making a building choice. Although the report focuses on buildings, MADA methods apply equally to the evaluation of non-building capital budgeting decisions. 


\section{Preface}

This is the seventh in a series of National Institute of Standards and Technology (NIST), formerly the National Bureau of Standards, reports ${ }^{1}$ on recommended standards related to applying economic evaluation methods to building decisions. The first four dealt with the theory and application of economic methods of analysis, including life-cycle costing, net benefits, benefit-to-cost and savingsto-investment ratios, internal rate of return, and payback. These reports were used as the bases for standard practices published by the American Society for Testing and Materials (ASTM).

The fifth NIST report was a recommended guide that focused on techniques that account for uncertainty in project input values and techniques that measure the risk that a project will have a less favorable economic outcome than what is desired or expected. ASTM used it as the basis for a standard guide for selecting among techniques for handling uncertainty and risk in project evaluation.

The sixth report was a recommended classification of building elements or systems. The purpose of the classification was to ensure consistency in the format used for the economic evaluation of building projects over time and from project to project, and to enhance reporting at all stages of building procurement--from feasibility and planning through the preparation of working documents, construction, maintenance, rehabilitation, and disposal. ASTM used the recommended classification, called UNIFORMAT II, as the basis for a standard classification of building elements and related sitework.

This report supports an ongoing standards development activity by ASTM's Building Economics Subcommittee (E06.81). It is in response to requests from the building community for a standard method that treats non-financial (i.e., non-monetary) benefits and costs in addition to the typical financial measures of benefits and costs referred to earlier. Multiattribute decision analysis (MADA), one of several classes of methods for evaluating alternatives with significant non-monetary attributes, is the focus of the report. It will be the technical basis for writing an ASTM standard method for multiattribute decision analysis. It complements existing ASTM standards on building economics by incorporating the existing financial measures of worth described in those standards into a more

\footnotetext{
${ }^{1}$ The previous six reports are as follows: Brian Bowen, Robert P. Charette, and Harold E. Marshall, UNIFORMAT II A Recommended Classification for Building Elements and Related Sitework, National Institute of Standards and Technology Special Publication 841, August 1992; Harold E. Marshall, Techniques for Treating Uncertainty and Risk in the Economic Evaluation of Building Investments, National Institute of Standards and Technology Special Publication 757, September 1988; Rosalie T. Ruegg, Stephen R. Petersen, and Harold E. Marshall, Recommended Practice for Measuring Life-Cycle Costs of Buildings and Building Systems, National Bureau of Standards Interagency Report 80-2040, June 1980; Harold E. Marshall and Rosalie T. Ruegg, Recommended Practice for Measuring Benefit/Cost and Savings-to-Investment Ratios for Buildings and Building Systems, National Bureau of Standards Interagency Report 81-2397, November 1981; Harold E. Marshall, Recommended Practice for Measuring Net Benefits and Internal Rates of Return for Investments in Buildings and Building Systems, National Bureau of Standards Interagency Report 83-2657, October 1983; and Harold E. Marshall, Recommended Practice for Measuring Simple and Discounted Payback for Investments in Buildings and Building Systems, National Bureau of Standards Interagency Report 84-2850, March 1984.
} 
comprehensive standard method of evaluation that includes non-financial (quantitative and nonquantitative) benefits and costs.

The focus of applications in this report is on buildings and building components. MADA methods, however, are equally applicable to the evaluation of non-building capital budgeting decisions. 


\section{Acknowledgments}

Thanks are due the members of ASTM who participated in the Building Economics Subcommittee activity on multiattribute decision analysis (MADA) and thereby helped determine the framework and content of this report. The authors are also grateful to their NIST colleagues Saul Gass, Barbara Lippiatt, and Stephen Weber for their helpful comments. Special appreciation is extended to George Lippert, for his initial proposal to write an ASTM MADA standard method and for his early drafts of a MADA standard which helped shape the report. 


\section{Contents}

Abstract. iii

Preface v

Acknowledgments .vii

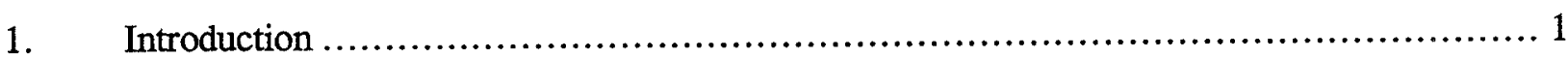

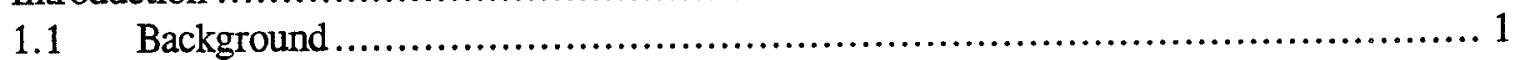

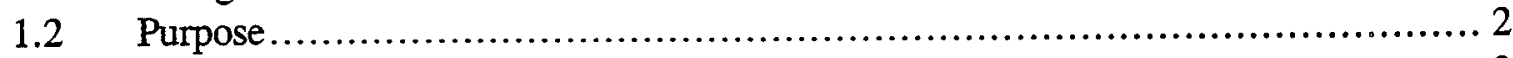

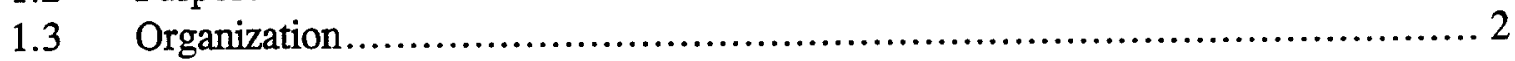

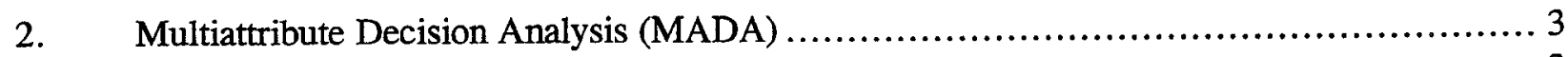

2.1 Elements of a MADA Problem .............................................. 3

2.1.1 Finite (Generally Small) Set of Alternatives ............................... 3

2.1.2 Tradeoffs Among Attributes............................................ 4

2.1 .3 Incommensurable Units .................................................. 4

2.1.4 Decision Matrix ....................................................... 4

2.2 Common Simplifying Assumptions ........................................... 6

2.3 Overview of MADA Methods .................................................. 6

2.3.1 Three Types of MADA Problems ......................................... 8

2.3.2 Compensatory versus Noncompensatory Methods .......................... 9

2.3.3 The Attribute Weighting Problem ....................................... 9

2.4 Summary Descriptions of MADA Methods .................................... 10

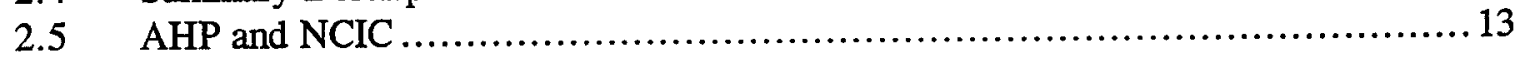

3. Recommended Attributes and Typical Building Decisions for MADA ................... 15

3.1 Attributes for Building Evaluations ........................................... 15

3.2 Types of Building-Related Decisions ......................................... 17

3.2.1 Choosing Among Buildings--Public Building Example ..................... 17

3.2.2 Choosing Among Buildings--Residential Example .......................... 18

3.2.3 Choosing Among Components........................................... 19

3.2.4 Choosing Among Materials ................................................ 19

3.2.5 Choosing Among Locations ........................................... 20

4. AHP $\quad$ (n)

4.1 Additive Weighting Methods ................................................. 23

4.1.1 Cardinal Alternative Scores ............................................. 23

4.1.2 Cardinal Attribute Weights............................................ 23

4.1.3 Contributions to Desirability ........................................... 23

4.1 .4 Additivity ........................................................ 24

4.1.5 AHP Relative to the Basic Additive Weighting Method .....................24 


\section{Contents (continued)}

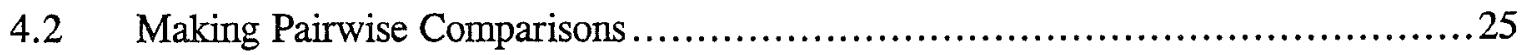

4.2.1 Matrix of Pairwise Comparisons (MPC) …............................25

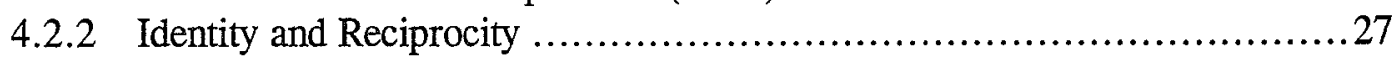

4.2.3 Establishing Order of Importance Before Comparing ........................28

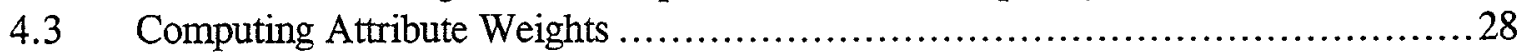

4.3.1 Perfect Cardinal Transitivity and Redundancy in the MPC ..................29

4.3.2 Principal Eigenvector Method ...........................................29

4.3.3 Saaty's Heuristic Check of Consistency ......................................30

4.4 Structuring the Problem with Hierarchy ............................................... 31

4.5 Developing Numerical and Comparable Attribute Values...............................34

4.5.1 Scoring Alternatives by Normalizing Quantitative Data........................35

4.5.2 Scoring Alternatives Using MPCs ............................................37

4.5.3 Normalizing Quantitative Data Versus Using MPCs ...........................37

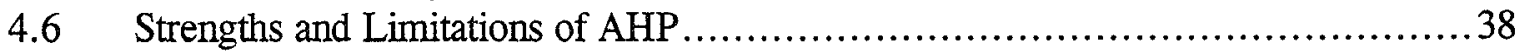

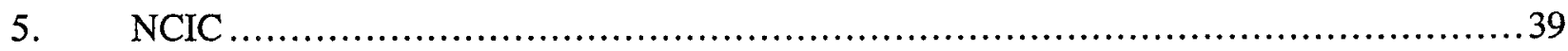

5.1 “Total Implied Value" Methods .................................................. 39

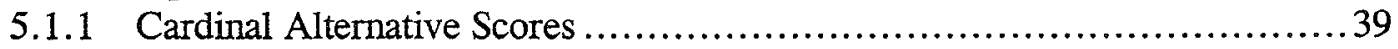

5.1 .2 No Cardinal Attribute Weights .........................................40

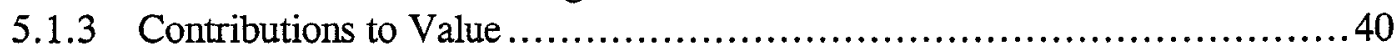

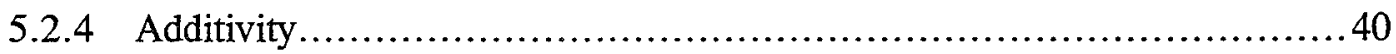

$5.2 \quad$ Features of NCIC ................................................................... 40

5.2.1 Pairwise Comparisons.........................................................40

5.2.2 Principal Eigenvector Method ......................................... 40

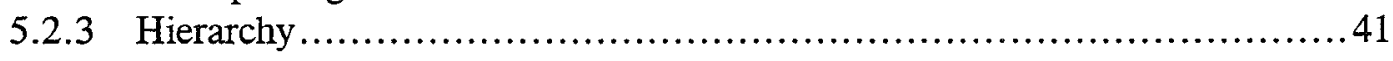

5.2 .4 Implied Increments of Value ..............................................4 41

5.2.5 Implied Value Functions................................................... 41

$5.3 \quad$ Specifying a Baseline Alternative .................................................. 41

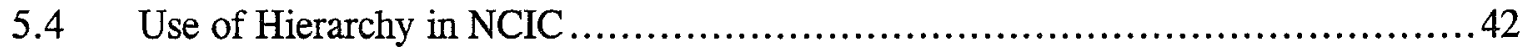

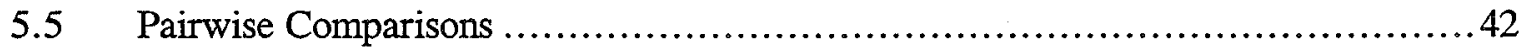

5.6 Computing Incremental Values .................................................... 43

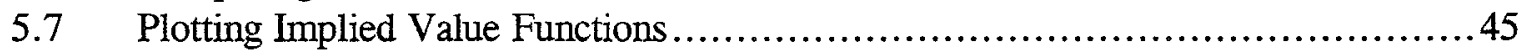

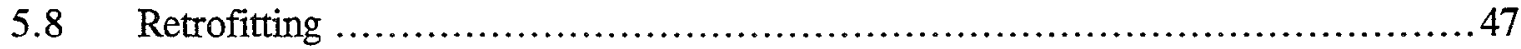

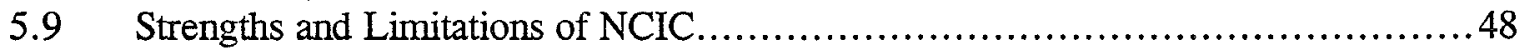

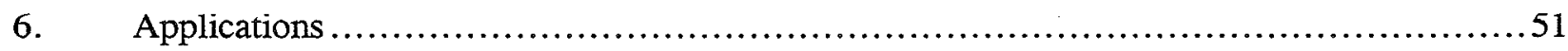

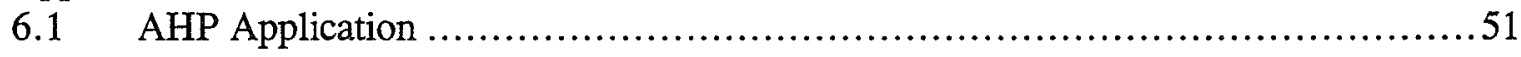




\section{Contents (continued)}

$6.2 \quad$ NCIC Application.................................................................. 59

6.2.1 Problem Definition ...................................................... 59

6.2.2 Defining the Base-Case Alternative........................................ 61

6.2.3 Calculating Implied Values Using Pairwise Comparisons .................. 62

6.2.4 Calculating Present Relative Values and Selecting the Best Alternative ..... 65

Appendix A. Definitions of Building-Related Attributes ......................................69

Appendix B. Algorithm to Compute Principle Eigenvectors and Eigenvalues .................... 71

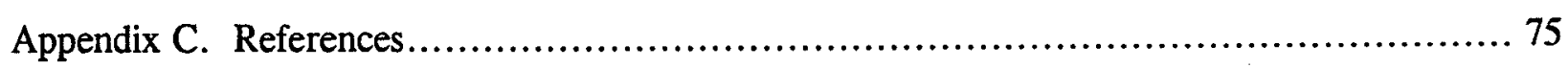

\section{LIST OF TABLES}

Table 4-1. Verbal scale for pairwise comparisons of attributes in AHP ......................... 27

Table B.1. List of input information ......................................................... 71

\section{LIST OF FIGURES}

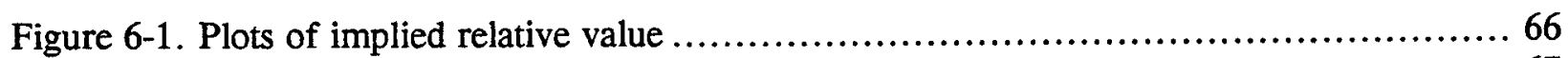

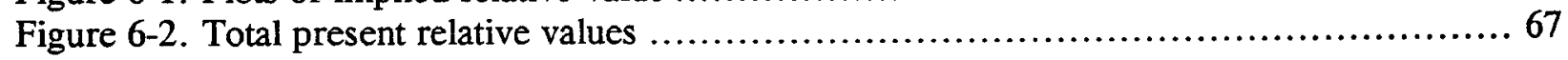

\section{LIST OF EXHIBITS}

Exhibit 2-1. Heating system decision matrix .....................................................

Exhibit 2-2. Classes of methods for multiattribute decision analysis.............................. 7

Exhibit 3-1. Attributes for building-related decisions ............................................. 16

Exhibit 3-2. An example hierarchy for the problem of selecting a building ..................... 17

Exhibit 3-3. An example hierarchy for the problem of selecting a residence...................... 18

Exhibit 3-4. An example hierarchy for the problem of selecting a building component ............ 19

Exhibit 3-5. An example hierarchy for the problem of selecting a building material ............... 20

Exhibit 3-6. An example hierarchy for the problem of selecting a building location............... 21

Exhibit 4-1. A matrix of paired comparisons (MPC) ............................................. 26

Exhibit 4-2. Illustration of a hierarchy of attributes with all leaf attributes shaded................ 32

Exhibit 4-3. Initial hierarchy with nine attributes in a set......................................... 33

Exhibit 4-4. Modified hierarchy employing set groups to avoid exceeding seven attributes per set 34 


\section{Contents (continued)}

Exhibit 4-5. Decision matrix for a simple equipment choice example ......................... 35

Exhibit 4-6. Two methods for normalizing attribute scores .................................. 36

Exhibit 5-1. Example plot of a consistent set of implied value results ......................... 46

Exhibit 5-2. Example plot of an inconsistent set of implied value results .................... 47

Exhibit 6-1. Hierarchy for the example building selection problem, with leaf attributes shaded... 52

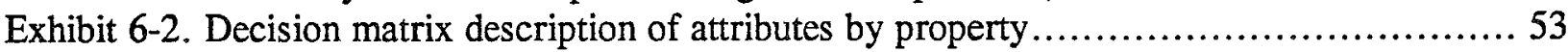

Exhibit 6-3. Scores of alternatives with respect to building style................................ 54

Exhibit 6-4. Scores of alternatives with respect to site/neighborhood ........................... 54

Exhibit 6-5. Scores of alternatives with respect to staff commuting accessibility ..................55

Exhibit 6-6. Scores of alternatives with respect to client/field staff accessibility .................. 55

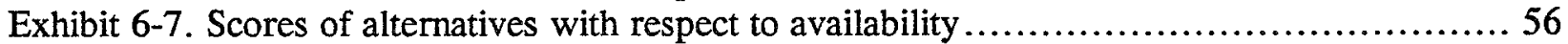

Exhibit 6-8. Scores of alternatives with respect to annual cost ................................ 56

Exhibit 6-9. Scores of alternatives with respect to aural privacy and ambient noise .............. 57

Exhibit $6-10$. Scores of alternatives with respect to inside and outside views ................... 57

Exhibit 6-11. Attribute weights ..................................................... 58

Exhibit $6-12$. Final desirability scores ...................................................... 58

Exhibit 6-13. Attribute hierarchy for the location selection example ........................... 60

Exhibit 6-14. Decision matrix description of attributes by location ............................. 61

Exhibit 6-15. Worst-case attribute values and deltas with respect to the composite worst case .... 62

Exhibit 6-16. Matrices of paired comparisons and calculated implied relative values ............. 64

Exhibit B-1. Program to compute the principal eigenvector and eigenvalue of an MPC ......... 74 


\section{Introduction}

\subsection{Background}

Capital investment decisions are often evaluated using traditional economic measures of worth such as net present value, life-cycle cost, rate of return, or payback. ${ }^{2}$ These methods incorporate the stream of costs and benefits of an investment over time into a single measure of project worth. The American Society for Testing and Materials (ASTM) has published standard methods for calculating traditional economic worth measures in the evaluation of investments in buildings and building systems. ${ }^{3}$

A common characteristic of economic worth measures is that they consider only monetary benefits and monetary costs associated with investment alternatives. That is, to be included in the economic analysis, positive and negative attributes of the alternatives must be denominated in dollar terms as monetary benefits and costs.

Yet building investment alternatives may differ in characteristics which decision-makers consider important, but which are not readily expressed in monetary terms. Some examples of characteristics that pertain to the selection of a building alternative (and its surroundings) are location/accessibility, site security, maintainability, quality of the sound and visual environment, and image to the public and occupants. ${ }^{4}$ Although these characteristics are important to building users, there is no obvious way to combine them into a single measure of project financial worth.

Non-financial characteristics may be either quantitative or qualitative. Quantitative, non-financial characteristics are those which are readily measured or quantified, but which require judgment to monetize. Police statistics on the number of muggings in a neighborhood are a quantitative measure of safety, but there is no agreed-upon technique for converting that to a monetary value.

Qualitative impacts are impractical, impossible, or too costly to measure. Building aesthetics may affect worker productivity, for example, but their quantitative impact is difficult to assess.

Because non-financial characteristics can be very important, decision makers need a method that accounts for characteristics (also called attributes) of a general nature when choosing among building

\footnotetext{
${ }^{2}$ Detailed descriptions of these methods are found in Marshall, Recommended Practice for Measuring Net Benefits and Internal Rates of Return for Investments in Buildings and Building Systems; Ruegg, Petersen, and Marshall, Recommended Practice for Measuring Life-Cycle Costs of Buildings and Building Systems; and Marshall, Recommended Practice for Measuring Simple and Discounted Payback for Investments in Buildings and Building Systems.

${ }^{3}$ American Society for Testing and Materials, ASTM Standards on Building Economics, Third Edition, Philadelphia, PA, 1994.

${ }^{4}$ These examples are based on ongoing work by Gerald Davis and the ASTM Subcommittee on Whole Building Performance to define the factors which contribute to a building's "serviceability." See, for example, Gerald Davis, "How to Get the Building You Need," ASTM Standardization News, 20(11), 1992.
} 
alternatives. A class of methods that can accommodate non-monetary benefits and costs is multiattribute decision analysis (MADA).

\subsection{Purpose}

This report presents an overview of MADA methods for making decisions where non-financial considerations are important. It then describes in detail two selected methods--AHP and NCIC--as they would be applied to making building investment decisions. It also describes the strengths and limitations of the two methods to help decision makers choose the method that best meets their needs.

Note that the focus of applications in this report is on buildings and building components. MADA methods, however, are equally applicable to the evaluation of non-building capital budgeting decisions, and this report is intended to be useful to those making non-building decisions as well.

\subsection{Organization}

Chapter 2 provides an overview of MADA methods and the types of problems they address. Chapters 4 and 5 present detailed treatments of two selected methods: AHP and NCIC. These chapters describe the theoretical substance of the two methods and list the strengths and limitations of each.

Chapter 3 provides a comprehensive list of selected attributes for evaluating building decisions. Definitions are provided in Appendix $A$ for each of the attributes in the list. The three types of building decisions to which the list applies are choosing among buildings, choosing among building components, and choosing among building materials. Use the list of attributes to build a customized model for your specific problem. Examples of typical building-related decisions are provided.

Chapter 6 describes, in detail, applications of the AHP and NCIC methods to building and location choice problems. 


\section{Multiattribute Decision Analysis (MADA)}

This chapter describes the elements that make up a MADA problem and, for perspective, provides an overview of alternative MADA methods. Chapters 4 and 5 provide detail on how to use two selected MADA methods.

MADA methods apply to problems where a decision maker is choosing or ranking a finite number of alternatives which are measured by two or more relevant attributes. The literature describing MADA theory, methods, and applications is vast. Thorough surveys of the literature and descriptions of the principal methods are found in Chen and Hwang, and Hwang and Yoon. ${ }^{6}$ The description of MADA elements and overview of methods provided here indicate the place of our selected methods within the larger set of approaches to the MADA problem.

\subsection{Elements of a MADA Problem}

There are four elements or characteristics common to all MADA problems.

\subsubsection{Finite (Generally Small) Set of Alternatives}

MADA problems involve analysis of a finite and generally small set of discrete and predetermined options or alternatives. In this way, MADA problems are distinguished from Multiple Objective Decision Analysis (MODA) problems, which involve the design of a "best" alternative by considering the tradeoffs within a set of interacting design constraints. In MODA problems, the number of alternatives is effectively infinite, and the tradeoffs among design criteria are typically described by continuous functions. "Resource allocation problems," as described by Ibaraki and Katoh, ${ }^{7}$ as well as "multicriteria optimization problems," as described by Stadler, ${ }^{8}$ both fall under the heading of MODA. The literature on MODA methods and applications was reviewed extensively by Hwang and Masud. ${ }^{9}$ MADA and MODA together fall under the heading of Multiple Criteria Decision Making. This classification is widely accepted. ${ }^{10}$

Screening the pool of buildings available for lease in a city to determine which ones satisfy a set of minimum requirements is a MADA problem. Selecting a replacement HVAC system for an existing

5 Shu-Jen Chen and Chin-Lai Hwang, Fuzzy Multiple Attribute Decision Making, Lecture Notes in Economics and Mathematical Systems, Springer-Verlag, Berlin/Heidelberg/New York, 1992.

${ }^{6}$ Ching-Lai Hwang and Kwangsun Yoon, Multiple Attribute Decision Making, Lecture Notes in Economics and Mathematical Systems, Springer-Verlag, Berlin/Heidelberg/New York, 1981.

7 Toshihide Ibaraki and Naoki Katoh, Resource Allocation Problems: Algorithmic Approaches, MIT Press, Cambridge, Massachusetts, 1988.

8 Wolfram Stadler, "Fundamentals of Multicriteria Optimization," Multicriteria Optimization in Engineering and in the Sciences, Plenum Press, New York, 1988.

9 Ching-Lai Hwang and A.S.M. Masud, in collaboration with S. R. Paidy and K. Yoon, Multiple Objective Decision Making, Springer-Verlag, New York, 1979.

${ }^{10}$ See, for example, Hwang and Yoon 1981, Multiple Attribute Decision Making, p. 3. 
building is another example of a MADA problem. In contrast, the integrated design and sizing of a future building and its HVAC system is a MODA problem.

\subsubsection{Tradeoffs Among Attributes}

Problems require MADA methods if no single alternative exhibits the most preferred available value or performance for all attributes. This is often the result of an underlying tradeoff relationship among attributes. An example is the tradeoff between low desired energy costs and large glass window areas (which may raise heating and cooling costs while lowering lighting costs and enhancing aesthetics).

\subsubsection{Incommensurable Units}

The attributes in a MADA problem will generally not all be measurable in the same units. In fact, some attributes may be either impractical, impossible, or too costly to measure at all. For example, life-cycle costs are directly measured in dollars, the number and size of offices are measured in other units, and the public image of a building may not be practically measurable in any unit. If all relevant attributes characterizing alternative buildings can be expressed in terms of financial costs or benefits scheduled to occur at specifiable times, then the ranking and selection of a building does not require the application of MADA.

\subsubsection{Decision Matrix}

A MADA problem can generally be characterized by a "decision matrix" (see eq 2.1). The decision matrix indicates both the set of alternatives and the set of attributes being considered in a given problem, and it summarizes the "raw" data available to the decision maker at the start of the analysis. A decision matrix has a row corresponding to each alternative being considered and a column corresponding to each attribute being considered. A problem with a total of $m$ alternatives characterized by $n$ attributes is described by an $m \times n$ matrix $X$ as shown in eq 2.1. Each element of the matrix is the "score" or "performance rating" of that row's alternative with respect to that column's attribute, and can be stated either numerically or verbally. When expressed in numerical terms, the element $x_{i j}$ is commonly termed the jth attribute value for alternative $i$.

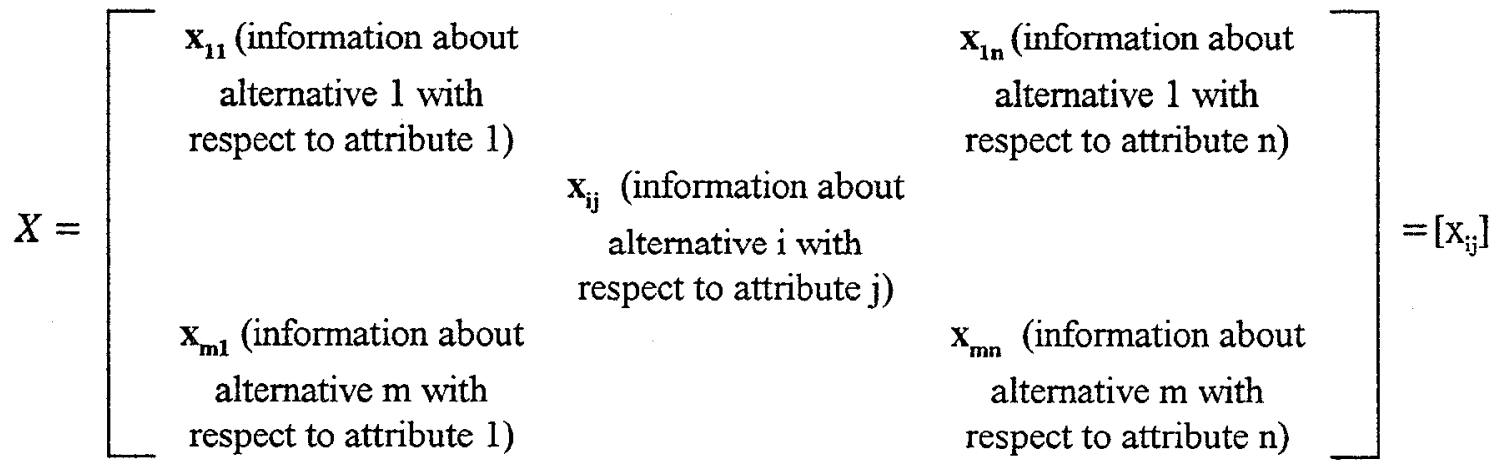


MADA approaches can be viewed as alternative methods for combining the information in a problem's decision matrix together with additional information from the decision maker in order to determine a final ranking, screening, or selection from among the alternatives. Besides the information contained in the decision matrix, all but the simplest MADA techniques require additional information from the decision maker in order to arrive at a final ranking, screening, or selection. For example, the decision matrix provides no information about the relative importance of the different attributes to the decision maker, nor about any minimum acceptable, maximum acceptable, or target values for particular attributes.

Exhibit 2-1 is a hypothetical and simplified decision matrix for the problem of selecting a heating system for a building. Note that the first column pertains to a financial attribute: life-cycle costs. The next attribute, warranty period, is measured quantitatively, but not in monetary terms. The last attribute, familiarity with the technology, is characterized only qualitatively.

$\begin{array}{ccc}\text { Life-Cycle } & \text { Duration of } & \text { Familiarity } \\ \text { Cost } & \text { Warranty } & \text { with the } \\ \text { (K\$) } & \text { (years) } & \text { Technology }\end{array}$

\begin{tabular}{l|ccc|} 
Alternative A & 10 & 3 & high \\
Alternative B & 15 & 1 & medium \\
Alternative C & 20 & 10 & low \\
\cline { 2 - 4 } & &
\end{tabular}

Exhibit 2-1. Heating system decision matrix.

It is important that the decision matrix include only those attributes which vary significantly among one or more alternatives and for which the decision maker considers this variation to be important. On this first point, location may be an important characteristic of buildings. But if all alternatives are in the desired neighborhood, then location is not a relevant attribute for the decision matrix. On the second point, some attributes may be important as "threshold" criteria, in that alternatives are excluded from further consideration if they do not meet the "threshold" requirement. But with respect to many such threshold attributes, variation among alternatives that all pass the screening requirement is irrelevant. In such cases these attributes should not be included in the decision matrix either, after the screening stage of the analysis. For example, heating capacity is an important threshold attribute for a heating system. However, as long as the Alternatives in Exhibit 2-1 all meet the heating capacity requirements of the application, further heating capacity variation is probably not important to the decision maker and should not be included in the decision matrix or the analysis. 


\subsection{Common Simplifying Assumptions}

For analytical and procedural simplicity, it is common practice when employing MADA to neglect both uncertainties and imprecision inherent in the decision matrix data, as well as in the additional information about attributes and alternatives elicited from the decision maker. Neglect of uncertainty occurs when uncertain values are represented by their expected values rather than by probability distributions. Neglect of imprecision occurs when ratings such as "good" and "bad" are converted to scalar numbers rather than ranges. All the methods described in this report follow this practice.

More elaborate MADA techniques have been proposed which take explicit account of either input imprecision or uncertainty in input estimates. Imprecise data can be treated formally using extensions of MADA techniques which employ "Fuzzy Set Theory," 11 while uncertain inputs can be treated using probabilistic methods. ${ }^{12}$ Chen and Hwang recently provided a comprehensive review of the state of the art of Fuzzy MADA Techniques. ${ }^{13}$ An overview of fuzzy approaches to MODA was recently provided by Sakawa. ${ }^{14}$ Software programs such as Logical Decisions and Decision Plus allow the user to incorporate uncertain input data into a MADA analysis using probabilistic techniques. These programs allow the user to treat uncertainty explicitly when using MADA methods such as AHP and the Simple MultiAttribute Rating Technique (SMART).

\subsection{Overview of MADA Methods}

Exhibit 2-2 describes 14 classes (col. 1) of MADA methods. The list is comprehensive, ranging from very simple screening methods to sophisticated ranking and selection algorithms requiring computer-assisted computations. The set of 14 methods includes only those which have been found to be practical for application to real world problems.

The names of the methods (or, in the case of additive weighting methods, method classes) are listed in column 1 of Exhibit 2-2. The second column indicates whether each method is useful for screening alternatives, rank-ordering alternatives, choosing a preferred alternative, or more than one of these purposes (see section 2.3.1). The third column reports whether the method is compensatory or not (see section 2.3.2).

${ }^{11}$ Fuzzy Set Theory was introduced by Lotfi Zadeh in "Fuzzy Sets," Information and Control, Vol. 8, 1965, pp. 338-353. More recent reviews of the field include Yager et al., Fuzzy Sets and Applications: Selected Papers by L. A. Zaheh, Wiley, New York, 1987; Dubois and Prade, Fuzzy Sets and Systems: Theory and Applications, Academic Press, New York, 1980; and Terano, Asai, and Sugeno, Fuzzy Systems Theory and Its Applications, Academic Press, New York, 1987.

${ }^{12}$ See, for example, M. Granger Morgan and Max Henrion, Uncertainty: A Guide to Dealing with Uncertainty in Quantitative Risk and Policy Analysis, Cambridge University Press, New York, 1990, and R. Slowinsky and J. Teghem, Stochastic vs. Fuzzy Approaches to Multiobjective Mathematical Programming Problems Under Uncertainty, Kluwer Adademic Publishers, Dordrecht, 1990.

${ }^{13}$ Chen and Hwang, Fuzzy Multiple Attribute Decision Making, 1992.

${ }^{14}$ Masatoshi Sakawa, Fuzzy Sets and Interactive Multiobjective Optimization, Plenum Press, New York, 1993. 


\begin{tabular}{|c|c|c|c|c|}
\hline \multirow{2}{*}{$\begin{array}{l}\text { Method (or } \\
\text { Class) Name } \\
\end{array}$} & \multirow[b]{2}{*}{ Purpose } & \multirow{2}{*}{$\begin{array}{l}\text { Compensatory or } \\
\text { Noncompensatory }\end{array}$} & \multicolumn{2}{|c|}{ Info. Req'd Beyond Decision Matrix Data } \\
\hline & & & About Attributes & About Alternatives \\
\hline$(1)$ & $(2)$ & (3) & $(4)$ & $(5)$ \\
\hline Dominance & Screening & N/A & none & none \\
\hline Maximin & $\begin{array}{l}\text { Ranking, } \\
\text { Choosing }\end{array}$ & Noncompensatory & none & none \\
\hline Maximax & $\begin{array}{l}\text { Ranking, } \\
\text { Choosing }\end{array}$ & Noncompensatory & none & none \\
\hline $\begin{array}{l}\text { Conjunctive } \\
\text { ("Satisficing") }\end{array}$ & Screening & Noncompensatory & $\begin{array}{l}\text { minimum performance } \\
\text { for each attribute }\end{array}$ & none \\
\hline Disjunctive & Screening & Noncompensatory & $\begin{array}{l}\text { minimum performance } \\
\text { for each attribute }\end{array}$ & none \\
\hline Lexicographic & $\begin{array}{l}\text { Ranking, } \\
\text { Choosing }\end{array}$ & Noncompensatory & $\begin{array}{l}\text { ordinal importance } \\
\text { rankings }\end{array}$ & none \\
\hline $\begin{array}{l}\text { Lexicographic } \\
\text { Semi-Order }\end{array}$ & $\begin{array}{l}\text { Ranking, } \\
\text { Choosing }\end{array}$ & Noncompensatory & $\begin{array}{l}\text { ordinal importance } \\
\text { rankings, and } \\
\text { ranges for "ties" }\end{array}$ & none \\
\hline $\begin{array}{l}\text { Elimination by } \\
\text { Aspects }\end{array}$ & Choosing & Noncompensatory & $\begin{array}{l}\text { ordinal importance } \\
\text { rankings, and } \\
\text { minimum performance }\end{array}$ & none \\
\hline $\begin{array}{l}\text { Linear } \\
\text { Assignment } \\
\text { Method }\end{array}$ & $\begin{array}{l}\text { Screening, } \\
\text { Ranking, } \\
\text { Choosing }\end{array}$ & $\begin{array}{c}\text { Partially } \\
\text { Compensatory }\end{array}$ & $\begin{array}{c}\text { cardinal } \\
\text { importance } \\
\text { "weights" }\end{array}$ & $\begin{array}{l}\text { ordinal } \\
\text { evaluation/performance } \\
\text { rankings }\end{array}$ \\
\hline $\begin{array}{l}\text { Additive } \\
\text { Weighting } \\
\text { (includes. AHP) }\end{array}$ & $\begin{array}{l}\text { Screening, } \\
\text { Ranking, } \\
\text { Choosing }\end{array}$ & Compensatory & $\begin{array}{l}\text { cardinal } \\
\text { importance } \\
\text { "weights" }\end{array}$ & $\begin{array}{c}\text { cardinal } \\
\text { evaluation/performance } \\
\text { ratings } \\
\end{array}$ \\
\hline $\begin{array}{l}\text { Weighted } \\
\text { Product }\end{array}$ & $\begin{array}{l}\text { Screening, } \\
\text { Ranking, } \\
\text { Choosing } \\
\end{array}$ & Compensatory & $\begin{array}{l}\text { cardinal } \\
\text { importance } \\
\text { "weights" }\end{array}$ & $\begin{array}{c}\text { cardinal } \\
\text { evaluation/performance } \\
\text { ratings } \\
\end{array}$ \\
\hline NCTC & $\begin{array}{l}\text { Screening, } \\
\text { Ranking, } \\
\text { Choosing } \\
\end{array}$ & Compensatory & $\begin{array}{r}\text { paired co } \\
\text { differences fro } \\
\text { among pairs of attrib } \\
\end{array}$ & $\begin{array}{l}\text { Darisons of } \\
\text { baseline values, } \\
\text { es, for each alternative }\end{array}$ \\
\hline TOPSIS & $\begin{array}{l}\text { Screening, } \\
\text { Ranking, } \\
\text { Choosing }\end{array}$ & Compensatory & $\begin{array}{l}\text { cardinal } \\
\text { importance } \\
\text { "weights" }\end{array}$ & $\begin{array}{c}\text { cardinal } \\
\text { evaluation/performance } \\
\text { ratings }\end{array}$ \\
\hline $\begin{array}{l}\text { Distance from } \\
\text { Target }\end{array}$ & $\begin{array}{l}\text { Screening, } \\
\text { Ranking, } \\
\text { Choosing } \\
\end{array}$ & Compensatory & $\begin{array}{l}\text { cardinal } \\
\text { importance } \\
\text { "weights" }\end{array}$ & $\begin{array}{c}\text { cardinal } \\
\text { evaluation/performance } \\
\text { ratings }\end{array}$ \\
\hline
\end{tabular}

Exhibit 2-2. Classes of methods for multiattribute decision analysis. 
The methods require different amounts and types of information about the attributes and alternatives, above and beyond the basic data included in the decision matrix. Some methods (the dominance, maximin, and maximax methods) require no additional information besides the basic decision matrix data. Others methods (including four of the last five methods listed in Exhibit 2-2) require cardinal attribute importance "weights" and cardinal performance ratings of the alternatives with respect to the attributes. Methods requiring this additional information place heavier demands on the decision maker (in terms of time, thought, and possibly information searching required), but in turn they are able to combine, evaluate, and trade-off the decision matrix data in more sophisticated ways than the simpler methods. Columns 4 and 5 of Exhibit 2-2 indicate the information requirements, above and beyond the decision matrix data, of each of the listed methods.

To arrive at this set of method classes, we started with an initial comprehensive taxonomy of MADA methods developed by Hwang and Yoon, ${ }^{15}$ which included 17 major method classes. Hwang later updated this taxonomy ${ }^{16}$ by adding three new methods and excluding six of the original methods which were deemed not practical for application to real-world problems. To Hwang's set of method classes we added a technique recently developed by Boucher and MacStravic ${ }^{17}$ labeled NCIC. We also deleted Benayoun's ELECTRE method, ${ }^{18}$ which Chen and Hwang found to provide only partial prioritization of alternatives, and to entail a particularly elaborate computational procedure which increases rapidly in computational intensity as the number of alternatives increases. ${ }^{19}$

In the next two sections, we discuss two important aspects of MADA methods: (1) the types of MADA problems which the methods are suited to solve, and (2) whether or not the methods allow the decision maker to trade off levels of performance among attributes. These considerations lead us to identify a subset of five method classes (shaded boxes in col. 1 of Exhibit 2-2) of particular interest to the evaluation of building investment alternatives. From this subset, we then select two particular methods--NCIC and AHP--for detailed examination, based on their demonstrated ability to practically accommodate problems with a large number of relevant attributes.

\subsubsection{Three Types of MADA Problems}

MADA methods can address three types of problems: screening alternatives, ranking alternatives, or choosing a final "best" alternative. Note that if a method generates a cardinal ranking of the alternatives, then it can be used for both screening and choosing as well as ranking. The last six of the 14 method classes listed in col. 1 of Exhibit 2-2 are of this "multi-purpose" variety.

${ }^{15}$ Hwang and Yoon, Multiple Attribute Decision Making, 1981, pp. 10-11.

${ }^{16}$ F. Hwang, An Expert Decision Making Support System for Multiple Attribute Decision Making, Ph.D. Thesis, Department of Industrial Engineering, Kansas City University, 1987.

${ }^{17}$ R. Boucher and E. L. MacStravic, "Multiattribute Evaluation Within a Present Worth Framework and Its Relation to the Analytic Hierarchy Process, "Engineering Economics, 37, 1991.

${ }^{18}$ R. Benayoun, B. Roy, and N. Sussman, "Manual de reference du programme Electre, Note do Synthese et Formation, "Direction Scientifique SEMA, No. 25, 1966.

${ }^{19}$ Chen and Hwang, Fuzzy Multiple Attribute Decision Making, 1992, p. 37. 
As indicated by the columns 4 and 5 of Exhibit 2-2, the six "multi-purpose" method classes tend to require more information and computations than the methods which only screen alternatives. Thus, in cases where the initial number of alternatives is large (e.g., in excess of 10), "narrowing the field" through the use of simple screening methods first will reduce the computational and information burdens of subsequent ranking or choice analyses. An instance where the prior use of simple screening methods is a "must" is when there exist minimum requirements with respect to one or more attributes; the conjunctive method is particularly well-suited to this situation.

\subsubsection{Compensatory versus Noncompensatory Methods}

In many cases, the decision maker may be of the view that high performance relative to one attribute can at least partially compensate for low performance relative to another attribute--particularly if an initial screening analysis has eliminated alternatives which fail to meet any minimum performance requirements. Methods which incorporate tradeoffs between high and low performance into the analysis are termed "compensatory." Those which do not are termed "noncompensatory." The last five of the 14 method classes listed in Exhibit 2-2 are fully compensatory.

Compensatory methods, in order to accommodate tradeoffs of low versus high performance among attributes, generally either require that the attributes be all measured in commensurate units, or that the methods incorporate procedures for normalizing data which is not initially commensurate in order to facilitate attribute tradeoff analyses.

\subsubsection{The Attribute Weighting Problem}

Most MADA methods, whether compensatory or noncompensatory, single purpose or multi-purpose, allow the decision maker to assign different levels of importance to different attributes. Among the subset of five methods which are both fully compensatory and multi-purpose, the relative importance of attributes is generally reflected by assigning separate numerical multipliers, or "weights," to each attribute.

In cases with more than two attributes, people often find it difficult to directly specify relative importance weights all at once. A common two-part approach for overcoming this difficulty is to: (1) convert the "all-at-once" weighting problem into one of making pairwise comparisons among attributes; ${ }^{20}$ and (2) specify a computational procedure for converting the paired comparison data into attribute weights. Several computational procedures for converting matrices of paired comparisons into weights are available. ${ }^{21}$

${ }^{20}$ The use of paired comparisons is reviewed in Arthur E. Mudge, Value Engineering, A Systematic Approach, 1989.

${ }^{21}$ Hwang and Yoon, in Multiple Attribute Decision Making, 1981, review four procedures for assessing weights, pp. 41-57. Other simpler procedures are described in Alphonse Dell 'Isola, Value Engineering in the Construction Industry, New York: Van Nostrand Reinhold, 1982. 
The number of possible attribute pairs grows rapidly as more attributes are added, ${ }^{22}$ which in turn increases the time and effort required to input the required set of pairwise comparisons. To alleviate this problem, some methods include procedures which allow decision makers to describe their problems in a hierarchical fashion by (1) grouping sets of attributes together when the number of attributes becomes too large, and (2) dividing complex attributes into sets of subattributes. Such techniques reduce the total number of paired comparisons required.

\subsection{Summary Descriptions of MADA Methods}

This section provides very brief descriptions for each of the 14 MADA methods which appear in Exhibit 2-2. The summaries provided here draw upon information in the third chapter of the review by Hwang and Yoon, ${ }^{23}$ and the second chapter of the review by Chen and Hwang. ${ }^{24}$

\section{Dominance}

An alternative is "dominated" if another alternative out-performs it with respect to at least one attribute, and performs equally with respect to the remainder of attributes. With the Dominance method, alternatives are screened such that all dominated alternatives are discarded. The screening power of this method tends to decrease as the number of independent attributes becomes larger.

\section{Maximin}

The principle underlying the Maximin method is that "a chain is only as strong as its weakest link." Effectively, the method gives each alternative a score equal to the strength of its weakest link, where the "links" are the attributes. Thus, it requires that performance with respect to all attributes be measured in commensurate units (very rare for MADA problems) or else be normalized prior to performing the method.

\section{Maximax}

The viewpoint underlying the Maximax method is one which assigns total importance to the attribute with respect to which each alternative performs best. Extending the "chain" analogy used in describing the Maximin method, Maximax performs as if one was comparing alternative chains in search of the best single link. The score of each chain (alternative) is equal to the performance of its strongest link (attribute). Like the Maximin method, Maximax requires that all attributes be commensurate or else pre-normalized.

\section{Conjunctive ("Satisficing")}

The Conjunctive method is purely a screening method. The requirement embodied by the Conjunctive screening approach is that in order to be acceptable, an alternative must exceed given performance thresholds for all attributes. The attributes (and thus the thresholds) need not be measured in commensurate units.

\footnotetext{
${ }^{22} \mathrm{Neglecting}$ comparison of an attribute with itself, the number of different attribute pairs is equal to $\mathrm{n}^{*}(\mathrm{n}-1) / 2$, where $\mathrm{n}$ is the number of attributes.

${ }^{23}$ Hwang and Yoon, Multiple Attribute Decision Making, 1981.

${ }^{24}$ Chen and Hwang, Fuzzy Multiple Attribute Decision Making, 1992.
} 


\section{Disjunctive}

The Disjunctive method is also purely a screening method. It is the complement of the Conjunctive method, substituting "or" in place of "and." That is, to pass the Disjunctive screening test, an alternative must exceed the given performance threshold for at least one attribute. Like the Conjunctive method, the Disjunctive method does not require attributes to be measured in commensurate units.

\section{Lexicographic}

The best-known application of the Lexicographic method is, as its name implies, alphabetical ordering such as is found in dictionaries. Using this method, attributes are rank-ordered in terms of importance. The alternative with the best performance on the most important attribute is chosen. If there are ties with respect to this attribute, the next most important attribute is considered, and so on. Note two important ways in which MADA problems typically differ from alphabetizing dictionary words. First, there are many fewer alternatives in a MADA problem than words in the dictionary. Second, when the decision matrix contains quantitative attribute values, there are effectively an infinite rumber (rather than 26 (i.e., A-Z)) of possible scores with a correspondingly lower probability of ties.

\section{Lexicographic Semi-Order}

This is a slight variation on the Lexicographic method, where "near-ties" are allowed to count as ties, without any penalty to the alternative which scores slightly lower within the tolerance ("tie") window. Counting near-ties as ties make the Lexicographic method less of a "knife-edged" ranking method, and more appropriate for MADA problems with quantitative data in the decision matrix. However, the method can lead to intransitive results, wherein $A$ is preferred to $B, B$ is preferred to $C$, but $C$ is preferred to $A$.

\section{Elimination by Aspects}

This method is a formalization of the well-known heuristic, "process of elimination." Like the Lexicographic method, evaluation proceeds one attribute at a time, starting with attributes determined to be most important. ${ }^{25}$ Then, like the conjunctive method, alternatives not exceeding minimum performance requirements--with respect to the single attribute of interest, in this case--are eliminated. The process generally proceeds until one alternative remains, although adjustment of the performance threshold may be required in some cases in order to achieve a unique solution.

\section{Linear Assignment Method}

This method requires, in addition to the decision matrix data, cardinal importance weights for each attribute and rankings of the alternatives with respect to each attribute. These information requirements are intermediate between those of the 8 methods described previously, and the 5 methods which follow, in that they require ordinal (but not cardinal) preference rankings of the alternatives with respect to each attribute. The primary use of the additional information is to enable compensatory rather than noncompensatory analysis, that is, allowing good performance on one attribute to compensate for low performance on another (see section 2.3.2.)

\footnotetext{
${ }^{25}$ As originally described the method entailed ranking attributes by their "discriminating power," which is a heuristic concept involving the probability of the alternatives to be differentiated with respect to the attributes. This concept is difficult to operationalize and so is not suggested for use in MADA analysis.
} 
Note at this point that quantitative attribute values (data in the decision matrix) do not constitute cardinal preference rankings. Attribute values are generally non-commensurate across attributes, preference is not necessarily linearly increasing with attribute values, and preference for attribute values of zero is not generally zero. However, as long as the decision maker can specify an ordinal correspondence between attribute values and preference, such as "more is better" or "less is better" for each attribute, then the ordinal alternative rankings with respect to each attribute which are needed by the Linear Assignment method are uniquely specified. Thus, the evaluation/performance rankings required by the Linear Assignment method are easier to derive than the evaluation/performance ratings required by the 5 methods which follow. The cost of using ordinal rankings rather than cardinal ratings is that the method is only "semi-compensatory," in that incremental changes in the performance of an alternative will not enter into the analysis unless the changes are large enough to alter the rank-order of the alternatives.

\section{Additive Weighting}

The additive weighting method is described in detail in chapter 4 of this report. To summarize, the score of an alternative is equal to the weighted sum of its cardinal evaluation/preference ratings, where the weights are the importance weights associated with each attribute. The resulting cardinal scores for each alternative can be used to rank, screen, or choose an alternative. The Analytical Hierarchy Process (AHP), which is described at length in chapter 4, is a particular approach to the additive weighting method.

\section{Weighted Product}

The weighted product is quite similar to the additive weighting method. However, instead of calculating "sub-scores" by multiplying performance scores times attribute importances, performance scores are raised to the power of the attribute importance weight. Then, rather than summing the resulting subscores across attributes to yield the total score for the alternative, the product of the scores yields the final alternative scores. The weighted product method tends to penalize poor performance on one attribute more heavily than does the additive weighting method.

NCIC

This method, too, is described at length later in the report (in chapter 5). The method entails pairwise comparisons of the performance gains (over a baseline alternative) among attributes, for a given alternative. One of the attributes must be measured in monetary units. These comparisons are combined to estimate the (monetary) value attributed to each performance gain, and these values are summed to yield the overall implied value of each alternative. These implied values can be used to select an alternative, to rank alternatives, or presumably to screen alternatives as well.

\section{TOPSIS}

The principle behind TOPSIS is simple: the chosen alternative should be as close to the ideal solution as possible, and as far from the negative-ideal solution as possible. The ideal solution is formed as a composite of the best performance values exhibited (in the decision matrix) by any alternative for each attribute. The negative-ideal solution is the composite of the worst performance values. Proximity to each of these performance poles is measured in the Euclidean sense (e.g., square root of the sum of the squared distances along each axis in the "attribute space"), with optional weighting of each attribute. The method, and results, are simple to depict graphically. 


\section{Distance from Target}

This method and its results are also straightforward to describe graphically. First, target values for each attribute are chosen, which need not be exhibited by any available alternative. Then, the alternative with the shortest distance (again in the Euclidean sense) to this target point in "attribute space" is selected. Again, weighting of attributes is possible. Distance scores can be used to screen, rank, or select a preferred alternative.

\subsection{AHP and NCIC}

In principle, any MADA method which requires cardinal weighting of attributes can utilize paired comparisons as a means to establish the attribute weights. But only two particular methods out of the five fully-compensatory, multi-purpose method classes appearing in Exhibit 2-2 incorporate directly a paired comparison procedure together with a pre-specified approach for converting the comparisons into attribute weights. Both methods also allow hierarchical descriptions of problems in order to keep the number of pairwise comparisons manageable. The two methods are the Analytical Hierarchy Process (AHP), ${ }^{26}$ and the Non-Traditional Capital Investment Criteria (NCIC) method. ${ }^{27}$

AHP is a type of additive weighting method. It has been widely reviewed and applied in the literature, and its use is supported by several commercially available user-friendly software packages.

NCIC was designed by its originators to address some of the criticisms of AHP which have appeared in the literature. It develops "scores" for alternatives which are denominated in monetary terms, making otherwise implied valuation of attributes explicit and allowing the results to be incorporated into traditional economic worth analyses. Its application to building investment decision making is not yet supported by user-friendly software. For this reason, a simple computer program which accomplishes the basic computations required to implement NCIC is included in Appendix $\mathbf{B}$ to this report.

${ }^{26}$ AHP was developed by Thomas L. Saaty, The Analytic Hierarchy Process: Planning, Priority Setting, Resource Allocation, Pittsburgh: University of Pittsburgh, 1980.

${ }^{27}$ NCIC was developed by Boucher and MacStravic, "Multiattribute Evaluation Within a Present Worth Framework and Its Relation to the Analytical Hierarchy Process, "Engineering Economics, 37, 1991. 


\section{Recommended Attributes and Typical Building Decisions for MADA}

Section 3.1 presents a list of attributes to help you perform a MADA in support of building-related decisions. Appendix A defines in more detail each of the attributes in the list. Use the list of attributes and other attributes that you define to develop a customized model for specific projects. Section 3.2 presents typical building-related decisions for which MADA is useful. For each decision example, we identify the objective, select attributes and display them in a hierarchy, and illustrate how to set up the MADA model.

\subsection{Attributes for Building Evaluations}

The alphabetical list of attributes in Exhibit 3-1 contains 15 attributes and corresponding subattributes that decision makers typically find important in making building-related choices. ${ }^{28}$ It gives building investment decision makers a ready-made set of building attributes to choose from when developing a MADA model for comparison of building alternatives. The attributes and subattributes in Exhibit 3-1 were condensed from two sources. One is the extensive list of serviceability factors that ASTM's Subcommittee E06.25 on Whole Buildings and Facilities is developing to rate a facility's capability to perform its desired functions. ${ }^{29}$ The second source is the collective experience and suggestions from the ASTM Subcommittees on Building Economics (Subcommittee E06.81) and Whole Building Performance (E06.25).

The descriptions of the attributes apply primarily to office or commercial buildings. The attributes are appropriate, however, for evaluating residential choices. For example, to make the location attribute applicable to a residential evaluation, substitute "homeowner" for "staff" and "friends and visitors" for "clients and customers."

Some of the attributes, such as durability, economics, location, and environmental impacts, are also appropriate when using AHP to evaluate constructed facilities other than buildings. This includes dams, water supply and waste treatment facilities, transportation infrastructure, and other public works type projects. Alter the attributes or subattributes cited in Exhibit 3-1 or add new attributes to make the decision model fit the type of facility being evaluated.

\footnotetext{
${ }^{28}$ Note that you may be limited to nine or fewer categories and attributes in each set of a hierarchy because that is the maximum number of elements that can be conveniently handled by some of the software programs that support AHP computations. If the computer program does not handle the attributes you need, then group them in sets that the program can support.

${ }^{29}$ Davis, "How to Get the Building You Need," 1992. Note that economics is not among the ASTM E06.25 list. When applying these serviceability factors in a MADA application, be sure to include economics as one of the attributes or at least consider it as a constraint on choices among alternatives.
} 


\begin{tabular}{|c|c|}
\hline Attribute & Subattribute \\
\hline \multirow[t]{2}{*}{ Aesthetics } & Image owner wants to project \\
\hline & Attractiveness of design inside and outside (building and site) \\
\hline \multirow[t]{4}{*}{ Building Functions } & Layout \\
\hline & Space (for office/shipping/storage/meeting/training) \\
\hline & Parking \\
\hline & Plant \\
\hline \multicolumn{2}{|l|}{ Durability } \\
\hline \multirow[t]{3}{*}{ Economics } & First cost budget requirements \\
\hline & Life-cycle costs, net savings, adjusted internal rate of return \\
\hline & OM\&R cost requirements \\
\hline \multicolumn{2}{|l|}{ Environmental Impacts } \\
\hline \multicolumn{2}{|l|}{$\begin{array}{l}\text { Flexibility in Functional } \\
\text { Use and Disposition }\end{array}$} \\
\hline \multirow[t]{2}{*}{ Information Technology } & Power supply and distribution \\
\hline & Telecommunications and computer infrastructure \\
\hline \multirow[t]{2}{*}{ Location } & Acceptance of clients, customers, or public who use it \\
\hline & Acceptance of staff (need to relocate? cause high staff turnover?) \\
\hline \multicolumn{2}{|l|}{ Occupancy Availability } \\
\hline \multirow{2}{*}{$\begin{array}{c}\text { Operation and } \\
\text { Maintenance }\end{array}$} & Ease and staff requirements of operations \\
\hline & Ease, frequency, and staff requirements of maintenance \\
\hline \multicolumn{2}{|r|}{ 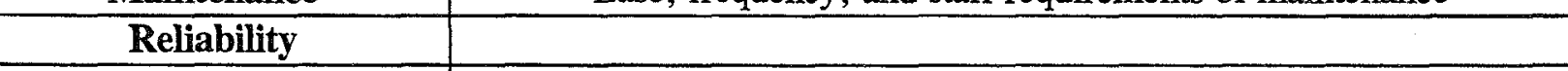 } \\
\hline Security & $\begin{array}{l}\text { Protection during and outside normal hours of workers and visitors } \\
\text { inside and outside the building on site }\end{array}$ \\
\hline \multirow{4}{*}{$\begin{array}{l}\text { Sound and Visual } \\
\text { Environment }\end{array}$} & Aural privacy and ambient noise \\
\hline & Light and glare \\
\hline & Occupant control of conditions \\
\hline & View to the outside \\
\hline \multirow{3}{*}{$\begin{array}{l}\text { Thermal Environment } \\
\text { and Air Quality }\end{array}$} & Air quality \\
\hline & Occupant control of conditions \\
\hline & Temperature, humidity, ventilation \\
\hline \multirow[t]{2}{*}{ Transportation } & $\begin{array}{l}\text { Availability, cost, and convenience of public and private transportation } \\
\text { to the site }\end{array}$ \\
\hline & Efficiency and ease of movement of people on site \\
\hline
\end{tabular}

Exhibit 3-1. Attributes for building-related decisions. 


\subsection{Types of Building-Related Decisions}

There are four common types of MADA building-related choice decisions: choosing among buildings, choosing among building components, choosing among building materials, and choosing the location for a business or household. The following sections illustrate for these four decision types how to identify the goal, select attributes, and display them in a hierarchy.

\subsubsection{Choosing Among Buildings-Public Building Example}

A state agency needs, within the next 18 months, office space for 300 workers. It seeks a location that will enable workers to go to and from the state capitol building by shuttle. The agency seeks to minimize the travel time and will not accept times greater than 10 minutes. It also has telecommunications and computer infrastructure requirements that will exclude many buildings. What is the best building for the agency?

The specification of 10 minutes maximum travel time from the site to the capitol eliminates all buildings outside a certain radius. Having up to 18 months to occupy allows either the construction of a new building or the retrofitting of an existing building, either of which could be rented or leased. Telecommunications and computer infrastructure requirements will limit the search even more.

A MADA analysis will help the agency evaluate the relative importance of its requirements. Attributes from Exhibit 3-1 that are significant in this case are occupancy availability (within 18 months); information technology (available telecommunications and computer support infrastructure); economics (life-cycle costs of alternative buildings, owned or leased); and location (how convenient to capitol building). Exhibit 3-2 displays these attributes in a hierarchy. The inclusion of additional attributes from Exhibit 3-1 depends on other perceived needs of the decision maker.

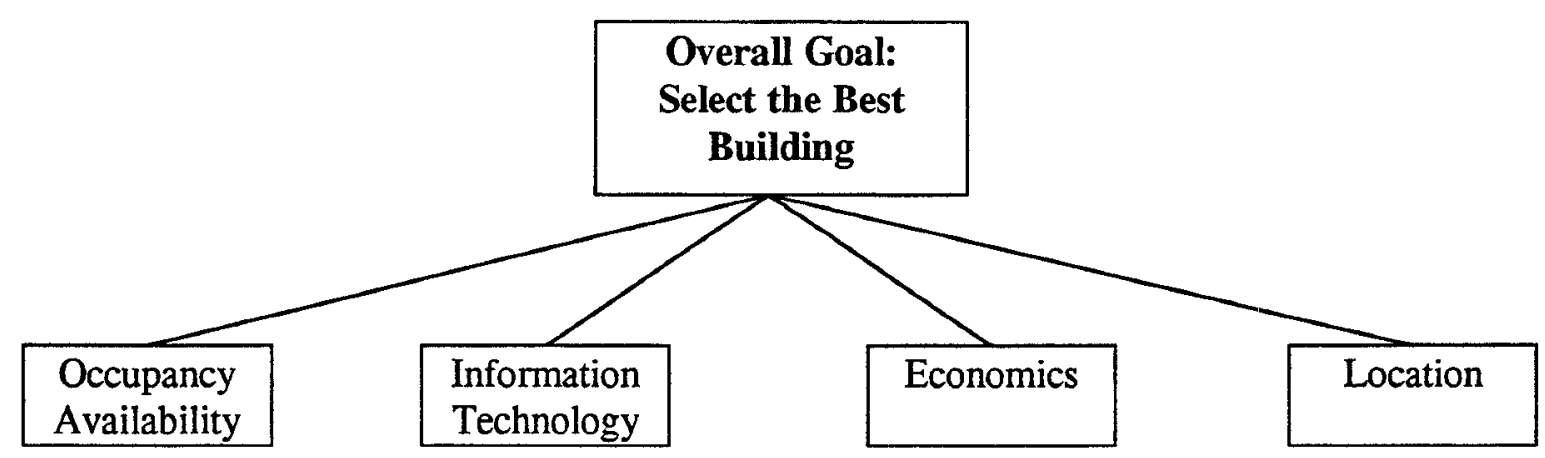

Exhibit 3-2. An example hierarchy for the problem of selecting a building. 


\subsubsection{Choosing Among Buildings--Residential Example}

A real estate company specializing in residential properties wants a computer-based decision tool to help clients select the "best" match between their individual housing wants and what is available on the multiple listing. An out-of-town client on a two-day house search comes to the real estate office and asks to be shown houses. The client wants a four-bedroom, three-bath, traditional home with two-car garage in the suburbs that is reasonably accessible to a commuter train station on route to the central business district. The client wants a highly regarded, safe neighborhood, and is willing to pay up to $\$ 200,000$ for the house. An important consideration to the client is the quality of the public schools. Find the best house for the client.

A MADA analysis is appropriate here in two stages. First, the real estate salesperson uses one of the MADA screening methods to help the client select the set of houses to visit. Attributes from Exhibit 3-1 that are significant are building functions (number and size of rooms and baths, capacity of garage); aesthetics (tastefully designed traditional home); location (accessibility to commuter station, desirability of neighborhood, proximity of good public schools); security; and economics (budget constraint). Exhibit 3-3 displays the hierarchy of attributes. The house-hunting client visits the houses which pass the screening analysis.

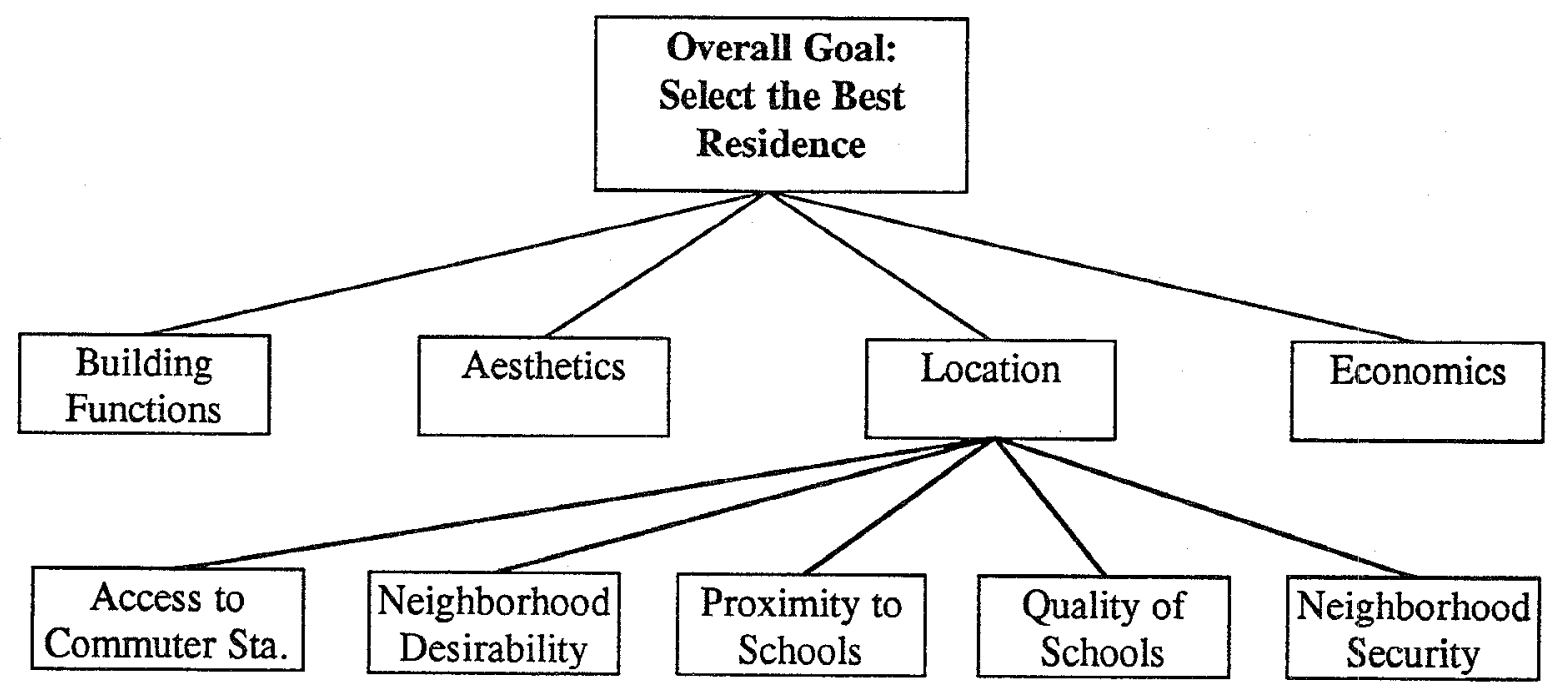

Exhibit 3-3. An example hierarchy for the problem of selecting a residence.

The real estate salesperson does the MADA analysis a second time once the client has seen the selected houses and has additional information for constructing a more detailed decision matrix. A MADA analysis with a plot or graph of the score of each house helps satisfy home buyers that they are selecting the house that is best for them. 


\subsubsection{Choosing Among Components}

A trade association representing the heating and cooling equipment industry is choosing among three high-technology systems for retrofitting its office building. It wants to show the state of the art in its choice of equipment components, but at the same time it does not want to appear to its constituency as being uneconomic in its choice of a heating and cooling system. Furthermore, the association does not want the equipment to impair the existing successful operation and maintenance of the building. Help the trade association identify the best alternative among the candidate systems.

The association selects several attributes from Exhibit 3-1 in evaluating the systems. In seeking to show the state of the art in equipment, the association acknowledges that image to the owner is important. They also agree that economics must be taken into account. Maintaining successful building functions, smooth operation and maintenance, a high level of thermal environment and air quality, and a high standard of sound and visual environment are also important. Exhibit 3-4 displays a hierarchy made up of these attributes.

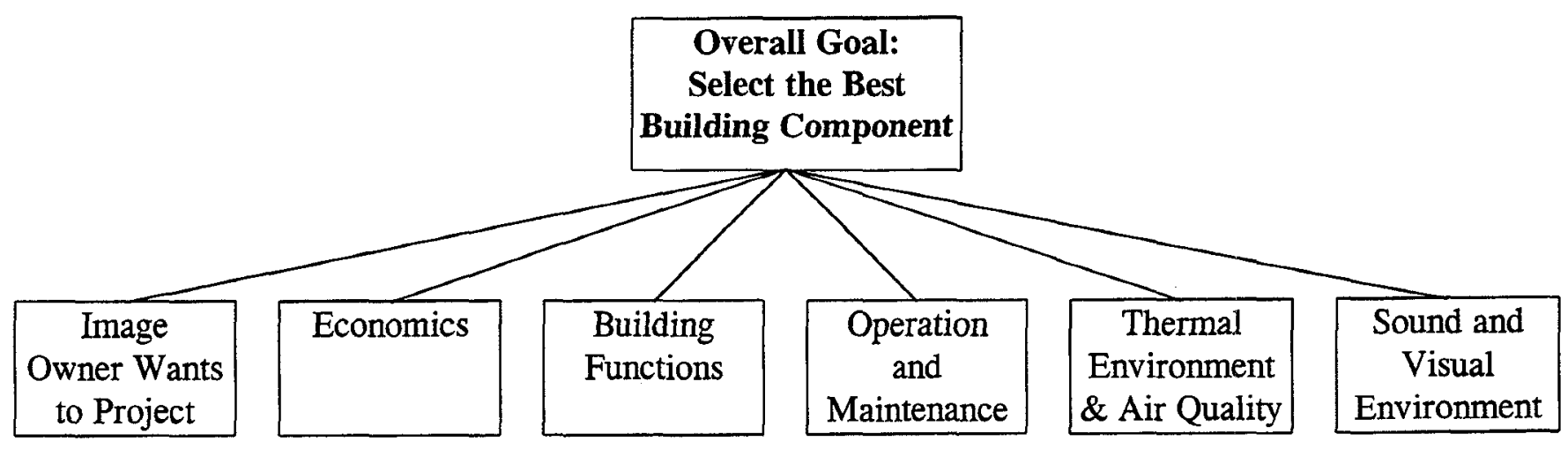

Exhibit 3-4. An example hierarchy for the problem of selecting a building component.

\subsubsection{Choosing Among Materials}

An architect is working with clients to select materials for a large office building. The clients tell the architect that they want a building made from materials that are friendly to the environment. The clients qualify their specifications, however, to say that they do not want the building's functions to be compromised by the design or choice of materials. They go on to say that, while they are willing to spend more money on materials to achieve a "green building," cost is still a consideration. The architect decides to use MADA to make the material choices that will best satisfy the clients' needs. 
Looking again at Exhibit 3-1, it appears that environmental impacts, economics, building functions, and operation and maintenance are important to the clients. Exhibit 3-5 displays a hierarchy made up of these attributes.

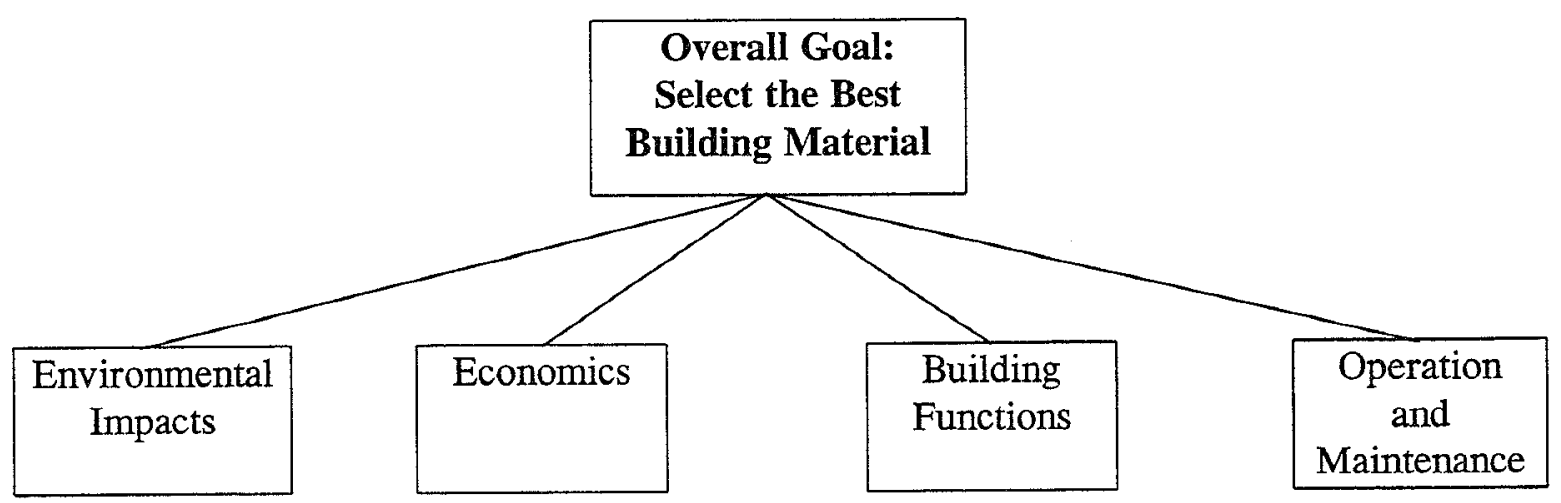

Exhibit 3-5. An example hierarchy for the problem of selecting a building material.

\subsubsection{Choosing Among Locations ${ }^{30}$}

A large corporation is seeking the best location in the U.S. for a new manufacturing plant. The search committee is seeking an area where there will be a continuing, abundant, sufficiently educated labor pool to staff an assembly line employing state-of-the-art technology. The company is looking for an area where the demand for labor is low, the community will offer incentives to a new company, there are amenities to attract and retain employees, and where management can likely operate a non-union plant. Convenient and centrally located transportation nodes are also important. The major objective is to hold down costs and remain competitive with foreign manufacturers. Environmental and cultural amenities are also important, however, to attract a high quality management team. The search committee uses MADA to find the best location.

The search committee identifies several attributes from Exhibit 3-1 and some others as important in their quest for the best location: economics (hold down costs to remain competitive); local education system that will provide adequately skilled employees (who are able to work in a state-of-the-art

${ }^{30}$ There is a literature on location theory which investigates the factors that influence location decisions by businesses and households, and which develops predictive or explanatory decision models. For a survey of how Fortune 500 corporations make location decisions, see Robert W. Schmenner, The Location Decisions of Large, Multiplant Companies: A Summary of Findings (Washington, DC: U.S. Department of Housing and Urban Development, HUD Report No. 0002353, 1981). See also by Schmenner, Service Sector Location Decision Making: Some Midwestern Evidence (Bloomington, IN: Institute for Development Strategies, Indiana University, 1990), and Making Business Location Decisions (Englewood Cliffs, NJ: Prentice-Hall, 1982). 
factory); transportation (efficiently moving raw materials in and finished product out); and environmental and cultural amenities. The committee structures their location choice problem as shown in Exhibit 3-6.

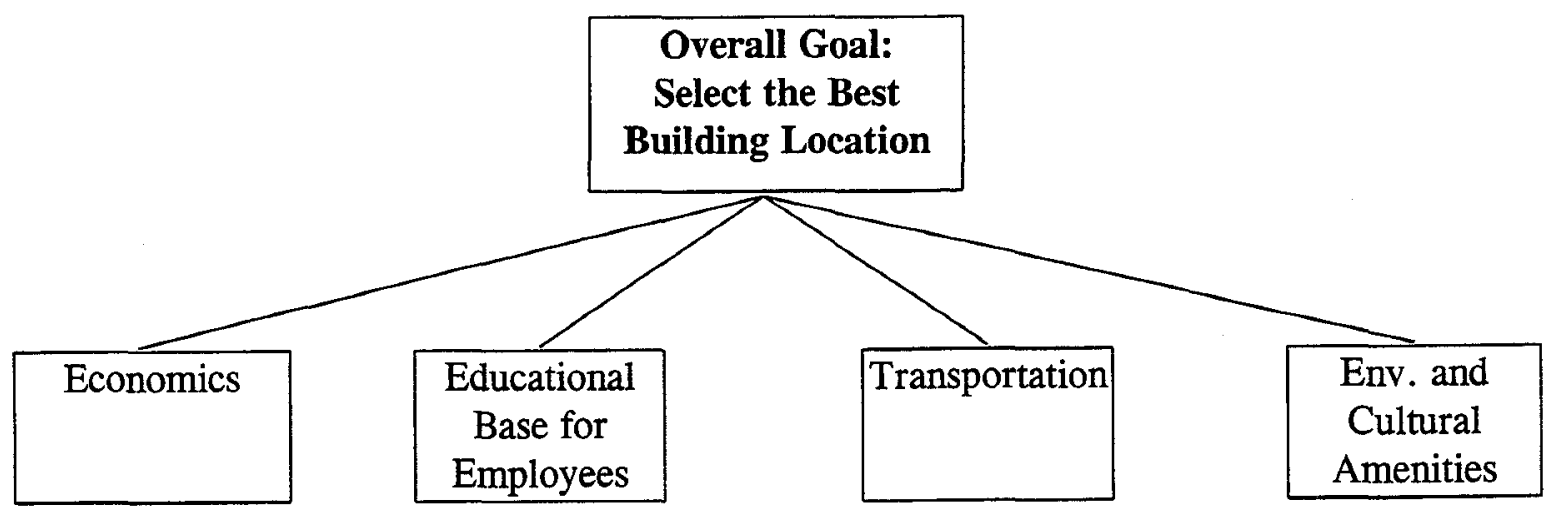

Exhibit 3-6. An example hierarchy for the problem of selecting a building location. 


\section{AHP}

The review of MADA methods in chapter 2 concluded by selecting two methods for detailed review. The first of these two methods is AHP. AHP is a MADA method which falls within the broader class of methods known as "additive weighting methods." For this reason, this chapter begins with a brief overview of additive weighting methods. We then describe the theoretical and practical substance of AHP in depth. The chapter concludes with a summary of the strengths and limitations of AHP as applied to building investment decisions.

\subsection{Additive Weighting Methods}

A comprehensive survey of MADA methods and applications found that additive weighting methods are probably the best known and most widely used of all MADA methods, ${ }^{31}$ owing to their simple and intuitive logic, their multi-purpose functionality, and their incorporation of compensatory tradeoffs among attributes. The basic logic of additive weighting methods consists of four principles, which are described below.

\subsubsection{Cardinal Alternative Scores}

Additive weighting methods use cardinal numerical scores which characterize the overall desirability of each alternative. These desirability scores, $D_{i}$ (for each of the $m$ alternatives, $i=1$, $\ldots, m)$, can then be used to rank the alternatives, to identify a subset of most preferred alternatives, or to select the single most preferred alternative.

\subsubsection{Cardinal Attribute Weights}

The relative importance of attributes to the decision maker is defined to be constant across alternatives, and is described using cardinal weights $\left(w_{j}\right)$ which the decision maker assigns to each of the $n$ attributes, $j=1, \ldots n$. The weights are generally normalized so that they sum to 1 .

\subsubsection{Contributions to Desirability}

The performance of each alternative with respect to each attribute must be expressed numerically, and the numerical "attribute scores" $\left(x_{i j}\right)$ must be comparable across attributes. ${ }^{32}$ An alternative's characteristics with respect to each attribute contribute a calculable amount to the total desirability score $\left(D_{j}\right)$ of the alternative. This contribution is calculated as the product of the attribute score $\left(x_{i j}\right)$ with the attribute importance weight $\left(w_{j}\right)$.

\footnotetext{
${ }^{31}$ Hwang and Yoon, "Multiple Attribute Decision Making," 1981, p. 99.

${ }^{32}$ Comparability of attribute scores is usually achieved by normalizing the scores within each attribute. This procedure is described later in Section 4.5.3.
} 


\subsubsection{Additivity}

The separate contributions of each attribute to the total desirability score of an alternative are considered to be additive. That is, the overall desirability score for an alternative is defined as the sum of the individual attributes' contributions:

$$
D_{i}=\sum_{j=1}^{n} w_{j} x_{i j}
$$

In summary, the additive weighting method facilitates the screening, ranking, and choosing of alternatives by developing a cardinal numerical score for each alternative. The score for a particular alternative trades off that alternative's different levels of performance among attributes in a compensatory way, by using cardinal attribute weights supplied by the decision maker, and by requiring that "performance" with respect to each attribute be characterized numerically and comparably for all attributes. ${ }^{33}$

\subsubsection{AHP Relative to the Basic Additive Weighting Method}

The Analytical Hierarchy Process was developed primarily by Saaty. ${ }^{34}$ It has been widely applied, and has been discussed extensively in the peer-reviewed literature. ${ }^{35}$

There are three important ways in which the AHP method extends the basic additive weighting method described in the previous section. These are its use of pairwise comparisons, the principal eigenvector method, and hierarchy. Sections 4.2-4.4 take up these three aspects of AHP in turn. Section 4.5 addresses the problem of converting the elements of the decision matrix to comparable numerical values in the context of AHP.

${ }^{33}$ Just like the additive weighting method, the weighted product method also generates cardinal numerical scores for each alternative (as shown in Exhibit 2-2), with fully compensatory inter-attribute tradeoffs which utilize cardinal attribute weights and which require that attribute values be both numerical and comparable. The only difference between the two methods lies in how they combine the attribute contributions (which equal $w_{f} x_{i j}$ in the additive weighting method) to form the final "desirability scores" $D_{i}$. The additive weighting method calculates $D_{i}$ as the sum of the attribute contributions, while the weighted product method calculates $D_{i}$ as the product of the attribute contributions (which are given in the weighted product method). The computational differences between the two methods have the effect that the weighted product method tends to penalize poor performance (i.e., low attribute values, $\boldsymbol{x}_{i j}$ ) more strongly than does the additive weighting method.

${ }^{34}$ See Thomas L. Saaty's books on The Analytic Hierarchy Process: Planning, Priority Setting, Resource Allocation, 1980, and Multicriteria Decision Making: The Analytic Hierarchy Process, 1988.

${ }^{35}$ See, for example, special issues of two separate journals: Socio-Economic Planning Sciences, Vol. 20, Number 6, 1986, and Mathematical Modeling, Vol. 9, Number 3-5, 1987. 


\subsection{Making Pairwise Comparisons}

Decision makers often find it difficult to accurately determine cardinal importance weights for a set of attributes simultaneously. As the number of attributes increases, better results are obtained when the problem is converted to one of making a series of pairwise comparisons. AHP formalizes the conversion of the attribute weighting problem into the more tractable problem of making a series of pairwise comparisons among competing attributes.

\subsubsection{Matrix of Pairwise Comparisons (MPC)}

AHP summarizes the results of pairwise comparisons in a "matrix of pairwise comparisons" (MPC), as shown in Exhibit 4-1. For each pair of attributes, the decision maker specifies a judgment about How much more important one attribute is than the other ${ }^{36}$ Each pairwise comparison requires the decision maker to provide an answer to the question: "Attribute $\mathrm{A}$ is how much more important than Attribute B, relative to the overall objective?"

There are two types of approaches for specifying pairwise comparison judgments in AHP: numerical and mediated. Both types of methods require the decision maker to answer a series of questions of the form: "how much more important is Attribute A than Attribute B?" When making numerical judgments, the decision maker answers each question with a number, as in "Attribute A is 3 times as important as Attribute B."

When decision makers find it difficult to translate their "fuzzy" judgments into precise numbers, mediated comparisons prove helpful. Two types of mediation are verbal and graphical. We discuss verbally mediated judgments here. ${ }^{37}$

Verbal mediation allows a decision maker to select (from a pre-specified list) a verbal answer for each judgment. Because verbal judgments express ordinal rather than cardinal judgments, some assumptions must be made when verbal judgments are translated into their pre-defined numerical equivalents in order to fill out the matrix of pairwise comparisons. Saaty has recommended using a 1-9 numerical scale with the verbal equivalents shown in Table 4-1. ${ }^{38}$ It is important that all comparisons for a given MPC rely on the same method (either direct numerical, verbally mediated,

${ }^{36}$ Note that the judgments in AHP's pairwise comparisons are therefore cardinal rather than simply ordinal. One specifies not only which attribute is considered to be more important, but also how much more important it is judged to be.

${ }^{37}$ Graphically mediated judgments are facilitated by software such as Expert Choice User's Guide by Decision Support Software, Inc., of Pittsburgh, PA. Such software allows the decision maker to express comparison judgments graphically, and then translates these graphical inputs into numerical comparison equivalents for use in calculations of the attribute weights.

${ }^{38}$ These verbal equivalents are taken from the Expert Choice Users Guide: "Getting Started", from Decision Support Software, Inc., Pittsburgh, PA, 1993, p. vii. Note that in earlier publications by Saaty (see, for example, Saaty, Multicriteria Decision Making: The Analytic Hierarchy Process, 1988, p. 54), the verbal equivalents were worded differently. 


\begin{tabular}{|c|c|c|c|c|c|c|c|}
\hline & Attribute 1 & Attribute 2 & $\ldots$ & Attribute $j$ & Attribute $k$ & $\ldots$ & Attribute $n$ \\
\hline Attribute 1 & 1 & $\begin{array}{l}\text { Importance } \\
\text { of Attribute } \\
1 \text { relative to } \\
\text { Attribute } 2\end{array}$ & & $\begin{array}{l}\text { Importance } \\
\text { of Attribute } \\
1 \text { relative to } \\
\text { Attributej }\end{array}$ & $\begin{array}{l}\text { Importance } \\
\text { of Attribute } \\
1 \text { relative to } \\
\text { Attribute } k\end{array}$ & & $\begin{array}{l}\text { Importance } \\
\text { of Attribute } \\
1 \text { relative to } \\
\text { Attribute } n\end{array}$ \\
\hline Attribute 2 & $\begin{array}{l}\text { Importance } \\
\text { of Attribute } \\
2 \text { relative to } \\
\text { Attribute } 1\end{array}$ & 1 & & $\begin{array}{l}\text { Importance } \\
\text { of Attribute } \\
2 \text { relative to } \\
\text { Attribute } j\end{array}$ & $\begin{array}{l}\text { Importance } \\
\text { of Attribute } \\
2 \text { relative to } \\
\text { Atribute } k\end{array}$ & & $\begin{array}{l}\text { Importance } \\
\text { of Attribute } \\
2 \text { relative to } \\
\text { Attribute } n\end{array}$ \\
\hline$\ldots$ & $\cdots$ & $\cdots$ & 1 & & & & \\
\hline Attribute $j$ & $\begin{array}{l}\text { Importance } \\
\text { of Attribute } j \\
\text { relative to } \\
\text { Attribute } 1\end{array}$ & $\begin{array}{l}\text { Importance } \\
\text { of Attribute } j \\
\text { relative to } \\
\text { Attribute } 2\end{array}$ & $\cdots$ & 1 & $\begin{array}{l}\text { Importance } \\
\text { of Attribute } j \\
\text { relative to } \\
\text { Attribute k }\end{array}$ & & $\begin{array}{l}\text { Importance } \\
\text { of Attribute } \\
\text { relative to } \\
\text { Attribute } n\end{array}$ \\
\hline Attribute $k$ & $\begin{array}{l}\text { Importance } \\
\text { of Attribute } \\
k \text { relative to } \\
\text { Attribute } 1\end{array}$ & $\begin{array}{l}\text { Importance } \\
\text { of Attribute } \\
k \text { relative to } \\
\text { Attribute } 2\end{array}$ & $\cdots$ & $\begin{array}{c}\text { Importance } \\
\text { of Attribute } \\
k \text { relative to } \\
\text { Attribute } j\end{array}$ & 1 & & $\begin{array}{l}\text { Importance } \\
\text { of Attribute } \\
k \text { relative to } \\
\text { Atribute } n\end{array}$ \\
\hline$\cdots$ & $\cdots$ & $\ldots$ & $\cdots$ & $\cdots$ & $\cdots$ & 1 & \\
\hline Attribute $n$ & $\begin{array}{l}\text { Importance } \\
\text { of Attribute } \\
n \text { relative to } \\
\text { Attribute } 1\end{array}$ & $\begin{array}{l}\text { Importance } \\
\text { of Attribute } \\
n \text { relative to } \\
\text { Attribute } 2\end{array}$ & $\cdots$ & $\begin{array}{l}\text { Importance } \\
\text { of Attribute } \\
n \text { relative to } \\
\text { Attribute } j\end{array}$ & $\begin{array}{c}\text { Importance } \\
\text { of Attribute } \\
n \text { relative to } \\
\text { Attribute } k\end{array}$ & $\cdots$ & 1 \\
\hline
\end{tabular}

Exhibit 4-1. A matrix of paired comparisons (MPC). ${ }^{A}$

A Note: only the $n(n-1) / 2$ shaded elements of the matrix (those above the matrix's diagonal) need to be filled in by the decision maker. The $n$ diagonal elements are all equal to 1 by definition, because each attribute is "exactly as important as itself." The $n(n-1) / 2$ elements below the diagonal are equal to the reciprocals of the corresponding elements above the diagonal; this is because, for example, if Attribute 1 is twice as important as Attribute 2, then Attribute 2 must be half as important as Attribute 1. 
or graphically mediated) and scale, in order to ensure direct comparability within the set of judgments.

Table 4-1. Verbal scale for pairwise comparisons of attributes in AHP

\begin{tabular}{|c|c|}
\hline Verbal Judgment & Numerical Equivalents \\
\hline \hline Extremely more important & 9 \\
\hline Between very strongly and extremely more important & 8 \\
\hline Very Strongly more important & 7 \\
\hline Between strongly and very strongly more important & 6 \\
\hline Strongly more important & 5 \\
\hline Between moderately and strongly more important & 4 \\
\hline Moderately more important & 3 \\
\hline Between equally and moderately more important & 2 \\
\hline Equally as important & 1 \\
\hline
\end{tabular}

Note that it can be proven mathematically that for some problems the decision outcome (selected alternative) can be altered by simply changing the scale of numerical equivalents, even when the verbal judgments all remain unchanged..$^{39}$ The decision outcome is particularly sensitive to the scale of numerical equivalents when numerical "performance" data is used directly to develop the alternative "ratings" (as described in section 4.5.1).

Because of this sensitivity of results to the selection of a numerical scale, we recommend the following precautions. First, avoid using verbal mediation when numerical performance data is used directly in calculating the ratings. Second, test the sensitivity of the decision to an alternative (but equally logical) set of underlying numerical equivalents, such as linear scales from 1-3, 1-5, or 1-20. If the conclusions of the analysis prove to be sensitive to the selection of the underlying numerical equivalents, then drop verbal mediation in favor of either graphically mediated or direct numerical judgments, or else derive numerical equivalents for the verbal judgments using a separate set of calibration questions.

\subsubsection{Identity and Reciprocity}

Note that in Exhibit 4-1, only the $n(n-1) / 2$ shaded elements of the MPC need to be filled with judgments (where $n$ is the number of attributes). This is due to two assumptions commonly made in the construction of MPCs: "identity," and "reciprocity." From the identity assumption, the elements along the diagonal of the MPC will always equal 1.0, since Attribute A is always "equally as important as itself." From the reciprocity assumption, the elements below the diagonal are set equal to the reciprocals of the corresponding elements above the diagonal. That is, if Attribute A

39 This effect is demonstrated with a numerical example and characterized analytically in an unpublished manuscript available from the authors. 
is judged to be three times as important as Attribute $\mathrm{C}$, then according to reciprocity, Attribute $\mathrm{C}$ must likewise be one third as important as Attribute A. These two assumptions reduce the total number of pairwise comparisons required.

\subsubsection{Establishing Order of Importance Before Comparing}

Note that the range of the most commonly-used scale in AHP is from 1 (equally important) to 9 (extremely more important). This range does not include scores for judgments such as "less important." Recall also that the $n(n-1) / 2$ upper elements of the MPC contain judgments about the importance of each row attribute relative to each column attribute. How do you apply the 1-9 scale in cases when the column attribute is judged to be more important than the row attribute?

To resolve this dilemma, use the reciprocity relationship described in the previous section. If the column attribute is judged to be more important than the row attribute, then reverse the attribute order in the judgment question, and enter the reciprocal of the answer into the upper element of the MPC.

We summarize the comparison procedure as follows. The first step in every pairwise judgment is to determine which of the two attributes in the pair is more important. If the row attribute is more important or equally as important as the column attribute, enter the chosen value from the 1-9 scale into the MPC. If the column attribute is more important than the row attribute, then use the 1-9 scale to answer the reverse question: "How much more important is the column attribute than the row attribute?" If the reverse question has been used, the reciprocal of its answer must be entered into the MPC.

\subsection{Computing Attribute Weights}

A second way in which AHP extends the basic additive weighting method is that AHP specifies the use of a particular technique (the principal eigenvector method) for converting the paired comparison data into attribute weights, and uses the results of these calculations in a heuristic check of inconsistency among paired comparisons.

Recall that the MPC is an intermediate step intended to facilitate the development of cardinal weights for the attributes. Once the MPC is complete, a computational procedure is required to translate the comparison data into weights. There are numerous computational methods available for this translation problem. ${ }^{40}$ AHP specifies the use of one particular computational translation method, involving the use of some basic concepts of linear algebra called "eigenvalues" and "eigenvectors." The outputs of this method are also used in a heuristic check of consistency among the pairwise comparisons in the MPC. As a background for both the eigenvector method for calculating weights, and Saaty's heuristic check of consistency, it is useful to consider the relationship between the MPC and cardinal weights.

\footnotetext{
${ }^{40}$ Hwang and Yoon, "Multiple Attribute Decision Making," 1981, pp. 41-57.
} 


\subsubsection{Perfect Cardinal Transitivity and Redundancy in the MPC}

Methods which construct an MPC from $n(n-1) / 2$ independent pairwise comparisons allow the decision maker to provide judgments which are not perfectly "consistent," in the sense that these judgments do not satisfy a property called "perfect cardinal transitivity."

Perfect cardinal transitivity means that for any three attributes $\mathrm{A}, \mathrm{B}$, and $\mathrm{C}$, if $\mathrm{A}$ is judged to be $x$ times as important as B, and B is judged to be $y$ times as important as $\mathrm{C}$, then $\mathrm{A}$ must be $(x \bullet y)$ times as important as C. A set of pairwise comparison judgments which satisfy perfect cardinal transitivity are said to be perfectly consistent.

A simple numerical example illustrates the concepts. Assume that $\mathrm{A}$ is judged to be twice as important as $\mathrm{B}$, and $\mathrm{B}$ is judged to be three times as important as $\mathrm{C}$. Then perfect cardinal transitivity implies that $A$ is exactly six times as important as $C$. If, when comparing $A$ with $C$, the decision maker specifies that $\mathrm{A}$ is indeed six times as important as $\mathrm{C}$, then these three pairwise comparisons are perfectly consistent.

Note that once comparisons are completed for the pairs $(A, B)$ and $(B, C)$, then if perfect cardinal transitivity is assumed, an independent comparison of $A$ and $C$ is redundant. In fact, once the first column (or row) of an MPC is filled with numbers resulting from pairwise comparison judgments, then both the cardinal weights and the remaining elements of the MPC are fully determined (and can be easily calculated) if perfect cardinal transitivity is assumed. With such an assumption, a matrix of pairwise comparisons is unnecessary; a vector of pairwise comparisons is sufficient.

The purpose of not assuming perfect cardinal transitivity is to provide the decision maker with a larger number of independent opportunities for expressing cardinal preferences. This is deemed useful since any subjective judgment process such as pairwise comparisons has an inherent possibility for error or bias. MPC-based methods then derive a vector of weights which provides a "compromise" between the weights implied by each of the individual columns (or rows) of the MPC. It is intended that, by using such a compromise solution, the biases or errors which may be present in the individual judgments will tend to cancel each other out.

AHP uses an eigenvector-based method for calculating the weights from the MPC. The eigenvector method provides two outputs which are of interest to the MADA problem: a "compromise" set of weights, and a measure of the degree of inconsistency (departure from perfect cardinal transitivity) exhibited by the set of pairwise comparisons in the MPC.

\subsubsection{Principal Eigenvector Method}

An MPC is a square matrix--that is, it has an equal number of columns and rows. Any square matrix $M$ with $n$ rows (and columns) has associated with it $n$ "eigenvectors" $\underline{e} i$ (which may not all be unique) that satisfy the following equation:

$$
\lambda_{\underline{i}} \underline{i}=M \underline{e_{i}}
$$


where $\lambda_{i}$ is the "eigenvalue" associated with the eigenvector $\underline{e}_{i}$. The "principal" eigenvector is the eigenvector $\underline{e}^{*}$ associated with the eigenvalue that has the largest absolute value, $\lambda_{\max }$ :

$$
\lambda \max \underline{e}^{*}=M \underline{e}^{*}
$$

To obtain a vector of weights by the principal eigenvector method, we first find the solution $e^{*}$ to eq 4.3, where the matrix " $M$ " is equal to the MPC. This principal eigenvector of the MPC is then normalized so that the elements in the final vector of weights $\underline{w}$ sum to 1 :

$$
\underline{w}=\underline{e}^{*}\left(\frac{1}{\sum_{j=1}^{n} \underline{e}_{j}^{*}}\right)=\left[w_{j}\right]
$$

In summary, the principal eigenvector method calculates a vector of cardinal weights which are derived from the principal eigenvector of the MPC and which are normalized to sum to one.

Solving eq 4.3 for MPCs with more than 2 or 3 attributes is straightforward (see Appendix B) using widely available computer algorithms. Simpler hand calculations which attempt to develop approximate solutions to eq 4.3 have been proposed, but they are not recommended for use with AHP since they can differ significantly from the principal eigenvector solution under certain conditions.

\subsubsection{Saaty's Heuristic Check of Consistency}

The principal eigenvalue is used in calculating a heuristic check of consistency among the pairwise comparisons. Since the MPC has ones along its diagonal, then according to a theorem of linear algebra, ${ }^{41}$ its principal eigenvalue will be exactly equal to $n$ if the pairwise comparisons are perfectly consistent. Another linear algebra theorem assures us that if the pairwise comparisons deviate only slightly from perfect consistency, then the principal eigenvalue will deviate only slightly from $n .^{42}$

Based on these two results of linear algebra, Saaty ${ }^{43}$ recommends using the difference between the principal eigenvalue and $n$ as a measure of the consistency of the pairwise comparisons. Roughly speaking, he suggests that if the difference between the principal eigenvalue and $n$ is more than $10 \%$ of the average difference which would arise from purely random pairwise comparison values,

${ }^{41}$ Listed as Theorem 7-15 on page 181 in Saaty, Multicriteria Decision Making: The Analytic Hierarchy Process, 1988.

${ }^{42}$ Ibid., Theorem 7-16, page 181.

${ }^{43}$ Ibid., p. 21. 
then there may be cause for concern about inconsistency. AHP software such as Expert Choice reports the results of this heuristic test for each MPC entered by the decision maker.

\subsection{Structuring the Problem with Hierarchy}

A third way in which AHP extends the basic additive weighting method is that AHP formalizes the use of hierarchy to keep the number of paired comparisons manageable and to facilitate handling MADA problems with numerous or multi-faceted attributes.

When a decision maker attempts to define a complex MADA problem in terms of highly detailed attributes or objectives, the number of attributes can become quite large. If a single MPC is used for such problems, the required number of pairwise comparisons (which equals $n(n-1) / 2$ ) becomes prohibitively high.

Alternatively, the decision maker may try to limit the number of pairwise comparisons required in these problems by neglecting much of the multiattribute complexity of the problem. In such cases, an attempt is made to "boil down" the large number of detailed requirements and objectives into a smaller number of very general, perhaps even vague attributes. This approach may fail to make use of available information or strong judgmental preferences which distinguish alternatives only at a finer level of detail.

By structuring a complex MADA problem hierarchically, a decision maker can include detailed attributes where they are useful or essential, while still keeping the number of pairwise comparisons generally manageable.

Saaty ${ }^{44}$ defines a hierarchy as "an abstraction of the structure of a system to study the functional interactions of its components and their impacts upon the entire system." In pragmatic terms, structuring a MADA problem hierarchically means dividing it into a series of levels of attributes, such that each attribute is a member of a small set of attributes on the same level which are all related to a single attribute on the level immediately above them.

An example hierarchy of attributes and subattributes is illustrated in Exhibit 4-2. Note that the overall goal of the analysis (e.g., "select the best building") is positioned at the top of the hierarchy. ${ }^{45}$ At the outer-most point (the bottom) of each branch of the hierarchy are the so-called "leaf" attributes; these are all shaded in Exhibit 4-2. In AHP, the alternatives are compared or scored only with respect to each of the leaf attributes.

${ }^{44}$ Ibid., p. 5.

${ }^{45}$ This formatting convention, with the goal at the top of the hierarchy diagram, is used consistently by Saaty (for example, The Analytic Hierarchy Process: Planning, Priority Setting, Resource Allocation, 1980, and Multicriteria Decision Making: The Analytic Hiearchy Process, 1988). It is also used in the principal AHP software Expert Choice (by Decision Support Software, Inc., of Pittsburgh, PA). 


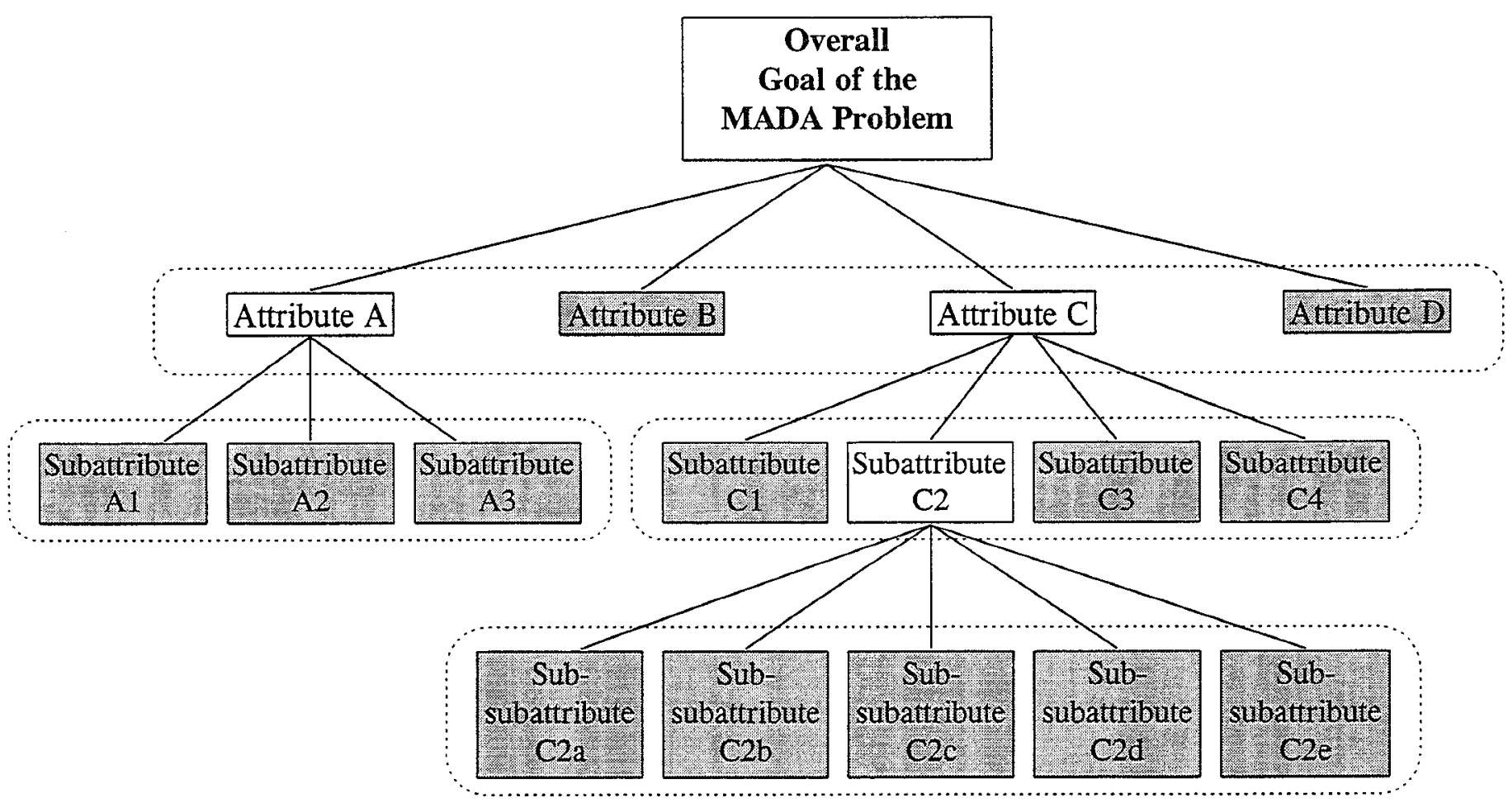

Exhibit 4-2. Illustration of a hierarchy of attributes, with all leaf attributes shaded.

Once the problem has been structured hierarchically, the attribute weighting problem becomes one of finding normalized weights for each set of attributes (and subattributes, and sub-subattributes, etc.) in the hierarchy. Thus, for the example hierarchy in Exhibit 4-2, four separate sets of weights need to be established--one each for the four attribute sets indicated by dashed encircling lines (A-D), (A1$\mathrm{A} 3$ ), (C1-C4), and (C2a-C2e). We develop an MPC for each of these four sets of attributes (or subattributes), and we compute a vector of weights from each MPC using the principal eigenvector method.

Operationally, the use of hierarchy in AHP generally calls for keeping the number of attributes in a set less than or equal to seven. ${ }^{46}$ If you need more detailed treatment of a multi-faceted attribute, create a new set of seven or fewer subattributes which relate to it. If the number of attributes in a set exceeds seven, group these attributes into two or more sets of fewer than seven attributes each.

${ }^{46}$ The limit of seven attributes per set is not a hard constraint of the AHP theory, but has been a limit posed by some software packages which facilitate the use of AHP. Newer versions of some software packages allow up to nine attributes per set. Still, keeping the number of attributes per set small helps limit the total number of pairwise comparisons as the total number of attributes becomes large. 


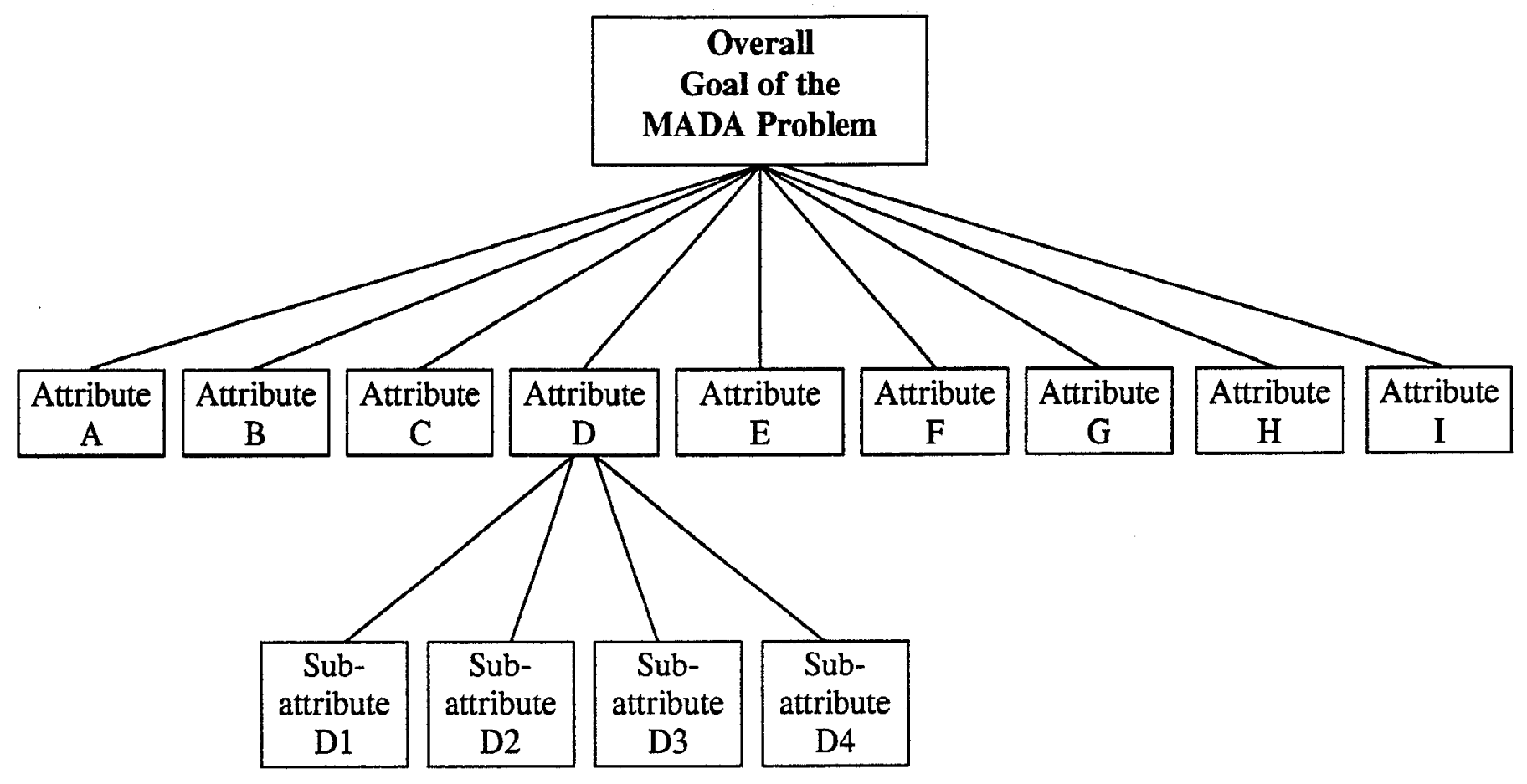

Exhibit 4-3. Initial hierarchy with nine attributes in a set.

The grouping of attributes into sets is illustrated in Exhibits 4-3 and 4-4. Exhibit 4-3 shows an illustrative initial hierarchy. Note that there are nine attributes, and that one of the attributes (Attribute D) is related to a set of four subattributes. The trouble with this initial hierarchy is that there are more than seven attributes in the A-I set. To rectify this situation, form two groups of attributes, as illustrated in Exhibit 4-4. ${ }^{47}$ Note that attribute groups 1 and 2 are formed simply to reduce the number of pairwise comparisons required and to size the problem so that existing AHP software can solve it. ${ }^{48}$

${ }^{47}$ In order to preserve the equal priority of the nine attributes prior to their weightings, weights for the attribute groups must be set based on the number of attributes in each group. In Exhibit 4-4, the weight for group 1 must be $5 / 9$, since there are five attributes in group 1 , out of a total of nine attributes at that level. Likewise, the weight for group 2 must be $4 / 9$.

${ }^{48}$ This example illustrates a case of expedient grouping of attributes--that is, the groups are formed simply to limit the total number of pairwise comparisons and to enable the problem to "fit" within the sevenattributes-per-set limit of existing software packages. It is possible that in some cases, logical groupings of the attributes may be apparent. In such cases, the decision maker may wish to assign weights to the attribute groups based on judgments of the relative importance of the attribute groups, rather than assigning the weights simply to preserve the a priori equivalence among the attributes as described in the previous footnote. 


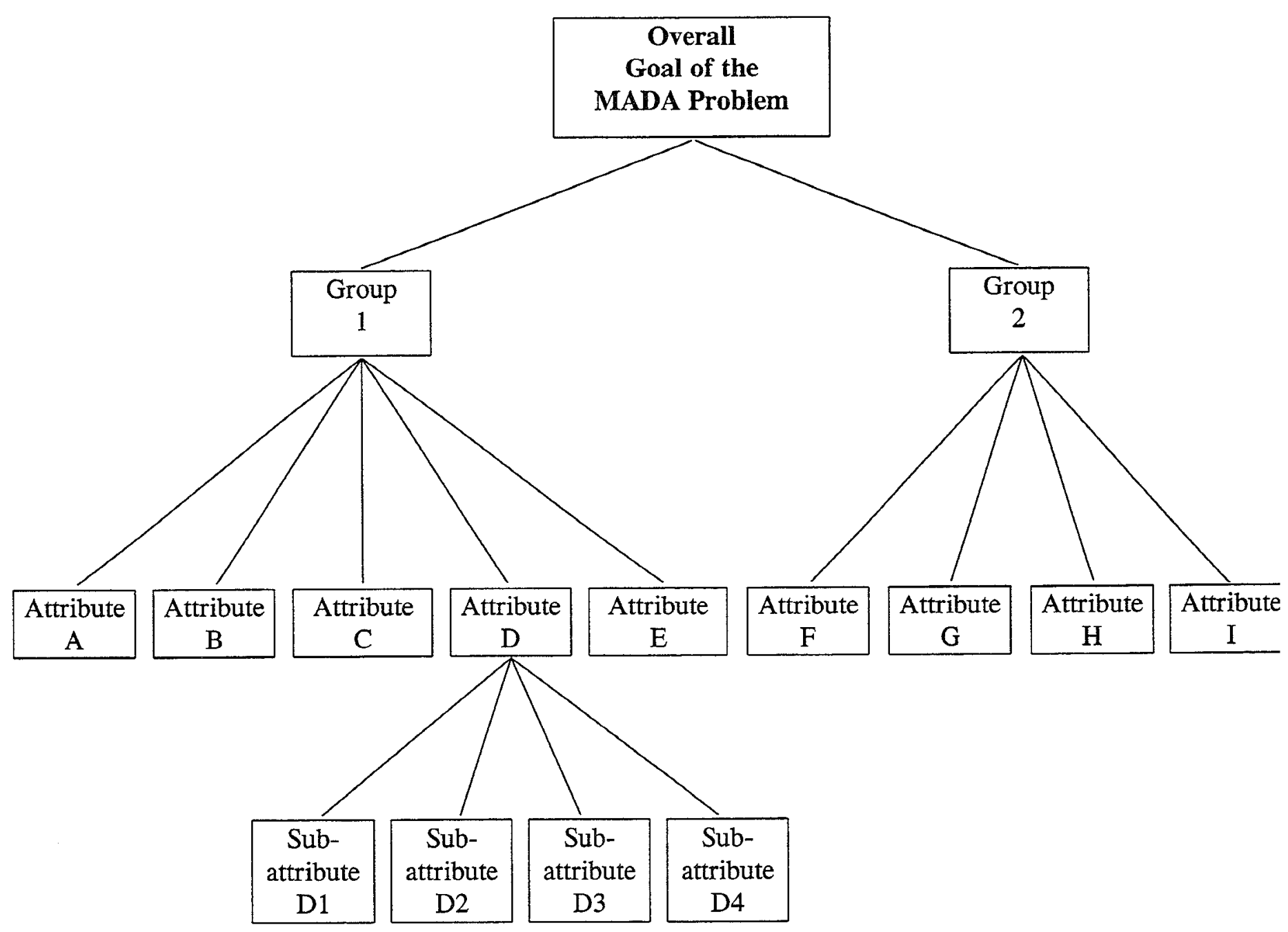

Exhibit 4-4. Modified hierarchy employing set groups to avoid exceeding seven attributes per set.

\subsection{Developing Numerical and Comparable Attribute Values}

Recall from eq 4.1 that, for simple additive weighting methods, the overall desirability score $\left(D_{j}\right)$ for an alternative is defined as the weighted sum of that alternative's "attribute scores" $\left(x_{i j}\right)$. For AHP problems with more than one level of attributes, this formula must include additional "nested" weighted sums. However, even for problems with many-level hierarchies, $D_{j}$ still comes down to a weighted sum of attribute scores. Having described in the three previous sections how to derive the weights using AHP, we now describe the problem of computing numerical and comparable attribute scores. 
Recall from section 4.5 and Exhibit 4-2 that, when using AHP, the numerical and comparable attribute scores must be derived with respect to each of the "leaf attributes" in the hierarchy. (The leaf attributes are those at the lowest level of each branch of the hierarchy.) There are two ways to derive numerical and comparable attribute scores: normalizing quantitative data and scoring alternatives using MPCs. We describe each approach in turn.

\subsubsection{Scoring Alternatives by Normalizing Quantitative Data}

Often the data characterizing the performance or desirability of the alternatives with respect to a leaf attribute are quantitative as opposed to merely qualitative scores such as "good," "bad," "high," or "low." In these cases, you either calculate the attribute scores directly from the performance data or develop them from MPCs. If you choose to calculate the attribute scores directly from the performance data, first normalize the data so that the attribute scores for different attributes can be compared and summed.

The need for normalization can be illustrated with a simple example. Say two attributes are of interest in selecting some piece of equipment: price (in dollars), and period of warranty (in years). Further assume that both attributes are judged to be of equal importance; each has a normalized weight of 0.5. Numerical data are available characterizing the three alternatives with respect to each attribute, as shown in the decision matrix, Exhibit 4-5. The final desirability score for each alternative equals the weighted sum of the two attribute scores (eq 4.1).

\begin{tabular}{|l|c|c|}
\hline & \multicolumn{1}{c}{ Price (\$) } & Warranty (years) \\
\cline { 2 - 3 } Alternative A & 100 & 1 \\
\cline { 2 - 3 } Alternative B & 150 & 2 \\
\cline { 2 - 3 } Alternative C & 200 & 3 \\
\hline
\end{tabular}

Exhibit 4-5. Decision matrix for a simple equipment choice example.

Clearly, the desirability score cannot equal the weighted sum of the decision matrix elements. We cannot add $(0.5)^{*}(\$ 100)+(0.5)^{*}(1$ year) to calculate a total desirability score for Alternative A. Prices and warranty periods are neither commensurate, comparable, nor summable. To achieve comparability, you must first normalize the data in the decision matrix. Two popular normalization methods are division by sum and division by maximum value.

Before describing both methods, we must differentiate between two types of attributes. We label attributes for which higher values are preferred (such as warranty period) "benefit attributes." Likewise, we label attributes for which lower values are preferred (such as price) "cost attributes."

For benefit attributes, the method of division by sum (DBS) entails dividing the values within each attribute category (e.g., within each column of the decision matrix) by the sum of those values. For benefit attributes, the method of division by maximum value (DBM) entails dividing the values within 
each attribute category by the highest among those values. The results of both methods are shown in Exhibit 4-6 for the benefit attribute "warranty period."

For cost attributes, a common technique which allows the use of $\mathrm{DBS}^{49}$ is to first invert the cost data, and then divide each inverted cost by the sum of the inverted costs. This inversion technique can also be used in conjunction with DBM. The cost data is first inverted, and then each inverted cost is divided by the highest value among the inverted costs. The results of both of these methods applied to the cost attribute "price" are shown in Exhibit 4-6.

\begin{tabular}{|c|c|c|c|c|c|c|c|c|c|}
\hline \multirow[b]{3}{*}{ Alternatives } & \multicolumn{3}{|c|}{ Warranty Data } & \multicolumn{4}{|c|}{ Price Data } & \multirow{2}{*}{\multicolumn{2}{|c|}{$\begin{array}{c}\text { "Desirability" } \\
\text { Scores }\end{array}$}} \\
\hline & & \multicolumn{2}{|c|}{ Normalized Data } & & & \multicolumn{2}{|c|}{ Normalized Data } & & \\
\hline & $\bar{W}$ & $(\mathrm{~W})_{\mathrm{DBS}}$ & $(\mathrm{W})_{\mathrm{DBM}}$ & $\begin{array}{l}\text { Price } \\
\text { (P) }\end{array}$ & $(1 / \mathrm{P})$ & $(1 / \mathrm{P})_{\mathrm{DBS}}$ & $(1 / \mathrm{P})_{\mathrm{DBM}}$ & $\left(D_{\mathrm{i}}\right)_{\mathrm{DBS}}$ & $\left(D_{i}\right)_{D B M}$ \\
\hline $\mathrm{A}$ & 1 & 0.17 & 0.33 & 100 & 0.010 & 0.538 & 1.000 & 0358 & 0.667 \\
\hline $\mathrm{B}$ & 2 & 0.33 & 0.67 & 200 & 0.005 & 0.269 & 0.500 & 0.301 & 0.583 \\
\hline $\mathrm{C}$ & 3 & 0.50 & 1.00 & 280 & 0.004 & 0.192 & 0.357 & 0.346 & 0.679 \\
\hline Col. Sum & $\overline{6}$ & & & & 0.019 & & & & \\
\hline
\end{tabular}

Exhibit 4-6. Two methods for normalizing attribute scores.

Note two things about the results in Exhibit 4-6. First, the two methods sometimes lead to different final results. In this example, division by sum (indicated by the subscript "DBS" in Exhibit 4-6) leads to selection of Alternative A, while division by maximum ("DBM") leads to selection of Alternative C. According to the Expert Choice User's Guide, ${ }^{50}$ DBS is the preferred approach in AHP except when the analysis is concerned only with identifying the highest-ranked alternative (rather than establishing a cardinal ranking among all alternatives), or when several alternatives exhibit very similar performance with respect to several attributes. A good practice when normalizing quantitative data is to try both methods; any instances where choice of the normalization method influences the final result should be examined more closely. In such instances it may be useful to try the MPC-based method described in the next section.

A second feature of the normalization methods is that they imply a strict functional relationship between the magnitude of the values in the decision matrix (e.g., the price in dollars, or warranty period in years) and the desirability of those values. For benefit attributes, the implied relationship is linear. That is, since Alternative B's warranty period is twice as long as Alternative A's, this is translated by both normalization methods into "Alternative B is twice as desirable as Alternative A with respect to warranty period." For cost attributes, the implied relationship is a linear one between

49 See, for example, Stephen F. Weber, "A Modified Analytic Hierarchy Process for Automated Manufacturing Decisions," Interfaces, July-August, 1993, pp. 75-84.

${ }^{50}$ Expert Choice User's Guide: "Getting Started," from Decision Support Software, Inc., Pittsburgh, PA, 1993, p. 63. 
desirability and the inverse of the cost data. In cases where there is a nonlinear relationship between the numerical values and the desirability of the attributes, use the MPC approach described in the next section rather than the normalization approaches described in this section.

\subsubsection{Scoring Alternatives Using MPCs}

Often the decision matrix includes qualitative rather than quantitative data for at least some of the attributes. In other cases, there may be a nonlinear relationship between quantitative performance data and the desirability of different levels of performance. In either of these cases, MPC-based scoring is a better way to derive comparable numerical attribute values than data normalization.

To derive attribute values using an MPC, the decision maker uses the same methods which were described in sections 4.3 and 4.4 for making a series of pairwise comparisons and synthesizing the results. The only difference is that, in this case, the alternatives are compared in terms of strength of preference (rather than importance) with respect to the attribute of interest. The principal eigenvector method can then be used to calculate a vector of attribute values based on the MPC.

Note that to ensure comparability of attribute values among attributes, the elements of the principal eigenvector must still be normalized. Thus, selection of a normalization method (division by sum, division by maximum, or some other method) is still an issue for the MPC method. As with the data normalization method, the best approach is to use both methods and re-examine any cases where choice of a normalization method alters the final conclusions of the analysis. The guidance cited earlier concerning when to use which method may also prove helpful.

\subsubsection{Normalizing Quantitative Data Versus Using MPCs}

The approach of normalizing quantitative decision matrix data has four advantages over the MPC approach:

(1) it makes full use of the precision in the decision matrix data by incorporating the values themselves into the computation of the normalized attribute values;

(2) it can be quicker than the MPC-based approach since it requires no pairwise comparisons and can be automated with a computer program or spreadsheet;

(3) the method can be straightforwardly and unambiguously described, and the results are fully explained by the input data and the normalization method chosen; and

(4) it is an objective method, in that no preference judgments are involved in scoring the alternatives.

The approach has three principal disadvantages in comparison to the MPC approach:

(1) the selection of a normalization method can appear arbitrary, yet it may influence the final results of the analysis;

(2) it requires quantitative performance data; and

(3) the approach implies a strict (linear or inverse linear) functional relationship between the numerical values and the desirability of those values. 
In comparison, the MPC-based approach to deriving attribute values is complimentary to the data normalization approach. Its two main advantages over normalizing quantitative data are:

(1) it is equally applicable whether the data in the decision matrix are qualitative or quantitative, objective or subjective; and,

(2) by relying on preference comparisons rather than numerical performance data, it implicitly takes account of the decision maker's "utility function"--that is, the relationship between performance and preference or desirability.

The disadvantages of the MPC-based method compared to the normalization approach are:

(1) it can be more time-consuming because it requires the specification of a separate MPC for every "leaf attribute;"

(2) the attribute scores are the result of subjective comparisons and judgments, which can be difficult to document or "justify" with any precision; and

(3) the final results can be sensitive to the selection of a particular eigenvector normalization method.

\subsection{Strengths and Limitations of AHP}

AHP provides a well-tested MADA method which allows building investment analysts to include consideration of multiple, conflicting, non-monetary attributes of alternatives into their decisionmaking. Another important strength related to AHP is the availability of a well-tested, flexible and user-friendly software package to facilitate its application.

The primary limitations of AHP are of a more theoretical nature, and have been the subject of some debate in the technical literature. ${ }^{51}$ Critics of AHP cite a number of limitations. Several authors have pointed out that, to be meaningful, the attribute weighting questions must be answered with respect to the average performance levels of the alternatives. ${ }^{52}$ Others have noted the possibility for rankreversal among remaining alternatives after one is deleted from consideration. ${ }^{53}$ Finally, some MADA theorists go so far as to state that as currently practiced, "the rankings of [AHP] are arbitrary. " ${ }^{54}$ Defenders of AHP, such as Saaty himself, respond that rank reversal is not a flaw because real-world decision-making occasionally exhibits this property as well.

While acceptance of AHP is not universal, its combination of flexibility and ease of use have contributed to its application in a large variety of practical MADA problems.

${ }^{51}$ A partial summary of the criticisms of AHP is given by James Dyer, "Remarks on the Analytical Hierarchy Process," Management Science, 36(3), 1990.

52 Boucher and MacStravic, "Multiattribute Evaluation Within a Present Worth Framework and Its Relation to the Analytic Hierarchy Process," p. 6, summarize the work of several authors on this topic.

${ }_{53}$ See, for example, James Dyer, "Remarks on the Analytical Hierarchy Process," 1990, pp. 249-258.

${ }^{54}$ Ibid., p. 249. 


\section{NCIC}

This chapter describes the Nontraditional Capital Investment Criteria (NCIC) method for multiattribute decision analysis. NCIC is a MADA method which falls within the broader class of methods which we designate as "total implied value" methods. For this reason, this chapter begins with a brief overview of total implied value methods. We then describe the theoretical and practical substance of NCIC in depth. The chapter concludes with a summary of the strengths and limitations of NCIC as applied to building investment decisions.

\section{1 "Total Implied Value" Methods}

NCIC was developed by Boucher and MacStravic ${ }^{55}$ as an alternative to the AHP method. It was intended to address some of the concerns about AHP which have appeared in the literature, and to tie multiattribute evaluation of alternatives more closely to traditional present worth analysis. To accomplish this latter objective, NCIC provides final scores in present valued monetary units, rather than producing unitless "desirability scores" as done by the other fully compensatory MADA methods included in Exhibit 2-2 such as additive weighting (including AHP), weighted product, TOPSIS, and distance to target methods.

Boucher and MacStravic developed NCIC by making a series of modifications to AHP rather than building it from a set of "first principles." However, we identify the set of first principles which underlie NCIC. Like other MADA methods, NCIC reflects both a set of underlying assumptions and a set of procedural and computational techniques used to practically implement the method. We describe the underlying assumptions in this section, and outline the practical features of $\mathrm{NCIC}$ in the next section.

The basic principles underlying NCIC could conceivably be implemented using practical features other than those of NCIC. We give the label "total implied value" (TIV) methods to the larger class of possible MADA methods based on the principles which underlie NCIC. These principles are related to those which underlie additive weighting methods (of which AHP is an instance), but the two method classes differ in some important respects. Compare the following list of principles with the list in section 4.1 , which described additive weighting methods, in order to see how the two method classes are related.

\subsubsection{Cardinal Alternative Scores}

TIV methods develop cardinal numerical scores which characterize the total implied value of each alternative. The total implied value scores, $V_{i}$ (for each of the alternatives, $i=1, \ldots, m$ ), can then be used to rank the alternatives, to identify a subset of most preferred alternatives, or to select the single most preferred alternative.

${ }^{35}$ Boucher and MacStravic, "Multiattribute Evaluation Within a Present Worth Framework and Its Relation to the Analytic Hierarchy Process," 1991. 


\subsubsection{No Cardinal Attribute Weights}

The relative importance of attributes to the decision maker is not assumed to remain constant across alternatives. Instead, the importance of attributes depends upon each alternative's performance relative to these attributes. Therefore, TIV methods do not use weights to characterize the relative importance of the attributes or subattributes.

\subsubsection{Contributions to Value}

The performance of each alternative with respect to each attribute contributes an independent increment of value $\left(v_{i j}\right)$ (which can be either positive or negative) to the total value of the alternative.

\subsubsection{Additivity}

The separate increments of value are additive. That is, the total implied value of an alternative is defined as the sum of the value increments associated with its performance relative to each of the $(n)$ leaf attributes in the hierarchy:

$$
V_{i}=\sum_{j=1}^{n} v_{i j}
$$

\subsection{Features of NCIC}

NCIC uses the following procedures and computational methods.

\subsubsection{Pairwise Comparisons}

For each alternative, NCIC converts the problem of specifying the increments of value $\left(v_{i j}\right)$ into the more tractable problem of making a series of pairwise comparisons. For each pair of attributes ("A" and "B") being compared, the decision maker responds to the question "How much more valuable is this alternative's performance relative to attribute $\mathbf{A}$ than its performance relative to attribute B?"

\subsubsection{Principal Eigenvector Method}

Like AHP, NCIC uses the principal eigenvector method for converting the matrix of paired comparison data into a vector of weights. Boucher and MacStravic recommend the use of the same heuristic check of consistency among pairwise comparisons which was suggested by Saaty for use in AHP. 


\subsubsection{Hierarchy}

Like AHP, the NCIC method allows the decision maker to describe a multiattribute decision problem hierarchically, dividing attributes into sets of contributing subattributes. Unlike AHP, NCIC allows the hierarchies of attributes to be different for different alternatives. For example, if there is an important attribute which is associated with only one of the alternatives, then include it only in the hierarchy defined for that alternative.

\subsubsection{Implied Increments of Value}

NCIC includes calculations which convert the vectors of leaf attribute weights into implied increments of value $\left(v_{i j}\right)$. In principal, the $v_{i j}$ can be expressed in the units of measurement associated with any one of the measurable attributes. However, NCIC uses the attribute "annual (monetary) benefits" for this purpose, so that the increments of value are all expressed in monetary terms.

\subsubsection{Implied Value Functions}

The results of NCIC can be summarized to indicate the differing levels of value attributed to differing levels of performance relative to each attribute. These "implied value functions" can be used in a separate check of consistency among the pairwise comparisons.

The following sections describe in greater detail how $\mathrm{NCIC}$ uses the procedures and computational methods introduced in sections 5.2.1-5.2.5.

\subsection{Specifying a Baseline Alternative}

At the start of a MADA analysis with NCIC, the decision maker must specify a baseline alternative against which all other alternatives will be judged. That is, for each alternative, decision makers assess the increments of value added (or subtracted) by each of the differences in performance between the alternative and the baseline.

Boucher and MacStravic ${ }^{56}$ recommend that the baseline alternative represent the "do-nothing" choice--that is, the choice to keep or renew the existing technology. In building investment applications, this definition of the baseline alternative is not always appropriate. In section 6.2 we propose and illustrate a new method for defining the baseline alternative in NCIC, which is more appropriate for evaluating building investment decisions.

\footnotetext{
${ }^{56}$ Ibid., p. 10.
} 


\subsection{Use of Hierarchy in NCIC}

Section 2.5 presented the rationale for structuring a complex MADA problem using a hierarchy of attributes and subattributes. This rationale holds for applications of NCIC just as for applications of AHP. There are, however, two practical differences in the use of hierarchy between the two methods.

First, NCIC acknowledges that one or more attributes may be relevant to only some of the alternatives. For example, "flexibility of heating fuel" may be a characteristic of some of the available building alternatives but not others. NCIC allows the decision maker to construct a separate hierarchy of attributes for each alternative (if needed), where the hierarchy for each alternative contains only those attributes which add or detract from the total value of that alternative.

Second, NCIC requires that each hierarchy contain an attribute called "annual benefits." This attribute refers to the sum of all of the annual benefits (minus costs) which can be expressed directly in monetary terms. The benefits and costs are measured with respect to the baseline alternative. As described in section 5.6, annual benefits becomes the numeraire attribute during the final stages of an NCIC analysis. That is, the value added by the other attributes is expressed in monetary units of annual benefits.

In the overview of NCIC provided in this report, we assume for simplicity that all annual monetary as well as non-monetary benefits are constant over the study period. This assumption is not required by NCIC, however. ${ }^{57}$ In fact, an important feature of the NCIC method is that once the implied annual value of all attributes has been calculated, the stream of annual values is used in a present value calculation for each alternative.

\subsection{Pairwise Comparisons}

The assumptions underlying the development of matrices of paired comparisons (MPCs) in NCIC are identical to those described in section 4.3 for AHP. However, the nature of the comparison questions is different.

In AHP, you make pairwise comparisons among attributes in terms of their relative importance, and among alternatives in terms of their relative desirability with respect to each attribute. In NCIC, you make a separate set of pairwise comparisons among the attributes for each alternative. Thus, in NCIC, you compare the increments of value attributed to each of the separate ways in which an alternative differs from the baseline alternative.

57 The Users Manual for NCIC: A Decision Support Software Package for Investment in Integrated Automation and Advanced Systems, Material Handling Industry, Charlotte, NC, pp. 17-20, describes how to treat attributes whose annual value is expected to change from year to year during the study period. 
Recall that the fourth basic assumption underlying TIV methods is that the individual value increments are additive. Therefore, if an attribute is composed of several subattributes, then the incremental value of an attribute is equal to the sum of the incremental values associated with each of its subattributes. For this reason, only the leaf attributes of a hierarchy should be included in the pairwise comparisons in NCIC. Recall from section 4.5 that leaf attributes are those which lie at the outermost point (the bottom) of each branch of the hierarchy, as illustrated by the shaded portions in Exhibit 4-2.

When the number of leaf attributes for a given alternative exceeds, say, 10 or so, the total number of paired comparisons can be reduced by grouping the leaf attributes into 2 or more sets. Then, a separate MPC is developed for each set of leaf attributes. Appropriate sets of attributes will generally be suggested by the hierarchy's structure, and the final results will not be affected by the particular sets of attributes which are formed.

The case of multiple MPCs brings up an important difference between AHP and NCIC: final synthesis of the results obtained from separate MPCs in NCIC requires that the decision maker establish some overlap of attribute membership between the sets. The simplest way to establish this overlap is to define a "bridge attribute"--an attribute which is present in each set of leaf attributes formed. Boucher and MacStravic recommend that "annual monetary benefits" be used as the bridge attribute. ${ }^{58}$

\subsection{Computing Incremental Values}

The MPCs in NCIC contain the decision maker's judgments comparing, for a given alternative, the value of differences from the baseline alternative with respect to pairs of attributes. That is, alternative $i$ differs from the baseline alternative with respect to attributes $j$ and $\boldsymbol{k}$. Each of these differences adds (or subtracts) an increment of value ( $v_{i j}$ and $v_{i k}$ respectively) to alternative $i$. The objective of NCIC is to draw out the decision maker's judgments about each of these increments of value, for each alternative. Rather than asking the decision maker to estimate these value increments directly, NCIC asks the decision maker to make pairwise comparisons of the value increments associated with pairs of attributes.

Thus, the elements of the MPC for alternative $i$, as shown in eq 5.2, are estimates of the ratios of the incremental contributions associated with two attributes:

${ }^{58} \mathrm{Ibid}$., pp. 2-5. Of course, you can use any attribute as the bridge attribute, or could even use a different "bridge" attribute common to each pair of leaf attributes. Choice of the bridge attribute is independent from choice of a numeraire attribute (for which annual monetary benefits is also the recommended choice, as described in section 5.2.4). However, using annual monetary benefits as the single bridge attribute ensures that each attribute is compared directly with annual monetary benefits when constructing the MPCs. It also makes exposition of the incremental value calculation (in section 5.6) simpler. 


$$
M P C \cong\left[\begin{array}{cccc}
\left(v_{1} / v_{1}\right) & \left(v_{1} / v_{2}\right) & \cdots & \left(v_{1} / v_{n}\right) \\
\left(v_{2} / v_{1}\right) & \left(v_{2} / v_{2}\right) & \cdots & \left(v_{2} / v_{n}\right) \\
\vdots & \vdots & \ddots & \vdots \\
\left(v_{n} / v_{1}\right) & \left(v_{n} / v_{2}\right) & \cdots & \left(v_{n} / v_{n}\right)
\end{array}\right]
$$

If the judgments were perfectly consistent, then the columns of the MPC would all be scalar multiples of each other, and any column could be chosen to represent the relative values. However, decision makers will not generally provide perfectly consistent judgments for the MPC. In this case, which vector should be chosen to represent the relative values? Instead of choosing any single one, it is best to somehow combine them all and find a compromise among them. NCIC (like AHP) uses the principal eigenvector method to derive a vector from the entire matrix which serves as such a compromise (see section 2.4 for more details). Also like AHP, NCIC utilizes an eigenvalue-based check of the consistency among the pairwise comparisons, as described in section 4.4.3.

Based on eq 5.2 and some results of linear algebra, if we divide the principal eigenvector $\underline{e}$ of the MPC by $\underline{e}$ 's first element $\left(e_{1}\right)$, we obtain a vector which serves as our approximation of the ratios of incremental values, as follows:

$$
\underline{e}^{*}\left(\frac{1}{e_{1}}\right) \cong\left[\begin{array}{c}
1 \\
v_{2} / v_{1} \\
v_{3} / v_{1} \\
\vdots \\
v_{n} / v_{1}
\end{array}\right]
$$

Now, recall that NCIC calls for including the attribute "annual monetary benefits" into each set of attributes. Let this attribute be attribute 1 in eqs 5.2 and 5.3. Annual benefits is the one attribute for which the monetary value of its incremental benefit $\left(\boldsymbol{v}_{i \mathrm{I}}\right)$ is explicitly known prior to the NCIC analysis. Then, by multiplying both sides of eq 5.3 by the known (monetary) incremental value, $v_{i 1}$, we obtain NCIC's estimate of the vector of incremental values: 


$$
\underline{e}\left(\frac{1}{e_{1}}\right) * v_{1} \cong\left[\begin{array}{c}
v_{1} \\
v_{2} \\
v_{3} \\
\vdots \\
v_{n}
\end{array}\right]
$$

These incremental values are summed (eq 5.1) to obtain the estimate of the total annual value of each alternative. The total annual value for each alternative is then converted to present value for final ranking and selection.

\subsection{Plotting Implied Value Functions}

For a MADA problem with $\boldsymbol{m}$ alternatives, the alternatives will exhibit between 2 and $\boldsymbol{m}$ different levels of performance with respect to each attribute. NCIC develops estimates of the incremental value associated with each of these levels of performance (relative to the baseline alternative). The estimated increments of value can be plotted versus the actual levels of performance to obtain a graphical version of an "implied value function" (IVF) as shown in Exhibit 5-1. Note that the xaxis for these plots will only be quantitative in the case of attributes for which performance is measurable (and known) in quantitative terms.

The developers of NCIC suggested that the usefulness of the implied value function is its ability to provide a second consistency check of the results. They suggested that the IVF should exhibit either constant marginal returns, diminishing marginal returns, or increasing marginal returns, and that results otherwise imply there has been some inconsistent valuing among alternatives.

In fact, under some circumstances, marginal returns could be increasing up to a point, beyond which marginal returns could decrease and even approach zero. This instance is portrayed in Exhibit 5-1. Therefore, rather than imposing the requirement that consistent judgments lead to a single type of marginal returns, the best approach to using the IVF in a second consistency check is for the decision maker to assess the "reasonableness" of the returns to scale which have been implied by his or her pairwise judgments. The implied returns, and marginal returns, should make sense and match (or inform) the decision maker's intuition.

Exhibit 5-2 illustrates an evidently inconsistent set of implied value results, because the implied value of an 18 month warranty period is not intermediate between the implied value of 12 and 24 month warranty periods. In this case, the decision maker should re-examine the set of comparisons made for the alternative which exceeds the baseline warranty period by 18 months (alternative 3 ). 
Table of Implied Values for the Attribute: "Warranty Period"

\begin{tabular}{|l|l|l|}
\hline Alternative & $\begin{array}{l}\text { Warranty Period } \\
\text { Exceeds Baseline by: }\end{array}$ & $\begin{array}{l}\text { Implied Increment of } \\
\text { Value (from NCIC) }\end{array}$ \\
\hline 1 & 6 months & $\$ 100$ \\
\hline 2 & 12 months & $\$ 400$ \\
\hline 3 & 18 months & $\$ 600$ \\
\hline 4 & 24 months & $\$ 700$ \\
\hline 5 & 30 months & $\$ 750$ \\
\hline
\end{tabular}

Plot of Table Data:

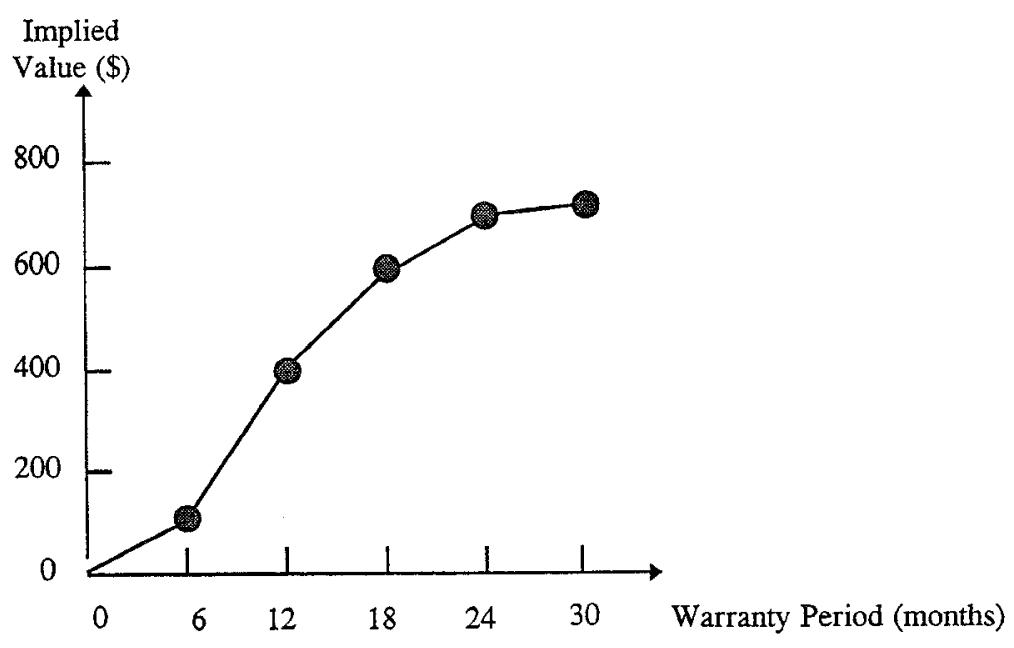

Exhibit 5-1. Example plot of a consistent set of implied value results. 
Table of Implied Values for the Attribute: "Warranty Period"

\begin{tabular}{|l|l|l|}
\hline Alternative & $\begin{array}{l}\text { Warranty Period } \\
\text { Exceeds Baseline by: }\end{array}$ & $\begin{array}{l}\text { Implied Increment of } \\
\text { Value (from NCIC) }\end{array}$ \\
\hline 1 & 6 months & $\$ 300$ \\
\hline 2 & 12 months & $\$ 440$ \\
\hline 3 & 18 months & $\$ 300$ \\
\hline 4 & 24 months & $\$ 520$ \\
\hline
\end{tabular}

Plot of Table Data:

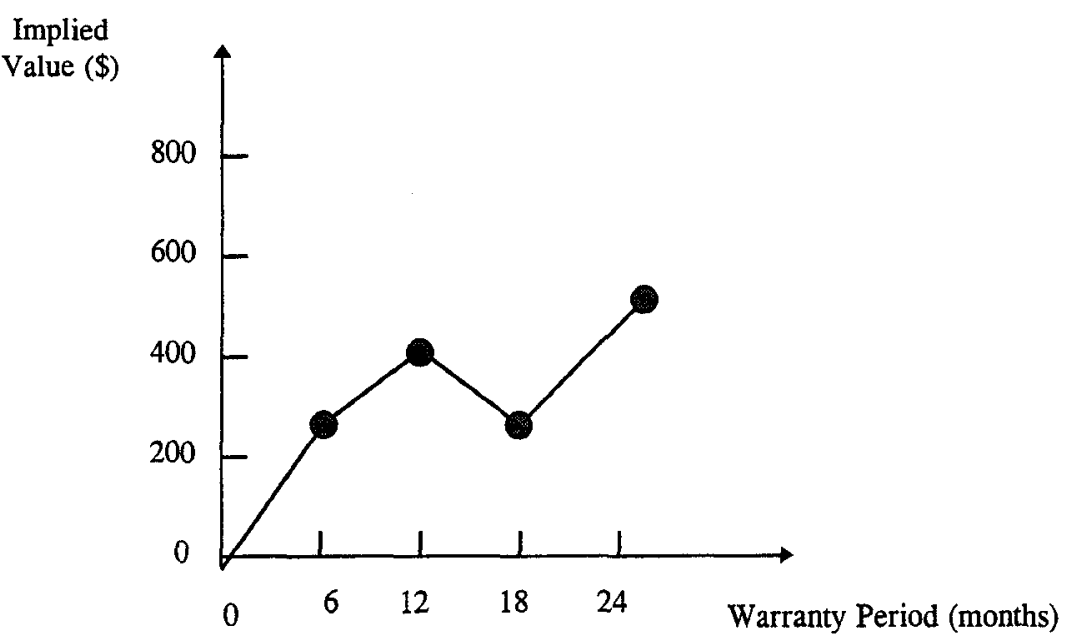

Exhibit 5-2. Example of an inconsistent set of implied value results.

\subsection{Retrofitting}

In some instances it is possible to retrofit a chosen alternative after it is purchased. Retrofitting is defined as modifying an alternative in order to improve its performance in some way. If there are a large number of ways in which the alternatives can be retrofitted, then the number of possible permutations becomes much too large to be dealt with directly with MPCs. Fortunately, the IVFs generated by an NCIC analysis allow the retrofit opportunities to be analyzed without increasing the number of pairwise comparisons required. If you have data on the full costs of possible retrofits and the incremental performance gains which the retrofit will achieve, these data can be used in conjunction with the implied value functions to derive the value added by each retrofit. 
Retrofits make economic sense if there are any alternatives for which the implied value of the retrofit's gain in performance exceeds its cost. Whenever this is the case, modify the total value of the alternative as follows:

(1) Use the performance data in conjunction with the plotted implied value functions to estimate the value associated with each performance attribute.

(2) Subtract the cost of the retrofit from the total implied monetary value of the alternative. This cost should directly include all costs associated with obtaining the retrofit, such as staff time spent procuring and overseeing the retrofit or the costs of any delays incurred waiting for the retrofit to be completed.

After these two adjustments, repeat the present value calculation for each alternative and select the alternative with the highest final modified total present value.

The method for analyzing retrofits described above uses the IVFs obtained from an initial NCIC analysis to determine the total implied value of additional alternatives. This same strategy can be used whenever the number of original alternatives is larger than, say, four or five. If the number of alternatives is large, select three or four alternatives whose performance levels tend to bound those exhibited within the larger set of alternatives. The IVFs resulting from this initial analysis can then be used together with the performance data on the other alternatives to calculate the total implied annual value of each alternative, minimizing the number of total pairwise comparisons required.

\subsection{Strengths and Limitations of NCIC}

NCIC provides a well-documented MADA method which allows building investment analysts to include consideration of multiple, conflicting, non-monetary attributes of alternatives into their decision-making. It is specially designed to make explicit the implied monetary value which the analyst's judgments assign to all of the non-financial benefits. This information, summarized in the form of "implied value functions," provides a check of consistency; and it also facilitates the subsequent analysis of additional alternatives or retrofit options without requiring further pairwise comparisons. The results of an NCIC analysis can also be integrated into traditional economic analyses. In instances where the results of a MADA analysis need to be translated back into monetary terms for presentation or subsequent integration, NCIC can be a very attractive approach.

NCIC allows the decision maker to describe a multiattribute decision problem hierarchically, dividing attributes into sets of contributing subattributes, and it utilizes paired comparisons to make the expression of a set of cardinal preferences tractable. NCIC allows the hierarchies of attributes to be different for different alternatives. For example, if there is an attribute which is present in only one of the alternatives, NCIC allows you to include it in just that alternative's hierarchy.

In some decision environments, NCIC's rendering of all values explicitly in monetary terms may prove controversial. However, the primary limitation of NCIC with respect to building investment 
decisions is the lack of software. The NCIC method is perfectly applicable to building investment decisions, but the currently available NCIC software is designed to evaluate manufacturing automation investments. 


\section{Applications}

\subsection{AHP Application}

To illustrate how to apply AHP, we use a hypothetical example of a private company making a choice among existing buildings. The company gives the following description of its needs to a commercial Realtor engaged to find appropriate space.

"Our company conducts business inside and outside the United States. The headquarters building, which is too small because of staff growth, is in a large metropolitan area. Management wants to lease a building for the new corporate headquarters in a prominent location somewhere in the same metropolitan area. We want the style and location of the building to portray an upscale public image of a company that is modern and progressive. We also want a location that will be attractive to the existing headquarters staff whom we hope will stay with the company after the move to the new building. Time is important. From the standpoint of fixing up the building to meet our special needs and to make possible an efficient move, the sooner the building is available the better."

To find the building that best suits the company's needs, the search firm decides to apply the AHP method in collaboration with the three-member property search committee of the company's board of directors. The steps, in order, are as follows: define the goal of the building search; identify important attributes; identify alternative buildings (called properties in the analysis); construct a decision matrix containing available data on the performance of each alternative with respect to each attribute; compare in pairwise fashion each alternative against every other alternative as to how much better one is than the other with respect to each leaf attribute; make pairwise comparisons, starting from the bottom of the hierarchy, of the relative importance of each attribute in a given set with respect to the attribute or goal above that set; and compute the final overall desirability score for each alternative.

The first step is to define the goal of the decision analysis. The goal of the building search is to find the building that best suits the company's needs, as described by the company to the search firm.

An initial set of attributes that the company feels are most important was identified in the description of space needs. The company identified building aesthetics, especially as related to the image that the company wants to project; location, both in terms of being attractive to staff and reflecting a successful company image; and occupancy availability within six months, sooner availability dates being preferred to later ones. The realty search firm gives the board of directors a questionnaire to see if there are other attributes that the company regards as important. The directors identify two more attributes: economics (rent, utilities, and maintenance costs) and the sound and visual environment. While yet additional attributes are considered, such as safety, building serviceability, and thermal environment, the company is able to specify minimum requirements for these. So the search firm uses them as screening attributes only, and does not address them explicitly in the AHP. That is, the company expects any candidate property presented by the search firm to meet the constraint values of those additional attributes. 
The AHP team, composed of the property committee of the board and the realty search firm, describe the problem using five attributes (and six subattributes) as shown in the hierarchy in Exhibit 6-1. Note that accessibility to clients and staff, both regular commuters and visiting field staff, emerges ultimately as an important attribute. Note also that characteristics related to location which were referred to in the company write-up become parts of two separate elements of the hierarchy: accessibility, and the site/neighborhood subattribute of aesthetics.

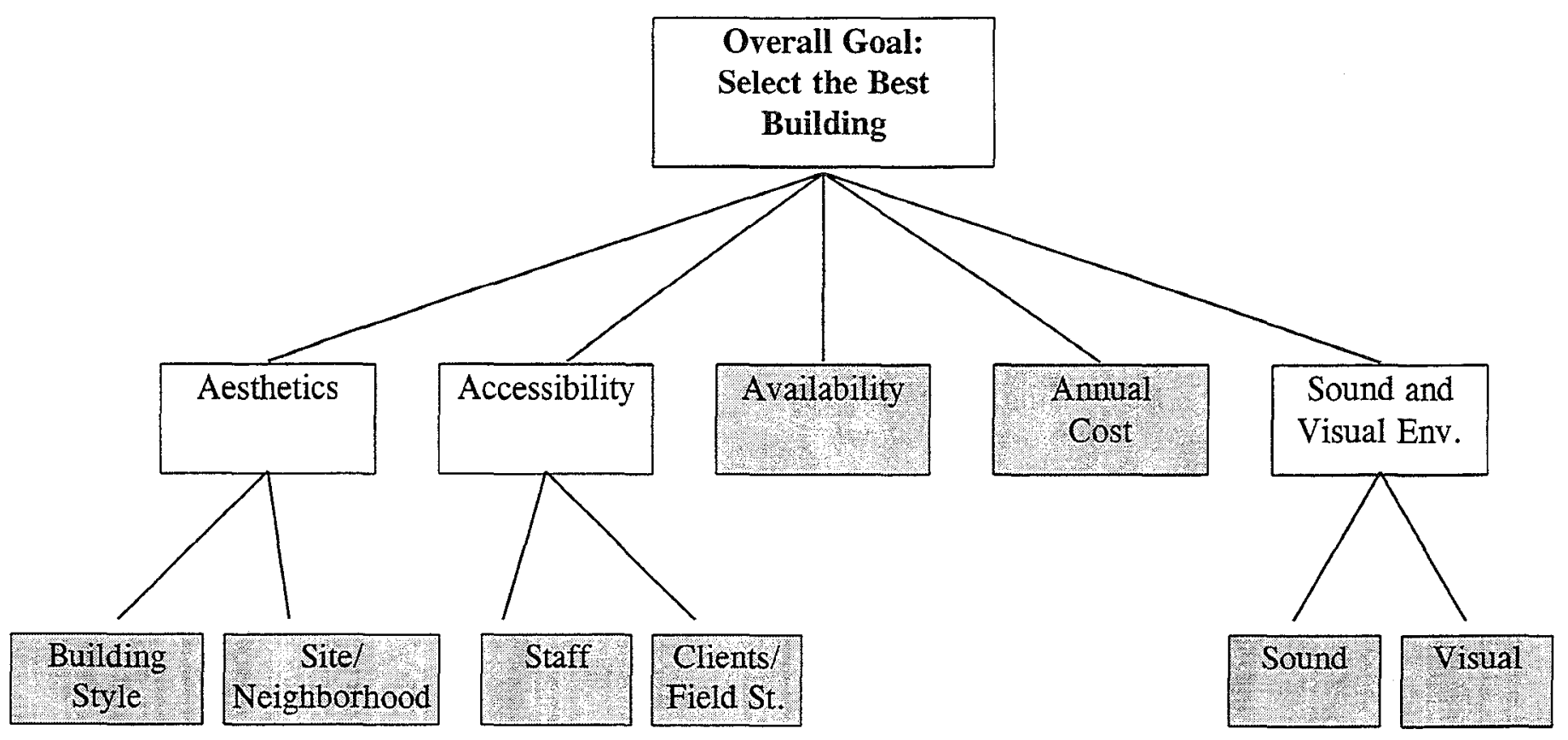

Exhibit 6-1. Hierarchy for the example building selection problem, with leaf attributes shaded.

Using the five AHP attributes and other constraint attributes to guide them, the search firm finds four building alternatives--Properties A, B, C, and D--that they feel meet the company's needs. The team makes a decision matrix to clarify what data they have on each alternative relative to each leaf attribute. Exhibit 6-2 shows how the committee scored each alternative with respect to each leaf attribute. Excellent is better than very good which is better than good with respect to aesthetics, accessibility, and sound/visual. The fewer months until the property becomes available, the better. The lesser the annual economic cost, the better. 


\begin{tabular}{|c|c|c|c|c|c|c|c|c|}
\hline \multirow[t]{2}{*}{ Property } & \multicolumn{2}{|c|}{ Aesthetics } & \multicolumn{2}{|c|}{ Accessibility } & \multirow{2}{*}{$\begin{array}{c}\text { Availa- } \\
\text { bility } \\
\text { Date }\end{array}$} & \multirow{2}{*}{$\begin{array}{l}\text { Annual } \\
\text { Costs } \\
(\mathrm{M} \$)\end{array}$} & \multicolumn{2}{|c|}{ Environment } \\
\hline & bldg. & site & $\begin{array}{l}\text { to } \\
\text { staff }\end{array}$ & $\begin{array}{c}\text { to } \\
\text { clients }\end{array}$ & & & sound & visual \\
\hline A & good & good & good & fair & $\begin{array}{c}2 \\
\text { months }\end{array}$ & 5.5 & $\begin{array}{c}\text { excel- } \\
\text { lent }\end{array}$ & $\begin{array}{l}\text { excel- } \\
\text { lent }\end{array}$ \\
\hline B & $\begin{array}{l}\text { very } \\
\text { good }\end{array}$ & good & $\begin{array}{l}\text { excel- } \\
\text { lent }\end{array}$ & good & $\begin{array}{c}4 \\
\text { months }\end{array}$ & 6.2 & good & $\begin{array}{l}\text { excel- } \\
\text { lent }\end{array}$ \\
\hline $\mathrm{C}$ & good & $\begin{array}{l}\text { very } \\
\text { good }\end{array}$ & $\begin{array}{l}\text { very } \\
\text { good }\end{array}$ & good & now & 5.8 & $\begin{array}{l}\text { excel- } \\
\text { lent }\end{array}$ & $\begin{array}{l}\text { very } \\
\text { good }\end{array}$ \\
\hline $\mathrm{D}$ & $\begin{array}{c}\text { excel- } \\
\text { lent }\end{array}$ & $\begin{array}{c}\text { excel- } \\
\text { lent }\end{array}$ & good & $\begin{array}{c}\text { excel- } \\
\text { lent }\end{array}$ & $\begin{array}{c}5 \\
\text { months }\end{array}$ & 7.8 & $\begin{array}{l}\text { very } \\
\text { good }\end{array}$ & $\begin{array}{c}\text { excel- } \\
\text { lent }\end{array}$ \\
\hline
\end{tabular}

Exhibit 6-2. Decision matrix description of attributes by property.

Starting from the bottom of the hierarchy, the committee makes pairwise comparisons of each alternative against every other alternative with respect to each leaf attribute in the hierarchy (the ones shaded in Exhibit 6-1). ${ }^{59}$ Exhibits 6-3 to 6-10 show the scores of alternatives with respect to each leaf attribute. A separate MPC was constructed for each leaf attribute. In Exhibit 6-3, for example, property $\mathrm{D}$ scores higher $(0.560)$ on building style than any other property.

The team then provides pairwise judgments of the relative importance of each subattribute with respect to the attribute above it in the hierarchy. Note from the hierarchy diagram in Exhibit 6-1 that there are three pairs of subattributes. This is also seen in Exhibit 6-2, by noting that Aesthetics, Accessibility, and Environment are each divided into a pair of subattributes. For brevity the results of these subattribute intercomparisons are not shown. The company then provides pairwise judgments of how important each of the attributes is with respect to the goal of finding the best building. The attribute weights in Exhibit 6-11 indicate the relative importance of the attributes with respect to the goal.

The last step is to use the computer program to calculate a final overall desirability score for each alternative. Exhibit 6-12 shows Property D, with a desirability score of 0.323 , to be the best building for the company. The overall in consistency index of $3 \%$ is a weighted average of the inconsistency indices for the separate MPC's, and indicates that the pairwise comparisons made throughout the analysis were highly (though not perfectly) consistent.

\footnotetext{
${ }^{59}$ The commercial AHP software program "Expert Choice" was used to work this problem.
} 


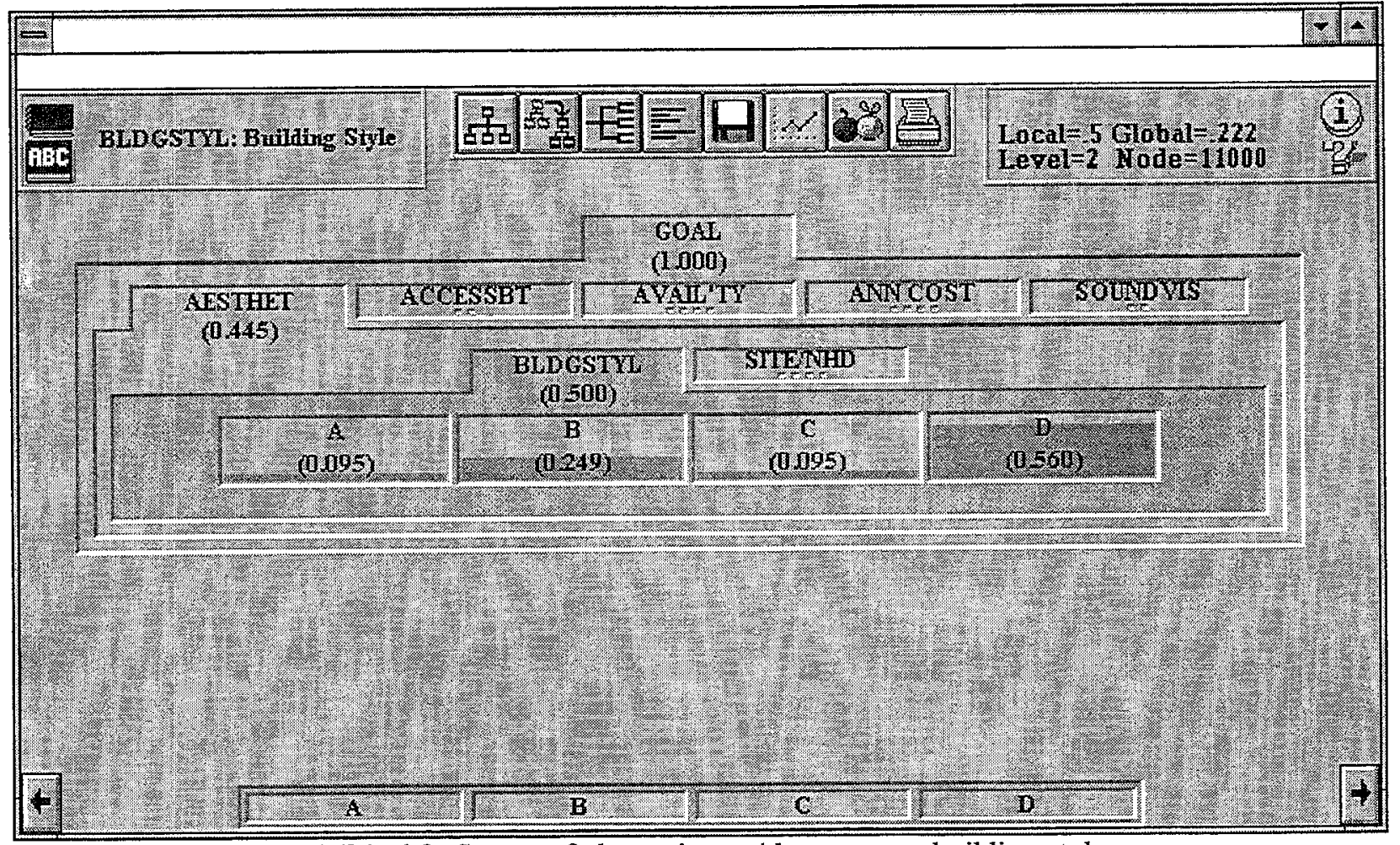

Exhibit 6-3. Scores of alternatives with respect to building style.

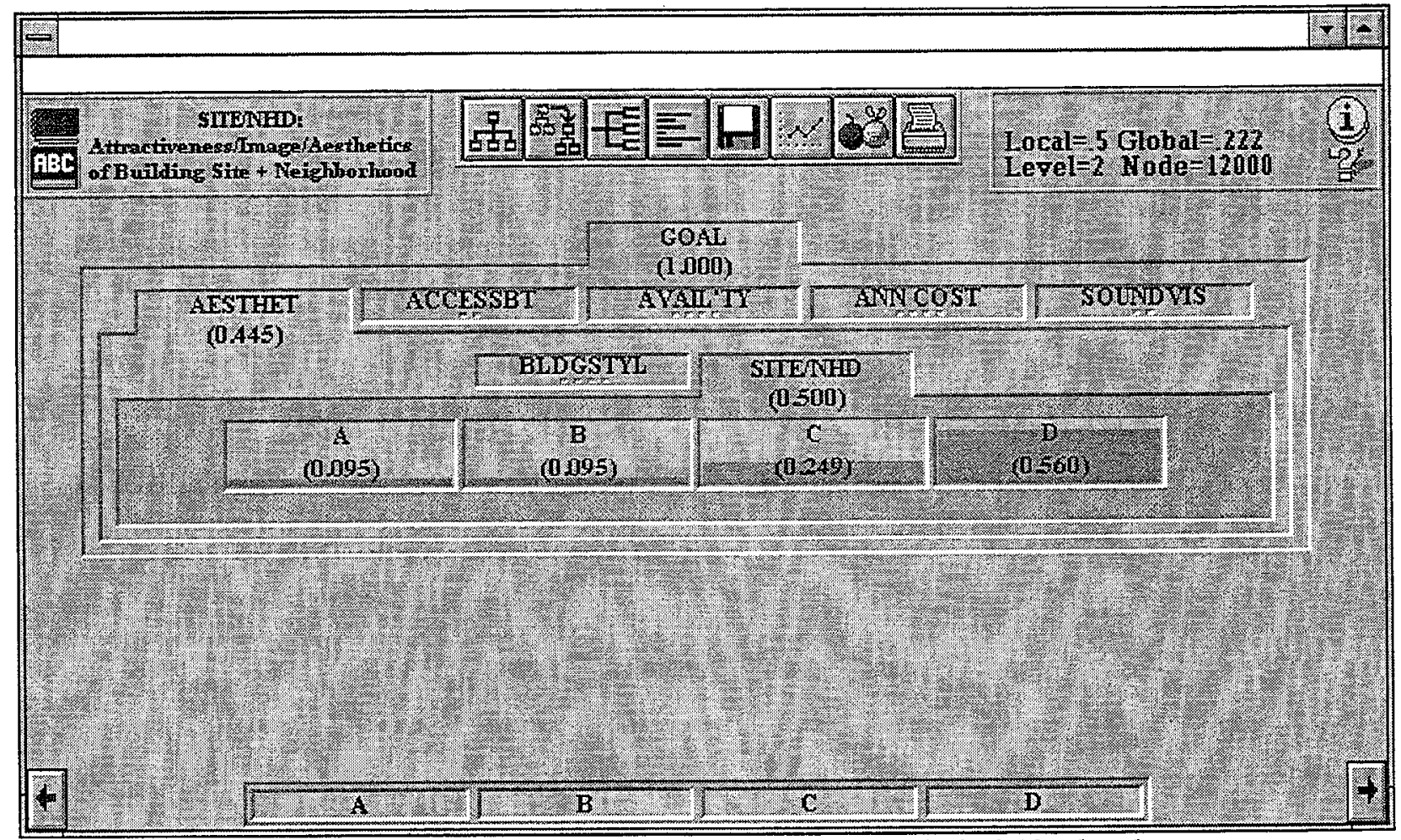

Exhibit 6-4. Scores of alternatives with respect to site/neighborhood. 


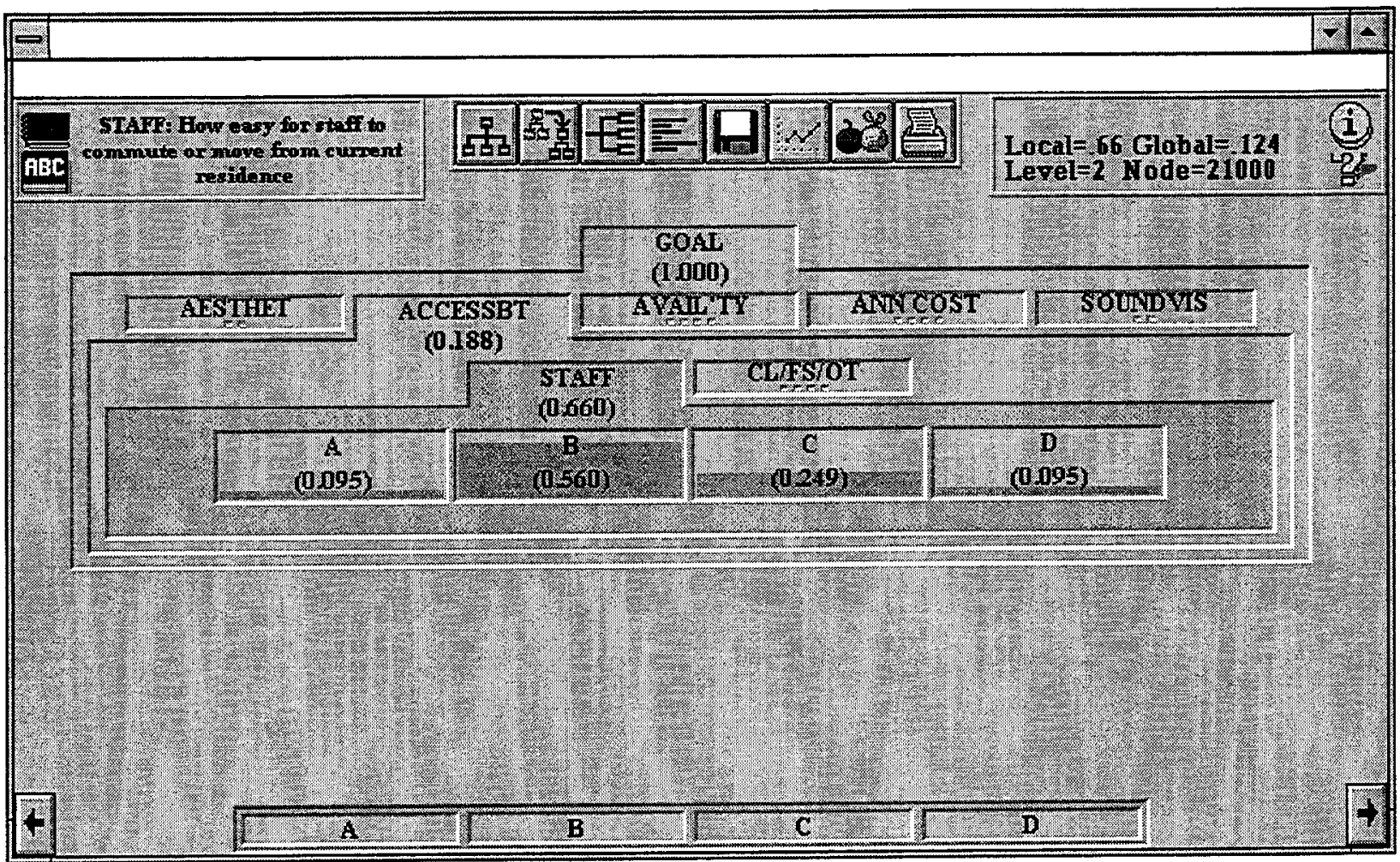

Exhibit 6-5. Scores of alternatives with respect to staff commuting accessibility.

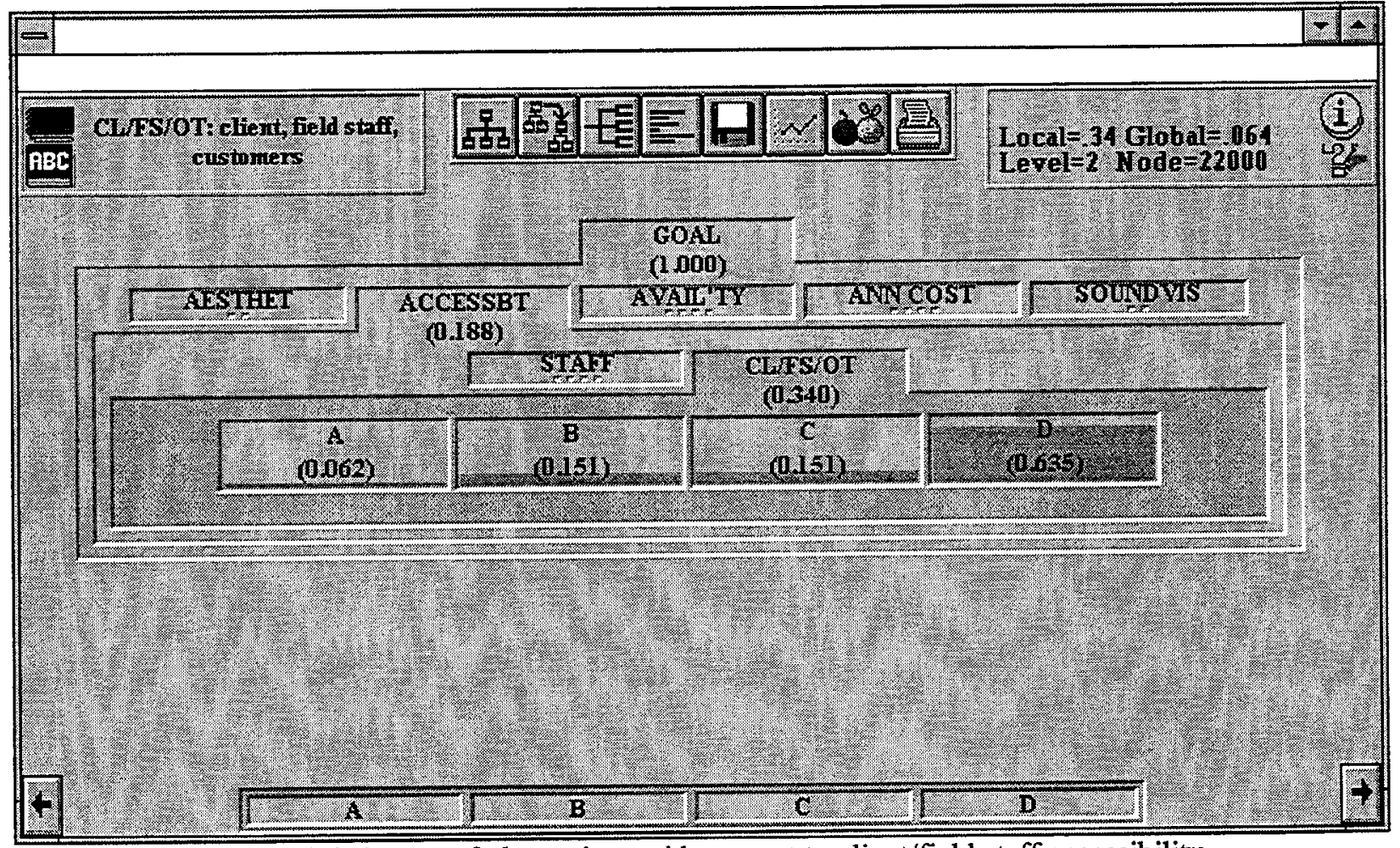

Exhibit 6-6. Scores of alternatives with respect to client/field staff accessibility. 


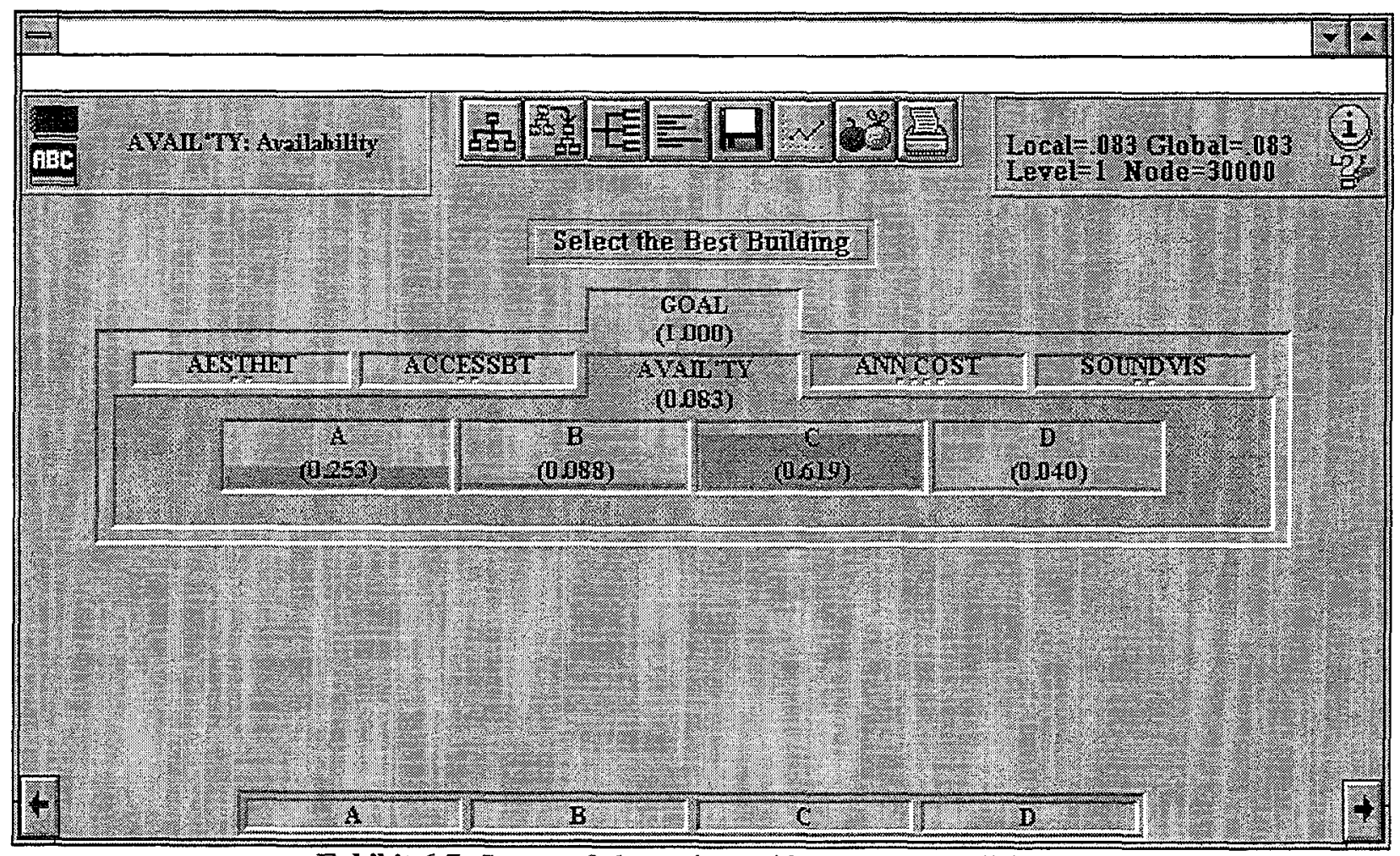

Exhibit 6-7. Scores of alternatives with respect to availability.

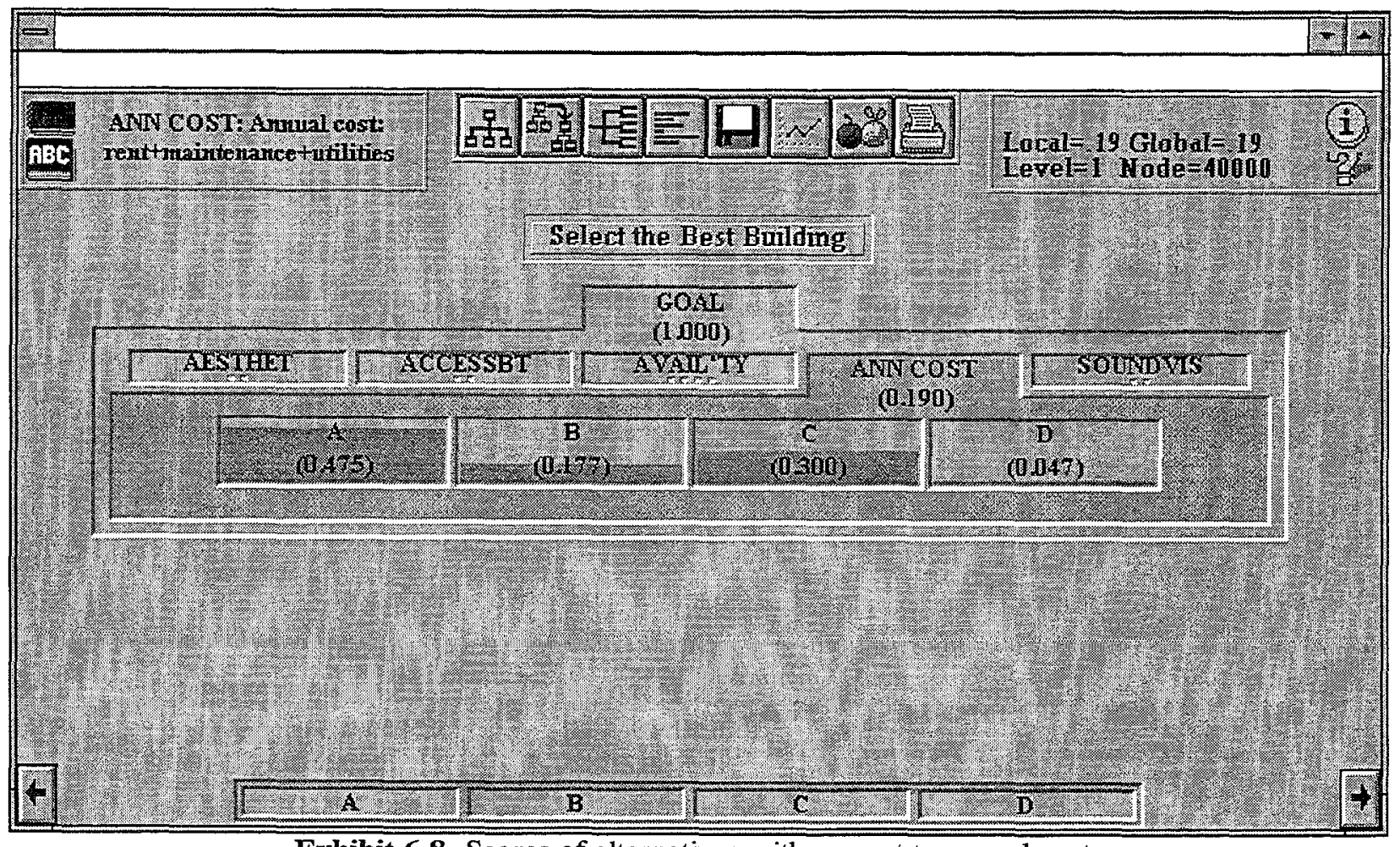

Exhibit 6-8. Scores of alternatives with respect to annual cost. 


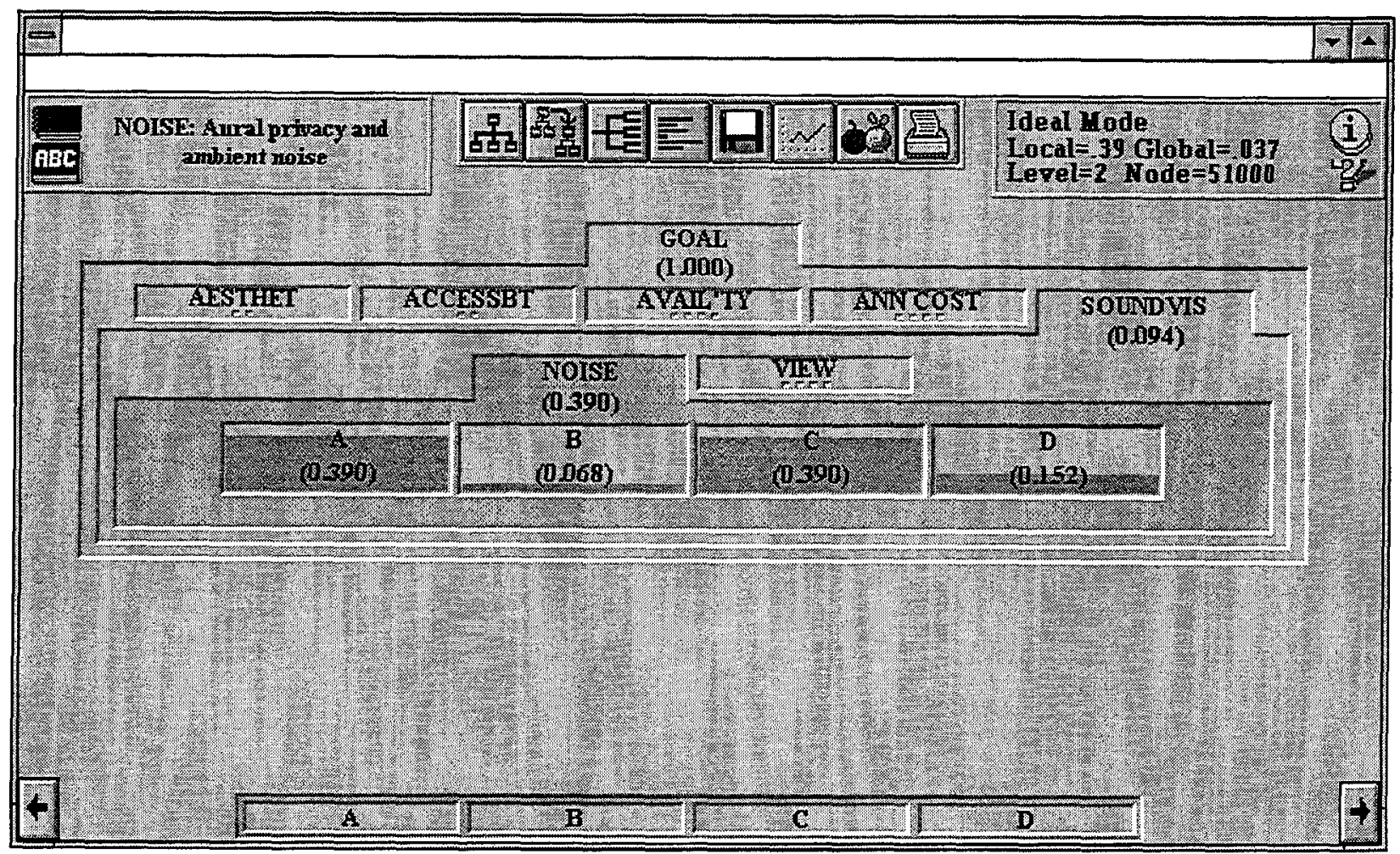

Exhibit 6-9. Scores of alternatives with respect to aural privacy and ambient noise.

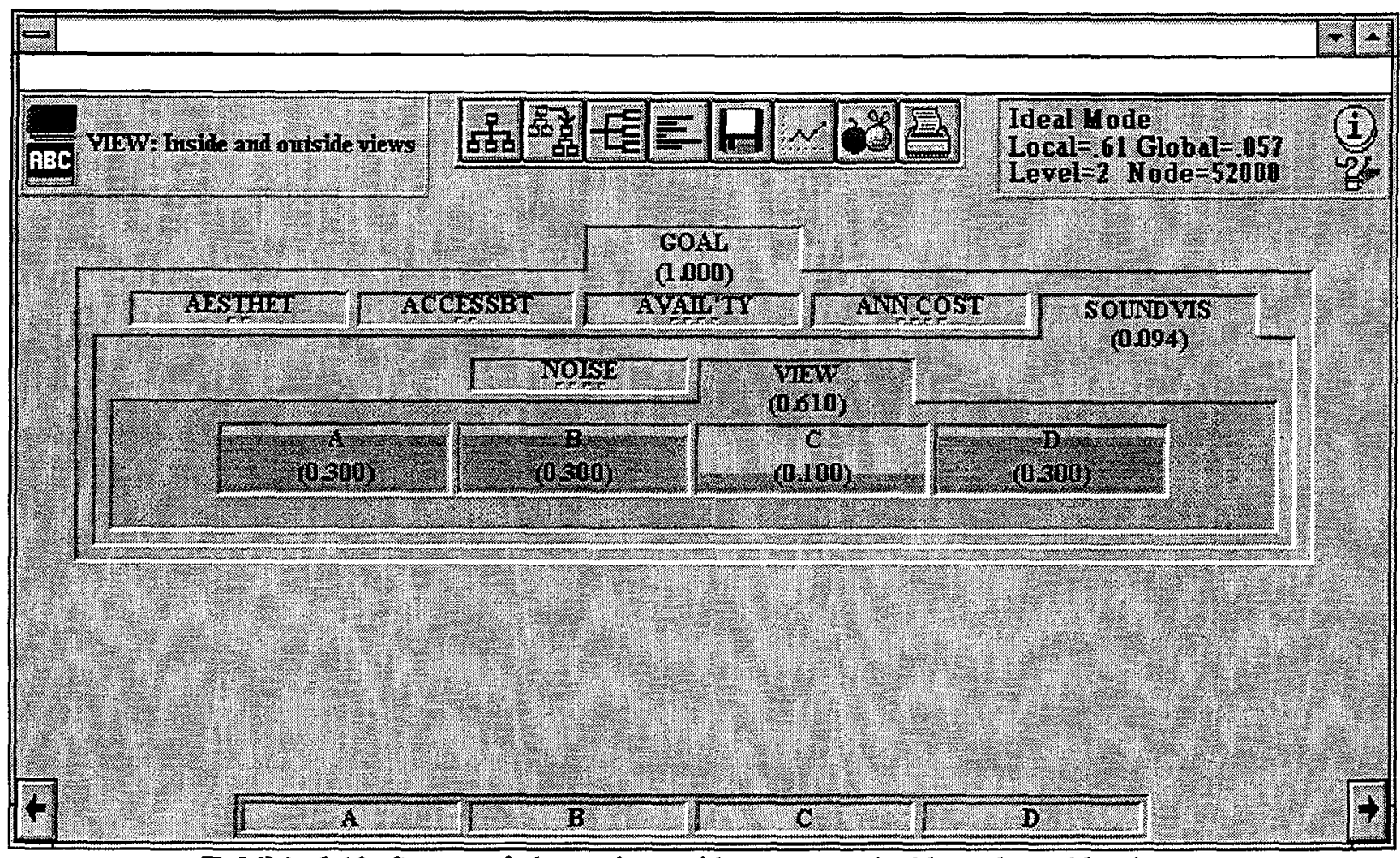

Exhibit 6-10. Scores of alternatives with respect to inside and outside views. 


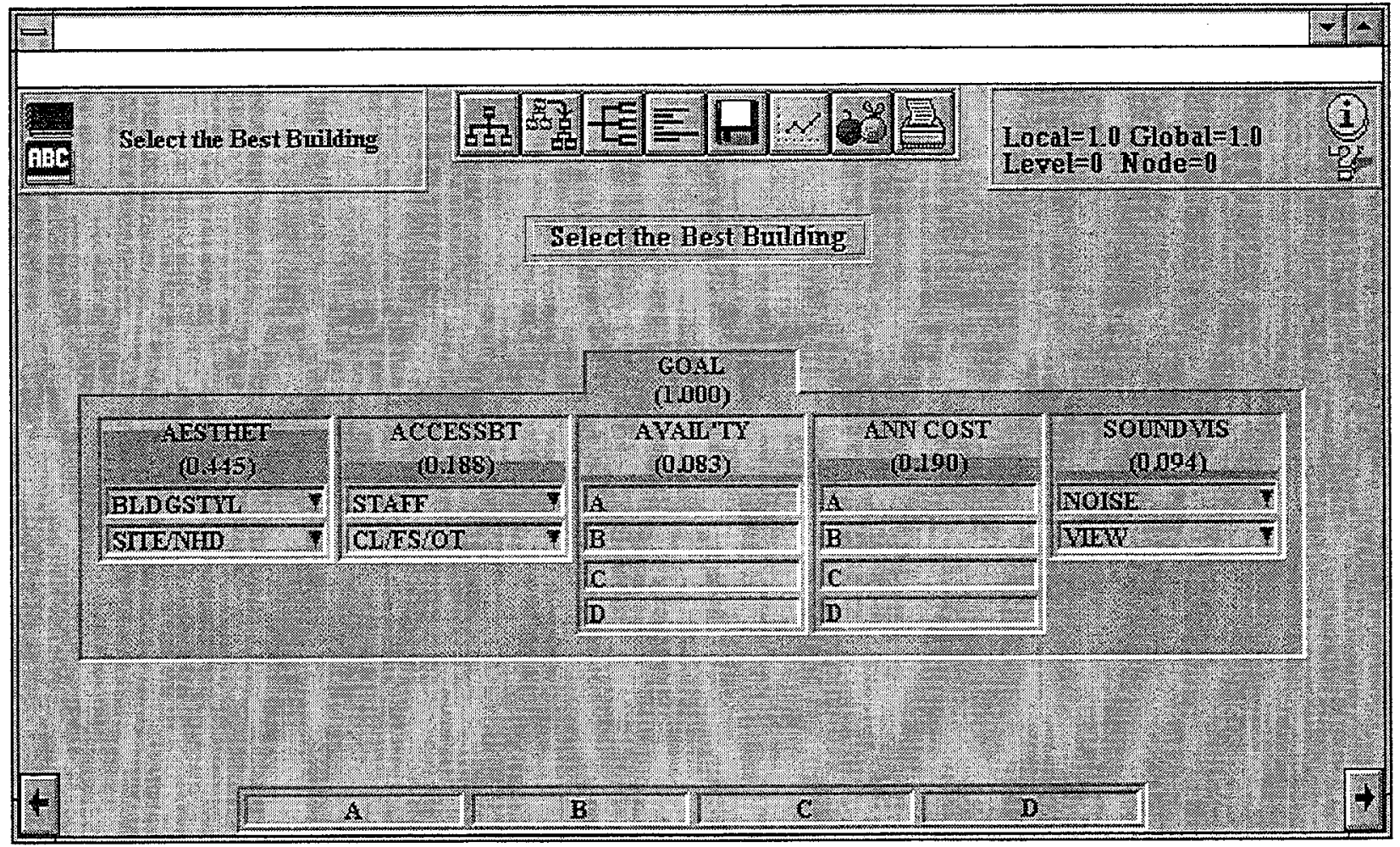

Exhibit 6-11. Attribute weights.

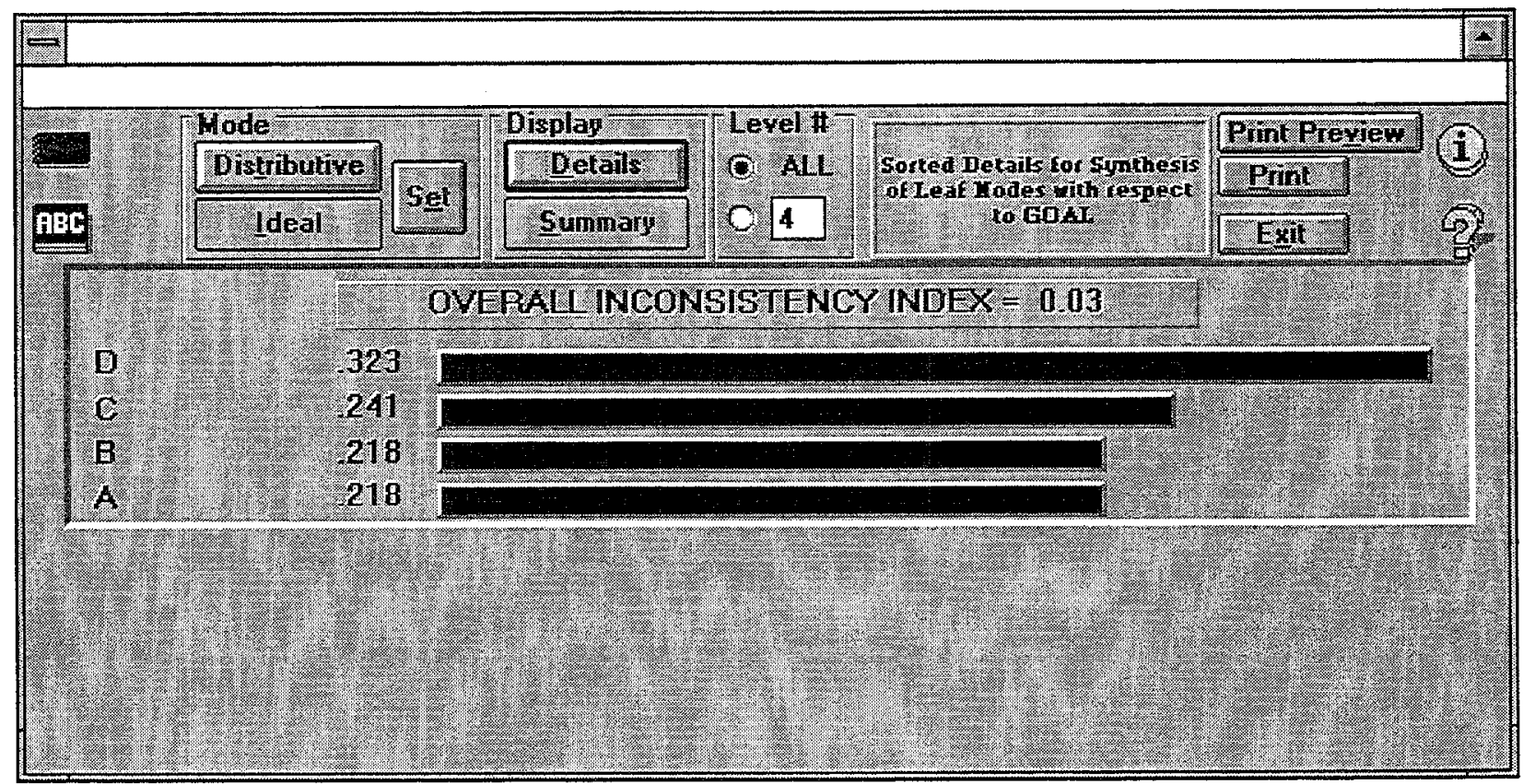

Exhibit 6-12. Final desirability scores. 


\subsection{NCIC Application}

\subsubsection{Problem Definition}

To illustrate how to apply NCIC, we use a hypothetical example of a small engineering services company choosing the best location among three U.S. cities for a branch office. The company specializes in government work, and it handles only clients in the local area. The owner thinks that the profitability of the company will go up with expanded business through a branch office. Based on the owner's experience in opening new branches in the past, he identifies four key attributes that are important to him when evaluating a new location.

The first attribute is profitability. He wants a location that will have a large, and potentially profitable market that generates substantial revenues for his company's services. He also wants a location where the government's allowable profit markup is generous. Government jurisdictions often have fee markup schedules that limit a contractor's profitability on public projects.

The second attribute is labor availability. The owner wants a location that has a sufficient supply of professional engineers to draw upon.

The third attribute is tax burden. Taxes obviously can reduce profitability. But minimizing the administrative burdens associated with taxes, such as paperwork requirements, is also important to the owner. He wants a location where tax/paperwork burdens are a minimum.

The final attribute is contract negotiations. Government purchasers of engineering services have various forms to fill out and procedures to follow in negotiating contracts. Some jurisdictions require more forms, have slower processing, carry out more auditing, and are simply more difficult to deal with than others. The owner wants a location with minimum negotiating hassles and contract processing times.

Note that all of these attributes are economic and affect profit to some extent. Labor availability and contract negotiations indirectly affect economics, and the other two deal directly with profitability. Given that the primary objective of most businesses is to maximize profits, this selection of attributes is not surprising. But monetary estimates of the impacts of each of the attributes upon profit are difficult and costly to make. A MADA method such as NCIC, on the other hand, is appropriate for making decisions on location with just this type of information.

The owner hires a consultant to come to his office for a day to work with him in structuring and carrying out an NCIC analysis of alternative locations.

The first step was to identify and define the attributes that the owner felt most important in selecting the best branch office location. The four attributes described earlier were chosen. Exhibit 6-13 shows them in hierarchical form. The owner did mention other attributes that proved useful in screening candidates for NCIC analysis. That is, the candidate locations had to meet minimum 
performance levels of those attributes. But the consultant discouraged including those other attributes in the analysis of the final alternatives since the performance on those attributes was similar for all the final alternatives. ${ }^{60}$

Using the four selected attributes and the constraint values of other attributes, the owner and consultant screened locations that they thought might be feasible. They came up with three-Atlanta, New York, and San Diego--for an NCIC analysis. Exhibit 6-14 shows the decision matrix they constructed as a start for the analysis. The decision matrix summarizes all available data, quantitative and qualitative, on the performance of each alternative with respect to each attribute.

Profitability streams were estimated for the first five years. They were based on projections of work availability and the allowed government markup in the three locations.

Labor availability depends in part on how active the construction industry is relative to its local labor pool. Atlanta scores low for availability, because current demands for Olympics-related work make it difficult to hire staff there. Availability in New York and San Diego is high because construction business is slow and there are some unemployed engineers looking for jobs.

The tax burden is scored on a verbal scale. The owner refused to take the time to research the local tax codes to find the actual tax consequences for different income scenarios. Moreover, the paperwork requirements are difficult to capture in monetary terms. So the owner estimated the tax burden on the basis of conversations with business people operating in those locations. $\mathrm{He}$ surmised that Atlanta taxes would be less burdensome than in San Diego, and San Diego would be less burdensome than in New York.

Contract negotiations were also scored on a verbal scale. As was the case with tax burden, the owner relied on personal interactions with other business people to learn what the relative difficulty might be in negotiating with government agencies in the three locations. He felt that San Diego would be the most difficult to deal with in contract negotiations.

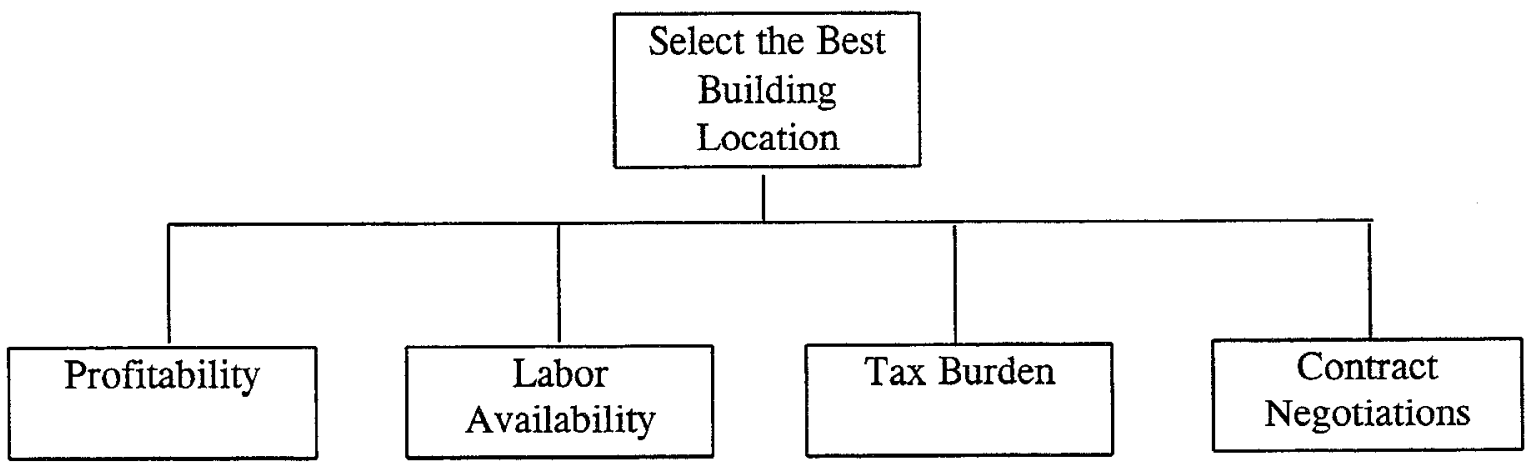

Exhibit 6-13. Attribute hierarchy for the location selection example.

${ }^{60}$ If performance beyond the constraint values were not particularly important to the owner, this would be another reason to exclude these attributes from the final analysis. 


\begin{tabular}{|l||c|c|c|}
\hline & Atlanta & New York & San Diego \\
\hline \hline Profit & 30 & 20 & \\
& year 1 & 30 & 25 \\
year 2 & 40 & 45 & 35 \\
year 3 & 40 & 60 & 40 \\
year 4 & 50 & 60 & 50 \\
year 5 & 50 & high & 50 \\
\hline Labor Availability & low & very high & high \\
\hline Tax Burden & moderate & high & high \\
\hline Contract Negotiations & moderate & & \\
Difficulty & & & \\
\hline
\end{tabular}

Exhibit 6-14. Decision matrix description of attributes by location.

\subsubsection{Defining the Base-Case Alternative}

In NCIC, pairwise comparisons are made versus a base-case alternative, as discussed in chapter 5 . The Base-Case alternative is the "status quo" alternative--that is, the choice to keep or renew the existing technology. In our building site selection problem, however, this is not a relevant alternative (the decision to establish a new office somewhere has already been made). We propose the following approach for defining the Base-Case alternative in such instances.

Establish a hypothetical "composite worst-case" (CWC) alternative. The non-monetary attributes of the CWC will be determined differently from its monetary attribute. For each non-monetary attribute, the CWC's performance is equal to the worst (least desired) level of performance exhibited in the set of alternatives. Then, for each of the real alternatives being considered, interattribute comparisons are made relative to the performance of the CWC. Thus, for each alternative, make pairwise comparisons among each of the actual alternative's differences (or "deltas") with these worst levels of performance. The CWC attribute values for our example problem are reported in Exhibit 6-15, along with the "deltas" computed for each alternative.

For the first year monetary benefit (which is "profit" in our example), the level of performance defined for the CWC is arbitrary. However, it must be less than the lowest value exhibited by the alternatives, to ensure that the resulting annual monetary benefit delta (against which all the nonmonetary performance deltas will be compared) is positive. Further, to promote the accuracy of subsequent pairwise comparisons with the non-monetary attribute deltas, the annual benefits worstcase should be chosen so that the resulting annual benefit deltas are judged to be within an order of magnitude of the value attributed to the non-monetary deltas. In our numerical example we set the CWC's annual monetary benefits (that is, the first-year profits) equal to $75 \%$ of the lowest exhibited (first-year) annual benefits among the actual alternatives. 
Note that for each non-monetary attribute, at least one alternative will exhibit the worst-case performance. In this case the delta (with respect to the CWC) is zero for that attribute, and so the attribute should not be included in the alternative's MPC. Thus, in our numerical example, as illustrated in Exhibit 6-16, the MPC for Atlanta does not include labor availability; the MPC for New York does not include tax burden; and the MPC for San Diego does not include contract negotiation difficulty.

\begin{tabular}{|c||c|c|c|c|}
\hline Attribute & $\begin{array}{c}\text { Worst-Case } \\
\text { Attribute } \\
\text { Values }\end{array}$ & $\begin{array}{c}\text { Atlanta } \\
\text { Deltas w/r/t } \\
\text { Worst Case }\end{array}$ & $\begin{array}{c}\text { New York } \\
\text { Deltas w/r/t } \\
\text { Worst Case }\end{array}$ & $\begin{array}{c}\text { San Diego } \\
\text { Deltas w/r/t } \\
\text { Worst Case }\end{array}$ \\
\hline \hline Profit, Year 1 & 15 & 15 & 5 & 10 \\
\hline Labor Availability & low & $\begin{array}{c}\text { [Atlanta } \\
\text { =low } \\
\text { worst case] }\end{array}$ & $\begin{array}{c}\text { high } \\
\text { instead of } \\
\text { low }\end{array}$ & $\begin{array}{c}\text { high } \\
\text { instead of } \\
\text { low }\end{array}$ \\
\hline Tax Burden & very high & $\begin{array}{c}\text { moderate } \\
\text { instead of } \\
\text { very high }\end{array}$ & $\begin{array}{c}\text { [New York } \\
\text { = very high } \\
\text { = worst case }]\end{array}$ & $\begin{array}{c}\text { high } \\
\text { instead of } \\
\text { very high }\end{array}$ \\
\hline $\begin{array}{c}\text { Difficulty of } \\
\text { Contract Negotiations }\end{array}$ & very high & $\begin{array}{c}\text { moderate } \\
\text { instead of } \\
\text { very high }\end{array}$ & $\begin{array}{c}\text { high } \\
\text { instead of } \\
\text { very high }\end{array}$ & $\begin{array}{c}\text { very high } \\
\text { = worst case] }\end{array}$ \\
\hline
\end{tabular}

Exhibit 6-15. Worst-case attribute values and deltas with respect to the composite worst-case.

\subsubsection{Calculating Implied Values Using Pairwise Comparisons}

The next step is to make, for each of the alternatives, a set of pairwise comparisons among the performance deltas appearing in Exhibit 6-15. Then compute the dominant eigenvalue and eigenvector for each of the resulting matrices of paired comparisons (MPC). Appendix B contains a simple computer program written in BASIC for this purpose. The MPCs and resulting calculations for the example problem are shown in Exhibit 6-16.

Use the dominant eigenvalues of the MPCs to assess the consistency exhibited in each set of pairwise comparisons. Recall that NCIC uses the same heuristic method as AHP to assess the level of consistency among pairwise comparisons. In all three of the hypothetical sets of judgments presented in Exhibit 6-16, the inconsistency ratio was a negligible 1\%, indicating a high level of consistency among the pairwise judgments.

Use the dominant eigenvectors of each MPC together with the actual value of the monetary attribute (the first-year profit "delta" in this case) to calculate the implied values for each of the non-monetary attribute deltas of each alternative. Then sum the implied values of all of the attribute deltas for a given alternative to assess the total value (in year 1) of that alternative's performance relative to the CWC. 
To provide a second check of consistency among the pairwise comparisons we plot the implied value results for each attribute versus the levels of performance. The resulting plots, shown in Figure 6.1, portray a set of "implied value functions." While the eigenvalue check described

\section{ATLANTA}

Matrix of Paired Comparisons (MPC)

\begin{tabular}{|c|c|c|}
\hline & $\begin{array}{c}\text { Reduced Tax Burden } \\
\text { (moderate vs. very high) }\end{array}$ & $\begin{array}{c}\text { Reduced Contract Negotiation } \\
\text { Difficulty (mod. vs. very high) }\end{array}$ \\
\hline $\begin{array}{c}\text { Profit Delta, Year 1 } \\
(15)\end{array}$ & 6 & 4 \\
\hline $\begin{array}{c}\text { Reduced Tax Burden } \\
\text { (moderate vs. very high) }\end{array}$ & $1^{\mathrm{A}}$ & $1 / 2$ \\
\hline
\end{tabular}

Calculation of Implied (Annual) Values Relative to CWC:

\begin{tabular}{|c|c|c|c|c|c|}
\hline \multicolumn{2}{|c|}{ Scaled eigenvector } & $\begin{array}{l}\text { multiplied } \\
\text { by }\end{array}$ & $\begin{array}{l}\text { Performance delta for } \\
\text { the monetary attribute } \\
\text { (first-year profits) }\end{array}$ & equals & $\begin{array}{l}\text { Implied (annual) values } \\
\text { of non-monetary } \\
\text { attribute deltas }(\$ K)\end{array}$ \\
\hline $\begin{array}{l}\text { labor avail. } \\
\text { tax burden } \\
\text { c. } n \text {. dif. }\end{array}$ & $\begin{array}{l}- \\
0.15 \\
0.28\end{array}$ & * & $\$ 15 \mathrm{~K}$ & $=$ & $\begin{array}{l}2.25 \text { [mod. tax burden] } \\
4.2 \text { [mod. c.n. dif.] }\end{array}$ \\
\hline \multicolumn{5}{|c|}{ utes with respect to CWC: } & 6.45 \\
\hline
\end{tabular}




\section{NEW YORK}

Matrix of Paired Comparisons (MPC)

\begin{tabular}{|c|c|c|}
\hline & $\begin{array}{c}\text { Increased Labor Availability } \\
\text { (high vs. low) }\end{array}$ & $\begin{array}{c}\text { Reduced Contract Negotiation } \\
\text { Difficulty (high vs. very high) }\end{array}$ \\
\hline $\begin{array}{c}\text { Profit Delta, Year 1 } \\
\text { (5) }\end{array}$ & 2 & 3 \\
\hline $\begin{array}{c}\text { Increased Labor Availability } \\
\text { (high vs. low) }\end{array}$ & $1^{\mathrm{A}}$ & 2 \\
\hline
\end{tabular}

Calculation of Implied (Annual) Values Relative to CWC:

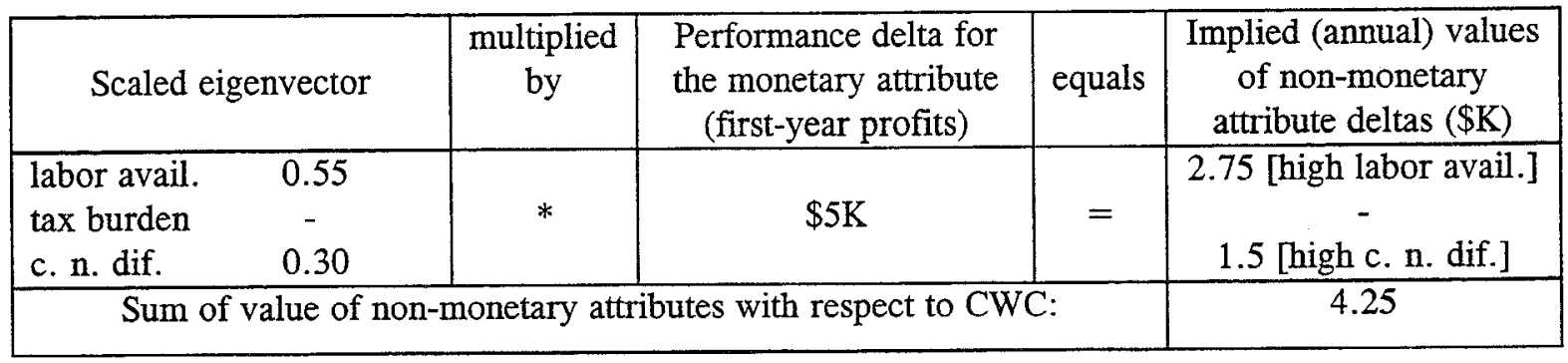

\section{SAN DIEGO}

Matrix of Paired Comparisons (MPC)

\begin{tabular}{|c|c|c|}
\hline & $\begin{array}{c}\text { Increased Labor Availability } \\
\text { (high vs. low) }\end{array}$ & $\begin{array}{c}\text { Reduced Tax Burden } \\
\text { (high vs. very high) }\end{array}$ \\
\hline $\begin{array}{c}\text { Profit Delta, Year 1 } \\
\text { (10) }\end{array}$ & 4 & 6 \\
\hline $\begin{array}{c}\text { Increased Labor Availability } \\
\text { (high vs. low) }\end{array}$ & $1^{\mathrm{A}}$ & 2 \\
\hline
\end{tabular}

Calculation of Implied (Annual) Values Relative to CWC:

\begin{tabular}{|c|c|c|c|c|c|}
\hline \multicolumn{2}{|c|}{ Scaled eigenvector } & $\begin{array}{l}\text { multiplied } \\
\text { by }\end{array}$ & Performance delta for & equals & Implied (annual) values \\
\hline $\begin{array}{l}\text { labor avail } \\
\text { tax burden } \\
\text { c. } \mathrm{n} \text {. dif. }\end{array}$ & $\begin{array}{l}0.28 \\
0.15 \\
- \\
\end{array}$ & $*$ & $\$ 10 \mathrm{~K}$ & $=$ & $\begin{array}{c}2.8 \text { [high labor avail.] } \\
1.5 \text { [high tax burden] } \\
-\end{array}$ \\
\hline \multicolumn{5}{|c|}{ Sum of value of non-monetary attributes with respect to CWC: } & 4.3 \\
\hline
\end{tabular}

Exhibit 6-16. Matrices of paired comparisons and calculated implied relative values.

${ }^{A}$ This is a diagonal element of the MPC, for which the entry is 1.0 by definition. 
earlier provides a check of the consistency among the pairwise comparisons for a given alternative, the implied value function plots allow the decision maker to assess the consistency among the judgments made across alternatives.

The plot for labor availability confirms that essentially the same value has been attributed to the equivalent levels of performance of New York and San Diego for this attribute. The plot of implied values for different levels of tax burden indicates that an increase in burden from high to very high is judged to subtract more value than does an increase from moderate to high. The decision maker should reflect on whether this result, which emerges when we pool the results of the separate MPCs, is consistent with his or her intuition about the value of reductions in tax burden over the exhibited levels of performance. Finally, the plot of implied values for different levels of contract negotiations difficulty indicates that an increase in difficulty from moderate to high subtracts more value than an increase from high to very high. Again, this result should be assessed for its consistency with the decision-maker's intuition about the marginal returns from reductions in contract negotiation difficulty.

\subsubsection{Calculating Present Relative Values and Selecting the Best Alternative}

Finally, NCIC calls for a standard present value assessment of the alternatives using the total implied values shown in Figure 6-1. The streams of expected net monetary benefits during the study period must be discounted to account for the time value of money. In addition, we assume that the benefits associated with the non-monetary attributes ultimately add financial worth to the alternatives; otherwise they would not be included in the analysis. These attributes are "nonmonetary" because their values are not feasibly measured directly in monetary terms. Nevertheless, they are included in the analysis because they affect the total value of the alternatives. Therefore, the NCIC method also calls for discounting the stream of benefits associated with the "nonmonetary" attributes.

In our example, we assume for simplicity that the annual implied value of the non-monetary attributes remains constant throughout the 5-year analysis period. The expected profits per year during the study period were shown in Exhibit 6-14. The total relative ${ }^{61}$ value (in each year) of each alternative is equal to the sum of the monetary benefits and the implied values of its nonmonetary attributes. Discount the stream of annual total relative values to compute the total present relative value for each alternative. Select the location with the highest total present relative value. The total present relative values for our example problem are plotted in Figure 6-2, indicating that Atlanta is the preferred alternative.

${ }^{61}$ These total values are relative because the value of performance levels has been measured with respect to the Base-Case alternative (which was the composite worst case in our example). Thus, the total relative values are appropriate to use for selecting the highest-value alternative among those evaluated in a given NCIC analysis, but they cannot be used as a measure of absolute value comparable with other investment options which were not included in the NCIC analysis. 

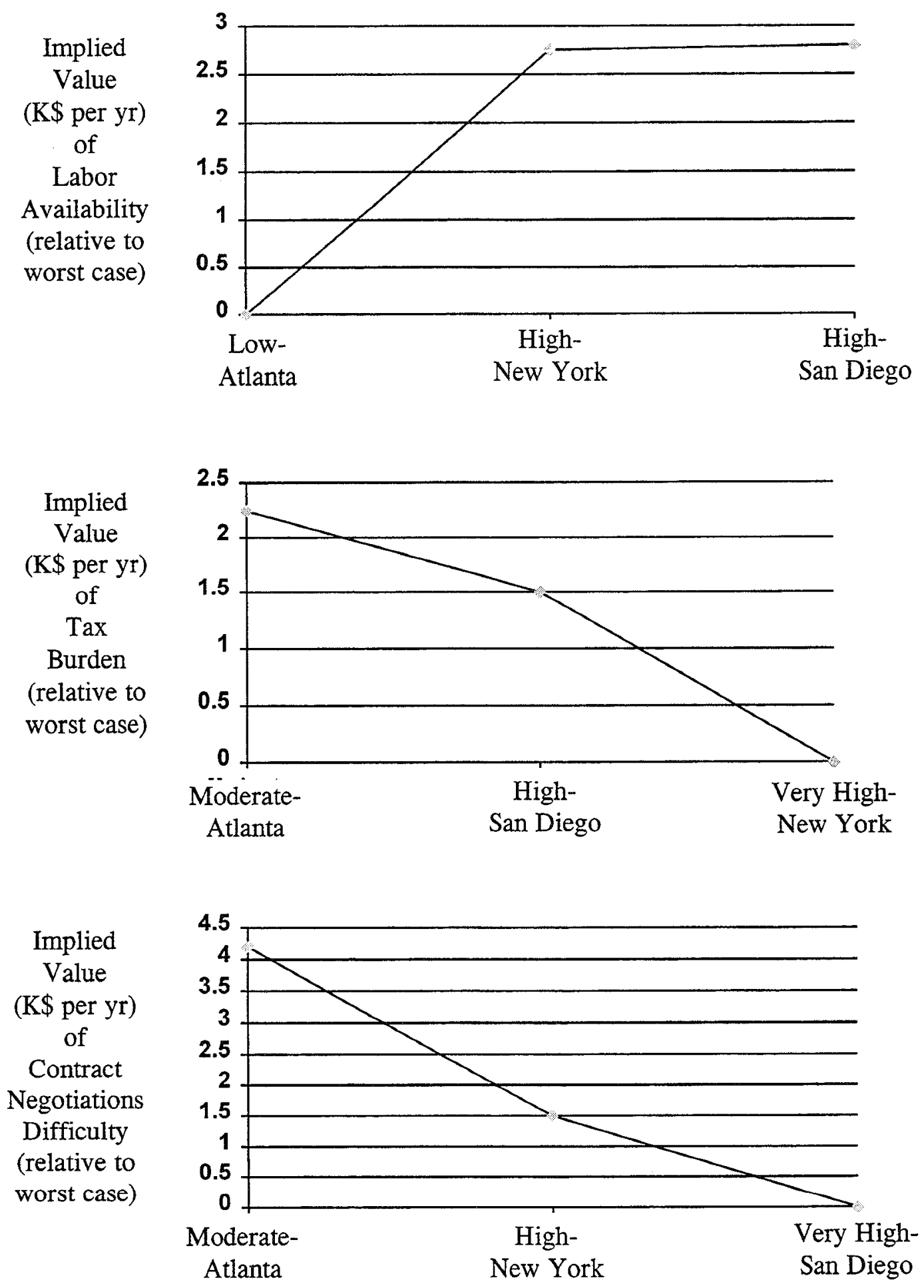

Figure 6-1. Plots of implied relative value. 


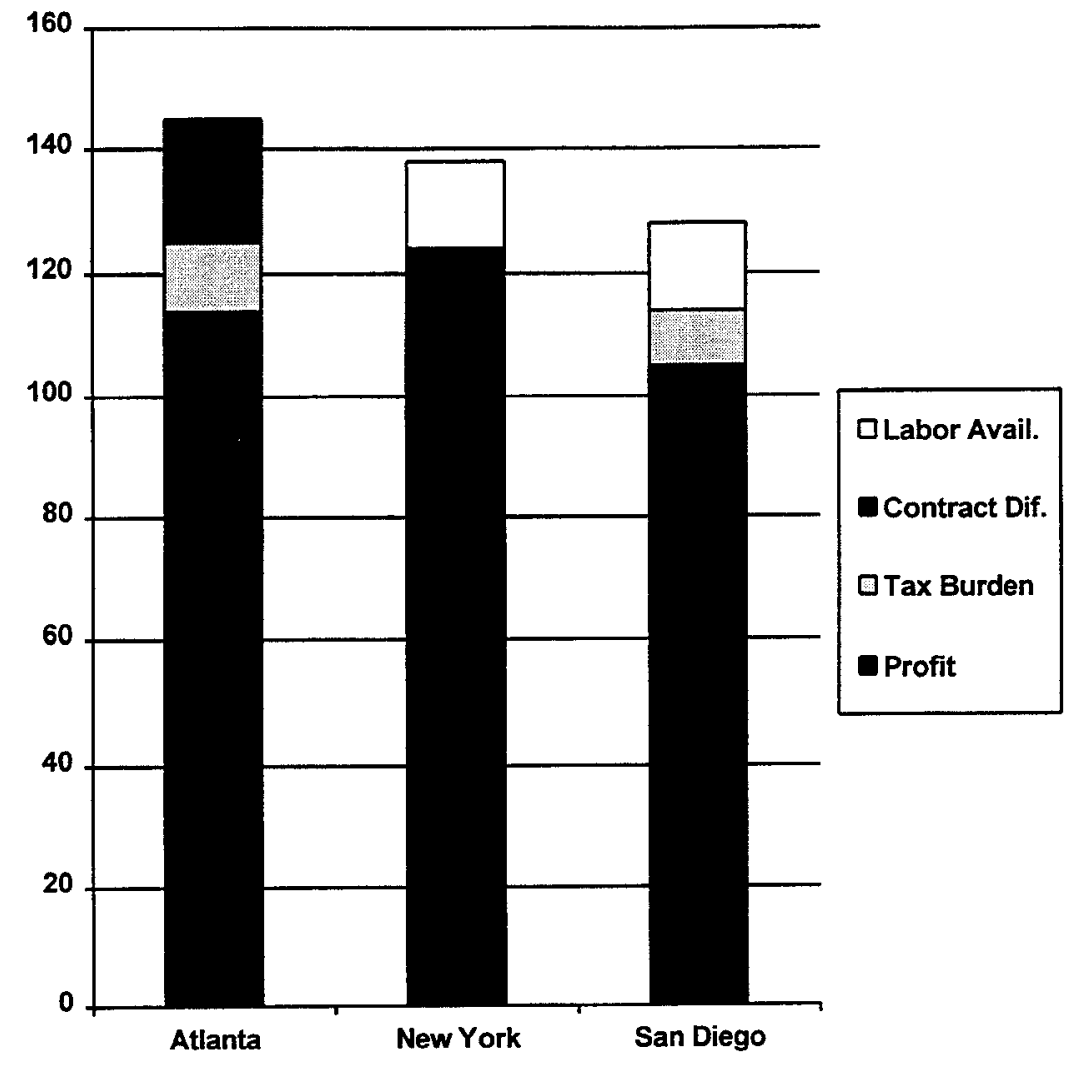

Figure 6-2. Total present relative values. 


\section{Appendix A}

\section{Definitions of Building-Related Attributes}

This list is a ready-made set of the attributes that most decision makers find important in building decisions. Use the attributes to generate MADA models for making building-related decisions. The emphasis is on users of commercial office buildings. The list does not include every attribute for every building evaluation. Nor does it include all attributes relevant to location and non building-related decisions. If you need attributes and definitions that are not here, identify and define additional attributes for a customized MADA model that best suits your project evaluation. ${ }^{62}$

The following definitions are in alphabetical order as they appear in Exhibit 3.1:

Aesthetics--The image the owner wants to project to the visiting public and the occupants working in the building. Aesthetics include the appearance and attractiveness of design both of the building (inside and outside) and of the site. Design, layout, material choice and condition, signage, and landscaping affect aesthetics.

Building Functions--The level of building performance in serving the needs of the owners/occupants. Typical office building functions include providing space for office work, meetings, training, storage, and shipping. Efficient layouts of these areas enhance the performance of the building. Adequate, convenient parking and a plant that keeps the building operating comfortably and efficiently also contribute to the building's performance.

Durability--The extent to which the building and its equipment are able to continue to meet performance requirements over time. Durability is particularly important in buildings whose functional use or layout changes over time. A laboratory, for example, must be durable to withstand changes in equipment and layout for conducting new experiments.

Economics--The value, efficiency, or profitability of the building or building component. Examples of economic measures that help you determine project value, efficiency, or profitability are life-cycle costs (LCC), net savings, and adjusted internal rate of return. ${ }^{63}$ You can choose measures that take into consideration benefits and revenues as well as costs. Costs include initial investment costs (also called first costs); operation, maintenance, and replacement (OM\&R) costs; rent and other building costs. Many decision makers look at initial investment costs separately from recurring costs because they are funded out of separate budgets. Take care not to double count costs in MADA analyses. For example, do not add investment costs to life-cycle costs, because investment costs are already included in life-cycle costs.

\footnotetext{
${ }^{62}$ See, for example, Davis, "How to Get the Building You Need," 1992.

${ }^{63}$ For a description of these and other measures, see ASTM compilation Standards on Building Economics, Third Edition, 1994.
} 
Environmental Impacts--The effects on air, water, land, and energy resources from buildingrelated decisions.

Flexibility in Functional Use and Disposition--The ease and economy of (1) retrofitting buildings or building components to serve alternative uses and occupancies and of (2) disposing of the buildings or building components when they are no longer needed.

Information Technology--The capability, capacity, and flexibility of the building's information technology infrastructure to meet occupant needs. This includes power supply and distribution, telecommunications and computer infrastructure, cabling, and cooling.

Location--The placement of a building regionally to support the owner's objectives. A desirable location is one that is attractive to staff, clients, customers, and other people who use the building. A good location is close to convenient, inexpensive transportation; is in a safe, upscale neighborhood; and provides a large customer base for purchasing goods or services provided by the building owner/occupant.

Occupancy Availability--The length of time before the building will be available for occupancy by the new tenant.

Operation and Maintenance--The ease and convenience of operating, maintaining, cleaning, making repairs and replacements, heating/cooling, and providing power to building components and the building.

Reliability--The dependability of building systems to operate under normal and abnormal conditions.

Security--The level of protection (1) to ensure personal safety of workers and visitors inside and outside the building on the site and (2) to ensure protection of individual and organization assets (building and contents) everywhere on the site.

Sound and Visual Environment--The privacy of conversations, level of ambient noise, quality of interior and exterior view, and level of lighting and glare; also, the degree of occupant and facility manager control over those conditions.

Thermal Environment and Air Quality--Levels of temperature, humidity, and ventilation; quality of the air; and the degree of occupant and facility manager control over these conditions.

Transportation--The efficiency and ease with which people and materials can be moved on the site, and the availability, cost, and convenience of public and private transportation to and from the site. 


\section{Appendix B}

\section{Algorithm To Compute Principal Eigenvectors And Eigenvalues}

Use the following program to compute the principal eigenvector and eigenvalue of a matrix of paired comparisons. These computations are required by both the NCIC and AHP multiple attribute decision making methods. The program listing which appears in Exhibit B-1 is written in the Microsoft BASIC language. ${ }^{64}$ It is simple enough to be easily translated into other popular computer languages. First edit the program to enter the required input information summarized in Table B-1. Then execute the program and record the printed results for use in final calculations of the alternatives' desirability scores.

Table B-1. List of input information

\begin{tabular}{ll}
\hline Variable name & \multicolumn{1}{c}{ Description } \\
\hline name $\$$ & $\begin{array}{l}\text { Name of the attribute or goal with respect to which } \\
\text { the set of comparisons has been made }\end{array}$ \\
size & Order of the matrix (number of rows or columns) \\
epsilon! & $\begin{array}{l}\text { A small number which specifies a threshold of change; } \\
\text { iterations cease when the vector sum of the changes to the } \\
\text { eigenvector's elements resulting from its multiplication by } \\
\text { (1/lambda)*mat is less than epsilon }\end{array}$ \\
mat $(\mathrm{i}, \mathrm{j})$ & $\begin{array}{l}\text { The matrix of paired comparisons; the user only specifies } \\
\text { the upper right portion of the matrix, since the diagonal } \\
\text { elements are set equal to } 1.0 \text { by default, and since the } \\
\text { lower left elements are set equal to the reciprocals of the } \\
\text { upper right elements by default }\end{array}$
\end{tabular}

${ }^{64}$ Microsoft BASIC, BASIC Language Reference, Microsoft Corporation, 1989. 


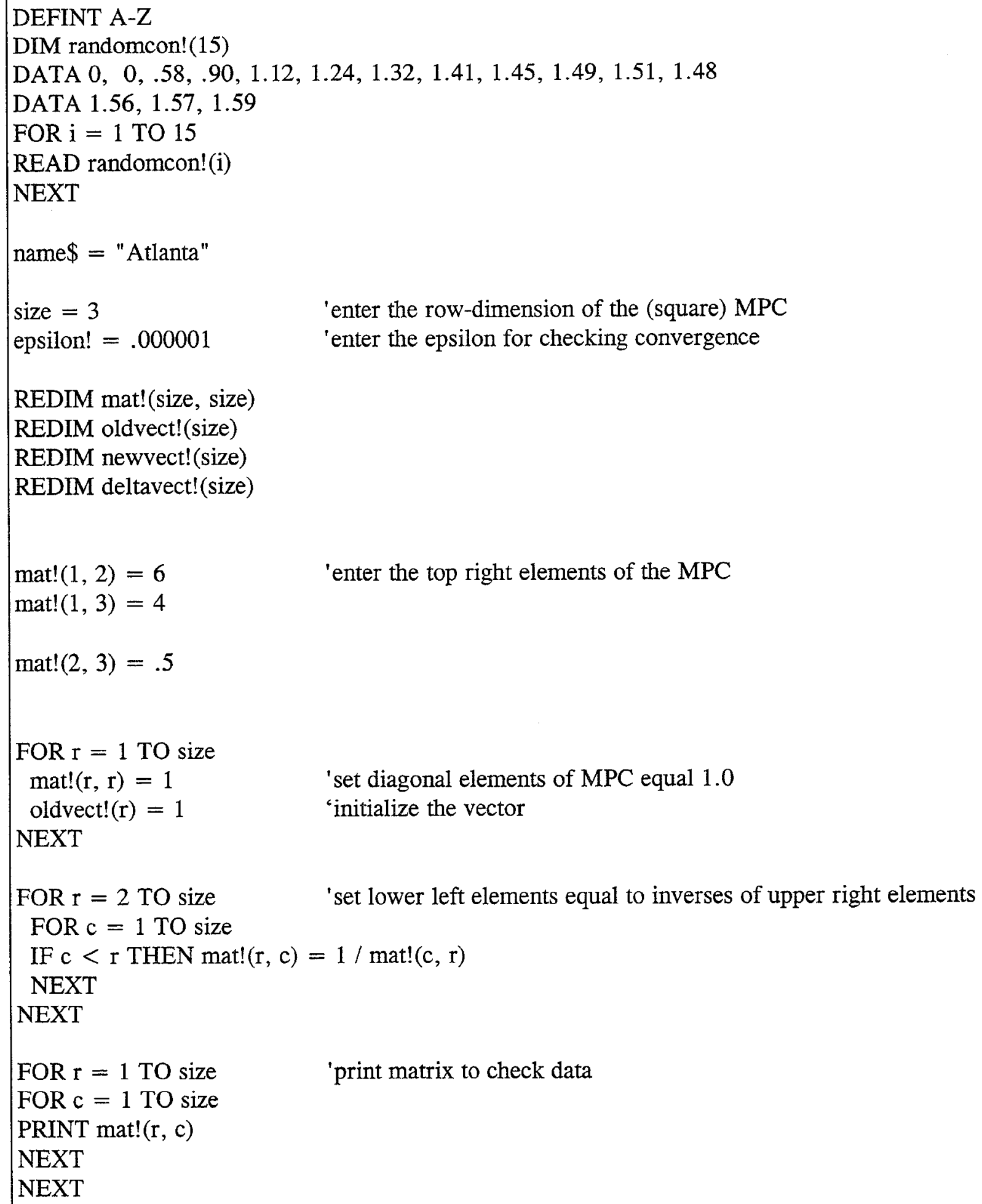




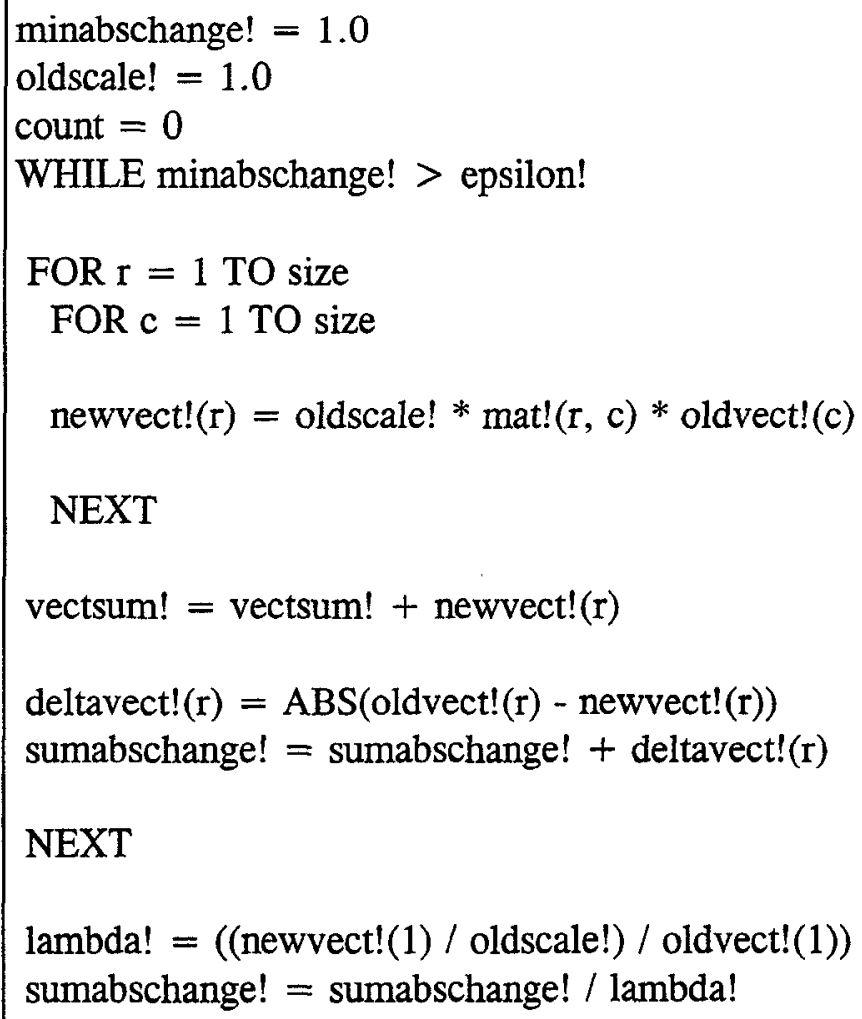

'Re-set values of re-used variables for next round

IF sumabschange! < minabschange! THEN minabschange! = sumabschange! oldscale $!=.9 /$ vectsum!

sumabschange! $=0$

oldvectsum! = vectsum!

vectsum! $=0$

FOR $\mathrm{r}=1$ TO size

oldvect!(r) = newvect!(r)

newvect! $(\mathrm{r})=0$

NEXT

count $=$ count +1

WEND 
FOR $\mathrm{r}=1$ TO size

'normalize the eigenvector so that its elements sum to 1.0

oldvect!(r) = oldvect!(r) / oldvectsum!

NEXT

'Calculate consistency index, as well as the

'consistency ratio to be compared with randomcon!

conindex! $=($ lambda! - size $) /($ size -1$)$

conratio! = conindex! / randomcon!(size)

LPRINT "MPC is for comparisons with respect to "; name\$

LPRINT

LPRINT "epsilon = "; epsilon!

LPRINT "number of iterations until convergence was "; count

LPRINT

LPRINT "eigenvector (normed so that its elements sum to 1.0 ) $=$ "

FOR $r=1$ TO size

LPRINT oldvect!(r)

NEXT

LPRINT

LPRINT "maximum eigenvalue $=$ "; lambda!

LPRINT "consistency ratio $=$ "; conratio!

END

Exhibit B-1. Program to compute the principal eigenvector and eigenvalue of an MPC. 


\section{Appendix C}

\section{References}

American Society for Testing and Materials (ASTM). Standards on Building Economics, Third Edition (Philadelphia, Pennsylvania: ASTM, 1994).

Benayoun, R., Roy, B., and Sussman N. "Manual de reference du programme Electre, Note de Synthese et Formation," Direction Scientifique SEMA, No. 25, 1966.

Boucher, T. O. and MacStravic, E. L. "Multiattribute Evaluation Within a Present Worth Framework and Its Relation to the Analytic Hierarchy Process," Engineering Economics, 37, 1991.

Brian Bowen, Robert P. Charette, and Harold E. Marshall. UNIFORMAT II-A Recommended Classification for Building Elements and Related Sitework, National Institute of Standards and Technology Special Publication 841, August 1992.

Canada, John R. and Sullivan, William G. Economic and Multiattribute Evaluation of Advanced Manufacturing Systems (Englewood Cliffs, New Jersey: Prentice-Hall, Inc., 1989).

Chen, Shu-Jen and Hwang, Chin-Lai, Fuzzy Multiple Attribute Decision Making (Heidelberg, Berlin: Springer-Verlag, 1992).

Davis, Gerald. "How to Get the Building You Need," ASTM Standardization News, 20(11), (Philadelphia, Pennsylvania: ASTM 1992).

Dell-Isolla, Alphonse. Value Engineering in the Construction Industry, Third Edition (New York, New York: Van Nostrand Reinhold, 1982).

Dubois and Prade, Fuzzy Sets and Systems: Theory and Applications, (New York, Academic Press), 1980

Dyer, James, "Remarks on the Analytical Hierarchy Process," Management Science, 36(3), 1990.

Expert Choice User's Guide (Pittsburgh, Pennsylvania: Decision Support Software, Inc., 1993).

Gass, Saul I. Decision Making, Models, and Algorithms (New York, New York: John Wiley and Sons, 1985).

Hwang, F. An Expert Decision Making Support System for Multiple Attribute Decision Making, Ph.D. Thesis, Department of Industrial Engineering, Kansas State University, 1987. 


\section{Appendix C}

\section{References (continued)}

Hwang, Ching-Lai and Yoon, Kwangsun. Multiple Attribute Decision Making. Lecture Notes in Economics and Mathematical Systems (Heidelberg, Berlin: Springer-Verlag, 1981).

Hwang, Ching-Lai and A.S.M. Masud. Multiple Objective Decision Making, Methods and Applications, (Heidelberg, Berlin: Springer-Verlag, 1979).

Ibaraki, Toshihide and Katoh, Naoki. Resource Allocation Problems: Algorithmic Approaches (Cambridge, Massachusetts: MIT Press, 1988).

Marshall, Harold E. Recommended Practice for Measuring Net Benefits and Internal Rates of Return for Investments in Buildings and Building Systems, National Bureau of Standards Interagency Report 83-2657, October 1993.

Marshall, Harold E. Techniques for Treating Uncertainty and Risk in the Economic Evaluation of Building Investments, National Institute of Standards and Technology Special Publication 757, September 1988.

Marshall, Harold E. Recommended Practice for Measuring Simple and Discounted Payback for Investments in Buildings and Building Systems, National Bureau of Standards Interagency Report 842850, March 1984.

Marshall, Harold E. and Ruegg, Rosalie T. Recommended Practice for Measuring Benefit/Cost and Savings-to-Investment Ratios for Buildings and Building Systems, National Bureau of Standards Interagency Report 81-2397, November 1981.

Mathematical Modeling, 9(3-5), 1987.

Morgan, M. Granger and Henrion, Max, Uncertainty: A Guide to Dealing with Uncertainty in Quantitative Risk and Policy Analysis (New York, Cambridge University Press, 1990).

Mudge, Arthur E. Value Engineering, A Systematic Approach (Pittsburgh, PA: J. Pohl Associates, 1989).

Ruegg, Rosalie T., Petersen, Stephen R., and Marshall, Harold E. Recommended Practice for Measuring Life-Cycle Costs of Buildings and Building Systems, National Bureau of Standards Interagency Report 80-2040, June 1980. 


\section{Appendix C}

\section{References (continued)}

Saaty, Thomas L. The Analytic Hierarchy Process: Planning, Priority Setting, Resource Allocation, (New York, New York: McGraw-Hill, 1980).

Saaty, Thomas L. Multicriteria Decision Making: The Analytic Hierarchy Process (Pittsburgh: Pennsylvania: University of Pittsburgh, 1988).

Sakawa, Masatoshi. Fuzzy Sets and Interactive Multiobjective Optimization (New York, New York: Plenum Press, 1993).

Slowinsky, R. and Teghem, J. Stochastic vs. Fuzzy Approaches to Multiobjective Mathematical Programming Problems Under Uncertainty (Dordrecht: Kluwer Academic Publishers, 1990).

Socio-Economic Planning Sciences, 20(6), 1986 (special AHP issue).

Stadler, Wolfram. "Fundamentals of Multicriteria Optimization," Multicriteria Optimization in Engineering and in the Sciences (New York: Plenum Press, 1988).

Terano, Asai, and Sugeno, Fuzzy Systems Theory and Its Applications, (New York, Academic Press), 1987.

Users Manual for NCIC: A Decision Support Software Package for Investments in Integrated Automation and Advanced Systems, (Charlotte, NC: Material Handling Industry, 1993).

Weber, Stephen F. "A Modified Analytic Hierarchy Process for Automated Manufacturing Decisions," Interfaces, July-August 1993.

Wicks, Elin M. and Boucher, Thomas O. "NCIC: A Software Tool for Capital Investment Analysis in Manufacturing," Computers and Industrial Engineering, 24(2), 1993.

Yager et al., Fuzzy Sets and Applications: Selected Papers by L. A. Zaheh, (New York, Wiley), 1987.

Zadeh, L. A. "Fuzzy Sets," Information and Control, Vol. 8, pp. 338-353, 1965. 